\title{
Marble decay caused by thermal expansion: microstructure-based mathematical and physical modeling
}

\author{
Dissertation \\ zur Erlangung des mathematisch-naturwissenschaftlichen Doktorgrades \\ "Doctor rerum naturalium" \\ der Georg-August-Universität Göttingen \\ im Promotionsprogramm Geowissenschaften / Geographie \\ der Georg-August University School of Science (GAUSS) \\ vorgelegt von \\ Victoria Shushakova \\ aus Zhambil, Kasachstan
}

Göttingen 2013 
Betreuungsausschuss

Prof. Dr. Siegfried Siegesmund

Abteilung Strukturgeologie und Geodynamik

Geowissenschaftliches Zentrum der Georg-August-Universität Göttingen

Prof. Dr. Edwin R. Fuller, Jr.

Department of Materials Science and Engineering

North Carolina State University, Raleigh

Mitglieder der Prüfungskommission

Referent: $\quad$ Prof. Dr. Siegfried Siegesmund

Geowissenschaftliches Zentrum der Georg-August-Universität Göttingen

Korreferent: Prof. Dr. Edwin R. Fuller, Jr.

North Carolina State University, Raleigh

2. Korreferent: Prof. Dr. Jonas Kley

Geowissenschaftliches Zentrum der Georg-August-Universität Göttingen

weitere Mitglieder der Prüfungskommission

Prof. Dr. Sharon Webb

Abteilung Experimentelle und Angewandte Mineralogie

Geowissenschaftliches Zentrum der Georg-August-Universität Göttingen

Dr. Helmut Klein

Abteilung Kristallographie

Geowissenschaftliches Zentrum der Georg-August-Universität Göttingen

Dr. Florian Heidelbach

Bayerisches Geoinstitut, Universität Bayreuth

Tag der mündlichen Prüfung: 19.04.2013 


\section{Abstract}

Marbles have been considered to be among the most important building materials since ancient times. Regarded as special stones, they are captivating because of their pureness, formability, and translucence. However, degradation of sculptures, architectural heritage, and façade stone made from marbles is problematic. Such deterioration of building stones depends mainly on ambient climate.

Environmental conditions such as temperature changes, both increases and decreases, induce significant deterioration. The rock-forming minerals in marble, like calcite and dolomite, have large anisotropy in their coefficients of thermal expansion. Hence, apart from the expansion (or contraction) that results from heating (or cooling), internal residual stresses will develop in the stone fabric due to the thermal expansion anisotropy between the constitutive crystalline grains. These stresses can result in thermally induced microcracking, and an additional concomitant expansion. Such behavior is exacerbated by moisture due to moisture-assisted subcritical crack growth, and hence degradation can accumulate with cycling and over time, resulting in significant time-dependent deterioration.

This research thesis presents the first systematic study of the prediction of degradation phenomena in marble structures caused by thermal expansion by applying numerical simulations and experimental techniques. The objective is to elucidate the influence of fabric parameters on factors that affect the marble degradation. Artificial microstructures with modeled textures as well as the real fabric of marble samples with different fabric parameters were examined. Microstructure-based finite-element simulations in combination with electron microscopy (EBSD technique), and experimental measurements of the thermal expansion behavior were used to study the influence of the rock's fabric on thermal-elastic responses and the extent of microcracking. Additionally, in order to characterize the degradation potential of a marble, a volumetric extension index was developed as a decay index and was evaluated and validated from thermal expansion measurements under dry and water-saturated conditions for the investigated marble samples. 
The results revealed that certain combinations of fabric parameters such as lattice preferred orientation (LPO), shape preferred orientation (SPO), marble composition, grain size and grain-boundary fracture toughness have a significant influence on the thermal-elastic response of marble and on the onset and extent of microcracking. It was seen that dolomitic marbles are more resistance to thermal-related marble decay than are calcitic marbles with the same structure and fabric parameters. However, fabric parameters, especially SPO and LPO, also play an important role in the thermal behavior of marble and therefore should be taken into account for the characterizing the durability and stability of marble.

Finally, it was shown that microstructure-based finite-element modeling provides excellent insight and elucidation of influences of rock fabric on the degradation phenomena of marble, since the results from simulations are in good agreement with experimental findings. 


\section{Contents}

1. General introduction 1

2. Fabric parameters: terminology 9

2.1 Marble composition 9

2.2 Shape preferred orientation (SPO) 10

2.3 Lattice preferred orientation (LPO) 11

2.4 Grain size $\quad 14$

2.5 Grain boundary configuration $\quad 14$

2.6 Microcracks $\quad 15$

3. Methods and materials 16

3.1 OOF approach 16

3.2 EBSD technique $\quad 19$

3.3 Thermal expansion measurements under dry and water-saturated $\begin{array}{ll}\text { conditions } & 20\end{array}$

3.4 Artificial microstructures and modeled texture $\quad 24$

3.4.1 Extremes of SPO 24

3.4.2 Extremes of LPO 25

3.5 Marble samples $\quad 27$

3.5.1 Microfabric 27

$\begin{array}{lll}3.5 .2 \text { Crystal texture } & \mathbf{2 8}\end{array}$

4. Influence of shape fabric and crystal texture on marble degradation phenomena: simulations $\quad 30$

4.1 Microstructural simulations: simulation design $\quad 30$

4.2 Results and discussion 32

4.2.1 Elastic strain energy density 32

4.2.2 Elastic strain energy density: influence of SPO 32

4.2.3 Elastic strain energy density: influence of LPO 35

4.2.4 Maximum principal stress: influence of SPO 35

4.2.5 Maximum principal stress: microstructural maps 37

4.2.6 Influence of marble composition: dolomitic marbles and marbles with the mixed content of calcite (50\%) and dolomite (50\%) 42

4.2.7 Coefficient of thermal expansion 45 
4.3 Summary and conclusions

5. Microcracking in calcite and dolomite marble: microstructural influences and effects on properties

5.1 Input parameters 50

5.2 Finite-element simulations 51

5.3 Results and discussion 52

5.3.1 Effect of SPO and LPO 52

5.3.2 Spatial distribution of microcracks 58

5.3.3 Effect of grain size and marble composition 59

5.3.4 Effect of grain-boundary toughness 62

5.3.5 Coefficients of thermal expansion 63

5.4 Summary and conclusions 66

6. Marble decay induced by thermal strains: simulations and experiments 69

6.1 Image processing 69

6.2 Finite-element simulations 71

6.3 Calculations of polycrystalline thermal expansion properties 73

6.4 Results and discussion 75

6.4.1 Thermal dilatation and residual strains 75

6.4.2 Thermal-elastic response

6.4.3 Thermal expansion: correlation between modeled and experimental results 81

6.5 Summary and conclusions 83

7. Decay index: A new quantitative measure of marble decay 85

7.1 Preface 85

7.2 Volume expansion index 85

7.3 Results and discussion 88

7.3.1 Verification of approach 88

7.3.2 Deterioration indexes for the investigated marbles 92

7.4 Summary and conclusions 95

8. Conclusions 96

References 101

Acknowledgments 112

Curriculum vitae 114 


\section{General introduction}

The wide use of marble began in Rome during the first century BCE. Marble has been used as decorative and constructive material. However, marbles can be extremely sensitive to weathering and to degradation, and hence can have limited durability. The Taj Mahal, the famous masterpiece of architectural art (see Fig. 1.1), is a white marble mausoleum situated in Agra, India. Due to acid rain generated from an oil refinery and foundries, the marble façades on the Taj Mahal have been losing their luster, brightness, and white color into a sickly shade. Siegesmund et al. $(2000,2007)$ pointed out that physical weathering is thought to be the initial stage of marble degradation.

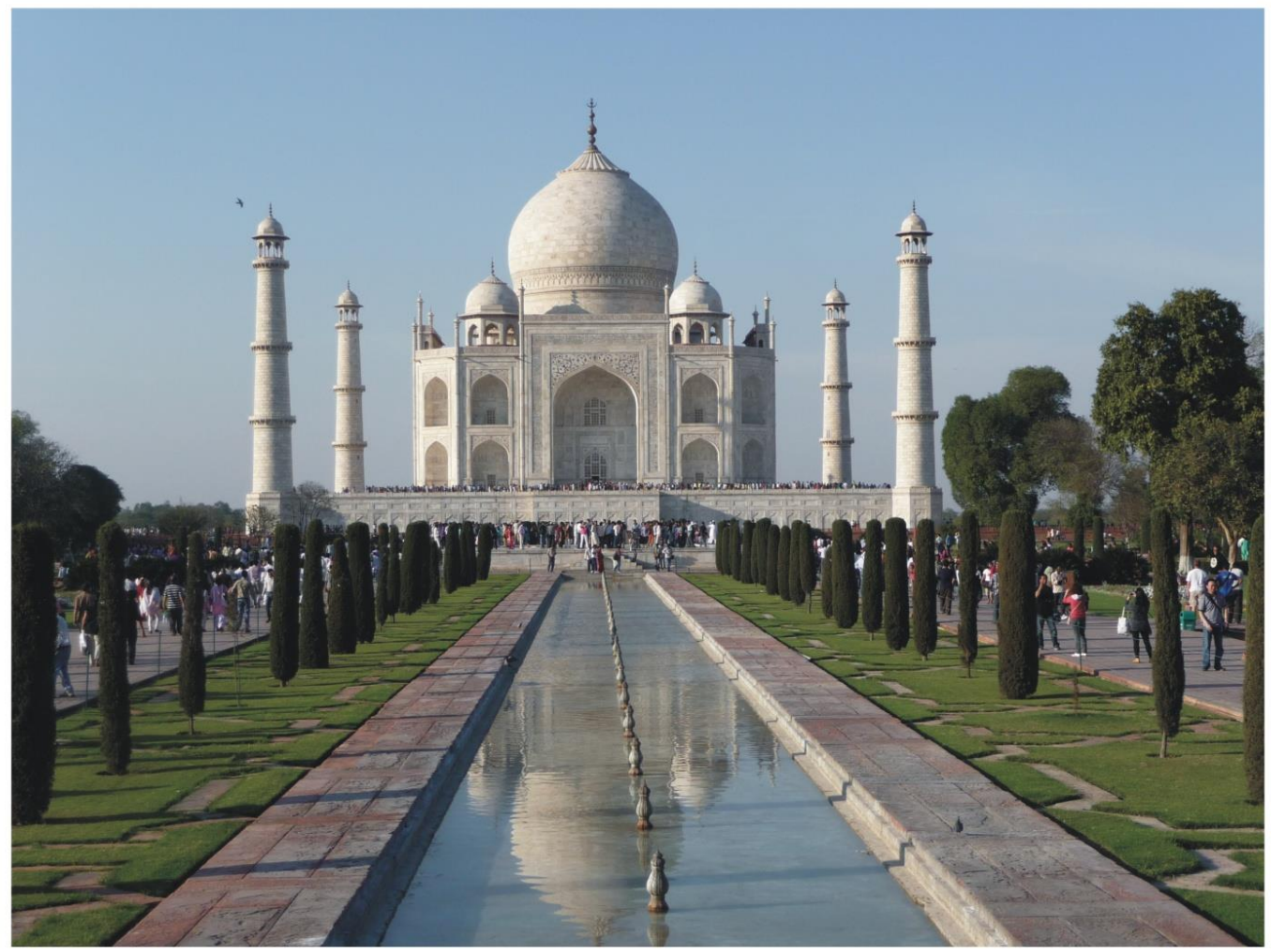

Fig. 1.1 Representative view of the façade of the Taj Mahal (Agra, India).

Many historical marble sculptures and monuments show clear evidence of deterioration. For some marbles the degradation process is expressed as a penetrative granular disintegration. This phenomenon is typical for Carrara marbles, although it is not restricted to only this marble type. At the sculpture surfaces a progressive fabric decohesion leads to a sugar-like crumbling of the isolated crystalline grains of calcite, resulting in a progressive deterioration of the stone. An example of this degradation phenomenon is shown in Fig. 1.2a. The Madonna and Child statue of Carrara marble is 
generally well preserved due to a thin, hardened outer layer. However, the interior rock fabric has undergone a progressive decohesion along the grain boundaries, resulting in the loss of the facial features.

A more spectacular deterioration phenomenon occurs for marble slabs, namely their bowing behavior. Due to progress in natural stone machining, unprecedented creative options are now available for economical cladding with natural stone slabs. This has led to a renaissance in the use of natural stone as a modern building material. Despite the aesthetic gains, there are structural and aesthetic issues. Exposed to the weather, stone claddings may be disaggregated in their structure, and thus irreversibly deformed. The bowing of marble façade slabs (Fig. 1.2b), or gravestones (see Fig. 1.2c), with thicknesses of typically $30 \mathrm{~mm}$ to $40 \mathrm{~mm}$, but occasionally up to $90 \mathrm{~mm}$, have been reported (Grimm 1999; Siegesmund et al. 2008). Both panel thickness and temperature influence the development of bowing (Koch and Siegesmund 2002, 2004; Grelk et al. 2004). Moreover, both convex and concave deformation can occur after only a few years of exposure.
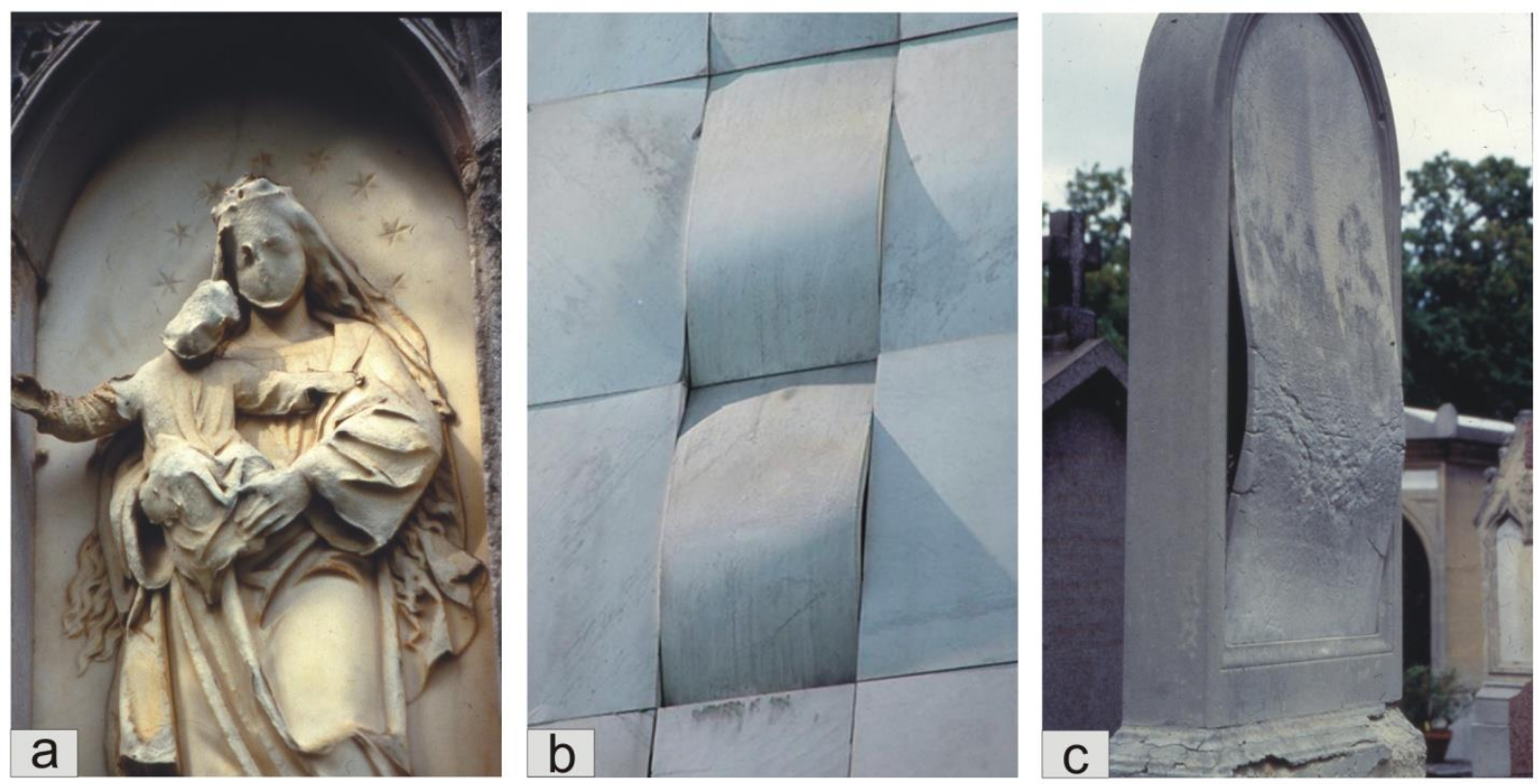

Fig. 1.2 Examples of marble degradation phenomena. (a) Madonna and Child statue of Carrara marble on a tombstone in the historic Munich cemetery. The statue is generally well preserved due to a thin, hardened outer layer. However, the interior rock fabric exhibits a progressive granular decohesion along the grain boundaries, the so-called sugaring phenomenon. (b) Details of a spectacular bowing phenomena of the Zagrepcanka building in Zagreb. Photo by bent Grelk and Jan Anders Brundin (www.geomasek.de and www.sp.se/building/team). (c) A warped gravestone of Carrara marble in the Montmartre Cemetery, Paris, France. 
Numerous cases of marble decay during environmental exposure have been investigated. For example, well-known buildings such as the Amoco building in Chicago (Trewitt and Tuchmann 1988), Finlandia Hall in Helsinki (Ritter 1992), the National Library in New York (Rabinowitzt and Carr 2012), and many others constructions made of marble shown progressive weathering. Weathering could be caused by temperature changes, moisture presence, frost actions, the presence of micro and macroorganisms, atmospheric pollution and salt solutions (Zezza et al. 1985, Bortz et al. 1988, Winkler 1994, Franzini 1995, Grimm 1999, Royer-Carfagni 1999, Tschegg et al. 1999, Fassina et al. 2002, Grossi et al. 2003, Schouenborg et al. 2003, Luque 2010, Ruedrich et al. 2011). Thereby, the study of marble decay mechanisms is vital for protecting historical heritage (Fig.1.3) and is also necessary from an economical perspective. Replacement of façade panels can be very expensive.
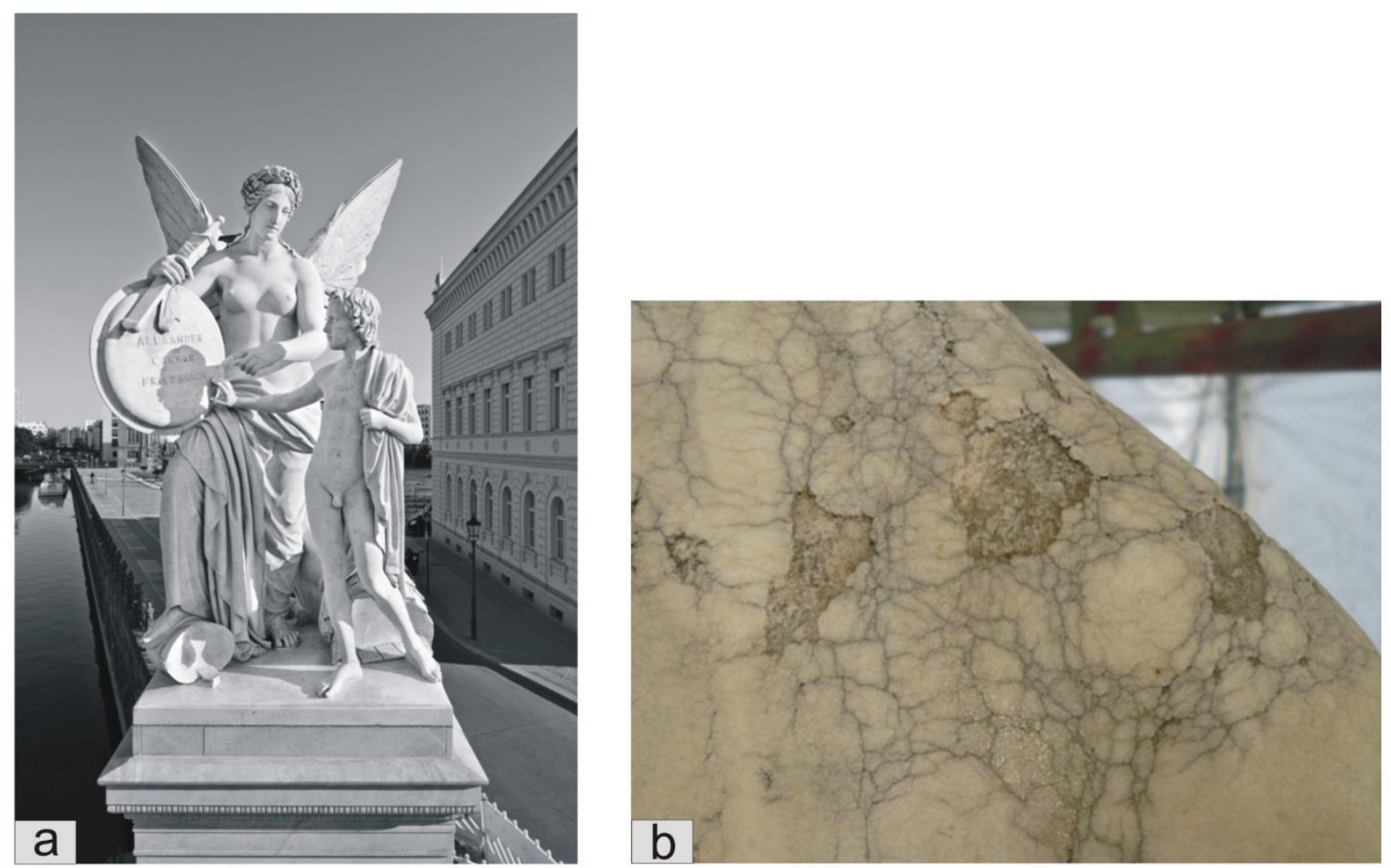

Fig. 1.3 (a) Marble Statuary from the Schlossbrücke, Unter den Linden (Berlin, Germany) "Nike instructs a boy in heroic history" by Emil Wolff, 1847 and (b) damage phenomena of intensive cracking and network of cracks (craquelling).

The reason for the degradation is mainly due to climate. Many studies have shown that increases and decreases of temperature can induce these degradation phenomena in marbles, e.g., Kessler (1919), Sage (1988), Battaglia et al. (1993), Winkler (1994), Logan et al. (1993), Siegesmund et al. (2000), Ondrasina et al. (2002), Zeisig et al. 
(2002). This deterioration is most spectacular for marbles, but is also observed for other rocks, like granite, Nagelfluh, and limestone, e.g., Weiss et al. (2004a), Siegesmund and Dürrast (2011).

Calcite and dolomite, the rock-forming minerals in marble, have a large anisotropy in their coefficients of thermal expansion along the different crystallographic directions. Consequently, in a polycrystalline structure the stochastic misfit strains produced by this thermal expansion anisotropy can produce large internal stresses, which occur mainly at triple junctions and along the grain boundaries (Siegesmund et al. 2000). Independently, or in combination with environment, e.g., moisture-assisted fracture (Henry et al. 1978; Atkinson 1984), these stresses can result in degradation phenomena, such as microcracking and granular disintegration (Koch and Siegesmund 2004, Siegesmund et al. 2008). Hot-stage environmental scanning electron microscopy (ESEM) can be used to provide direct evidence of such degradation phenomena during thermal cycling. In Fig. 1.4 one can observe the formation and propagation of microcracks near a triple junction in marble during the first heating and then cooling cycle. Such in-situ experiments provide great in-depth knowledge of degradation processes, e.g., the loss of cohesion and concomitant microcrack formation along grain boundaries, and confirm that the initial decay process in marbles results from temperature changes and the misfit strains that result from the anisotropy in thermal expansion of the marble crystals. 

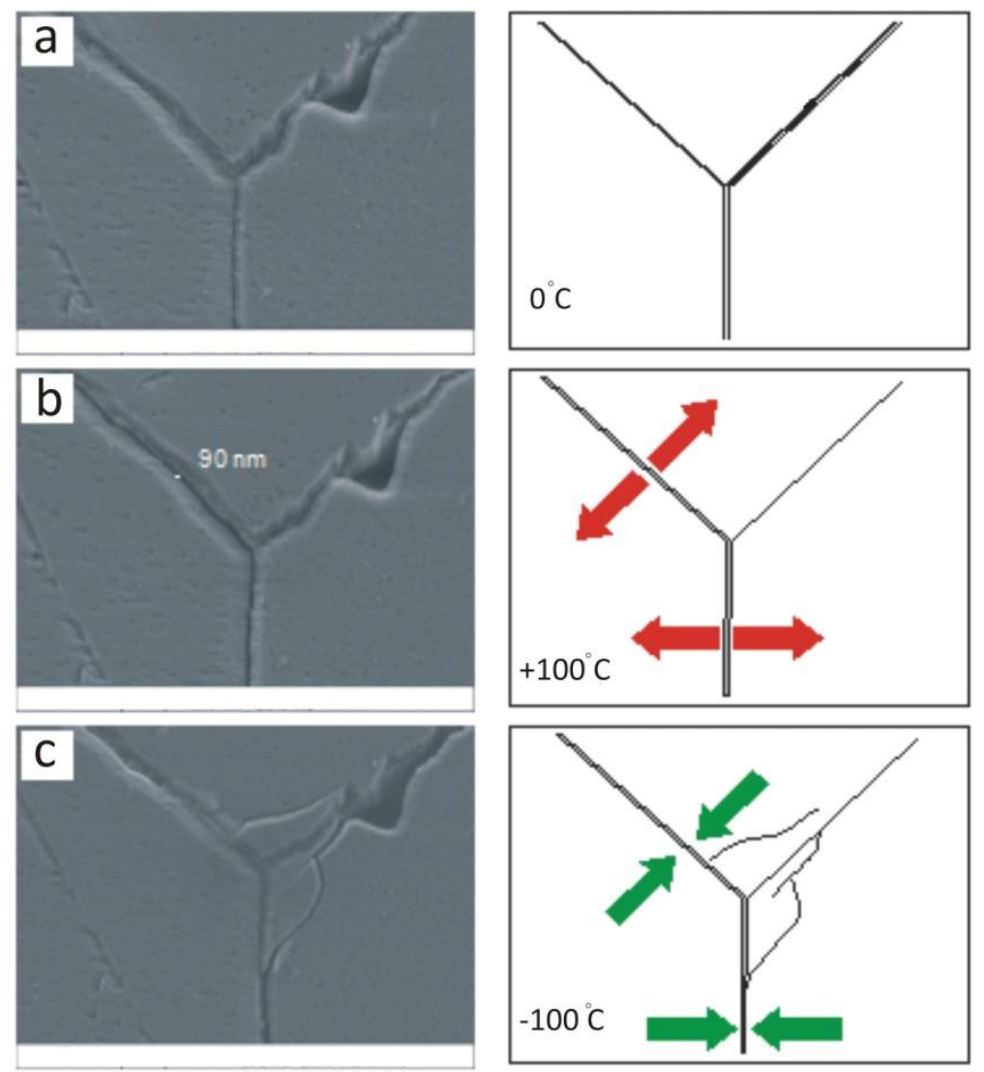

Fig. 1.4 Thermal-induced microcrack formation observed in a hot-stage environmental scanning electron microscopy (ESEM) on a marble sample upon heating and then cooling. Sketches in the right column illustrate schematically: (a) the initial rock fabric; (b) the red arrows shows the crack opening onset during heating due to dilatation; and (c) the green arrows illustrate the crack closure on cooling and the resulting formation of new cracks, when closure is hindered.

Additionally, thermal treatment can lead to the increasing of porosity in marble and hence to decreasing its strength (Bland and Rolls 1998, Ruedrich et al. 2002). Figure 1.5 illustrates the opening of grain boundaries for two Carrara marbles deformed to a different degree. The Carrara marble (S7) is characterized by open grain boundaries and significant higher bowing $(>11 \mathrm{~mm} / \mathrm{m})$ compared to the $\mathrm{S} 1$ marble $(<1 \mathrm{~mm} / \mathrm{m})$. The samples belong to the university library (SUB) in Göttingen, Germany. The increase in the grain-boundary opening is further documented by the measured total porosity: $0.45 \%$ for the S1 sample and $2.03 \%$ for the S7 sample. Moreover, the pore size maximum moves towards larger pore radii with an increase in the amount of bowing (Siegesmund et al. 2008). The maximum pore diameter of the sample S7 is around $1 \mu \mathrm{m}$, and hence in the range of capillary pores, while in sample $S 1$ the maximum pores are significant smaller. The increase in porosity and the resulted bowing were caused by the thermal behavior of calcite crystals described above. 

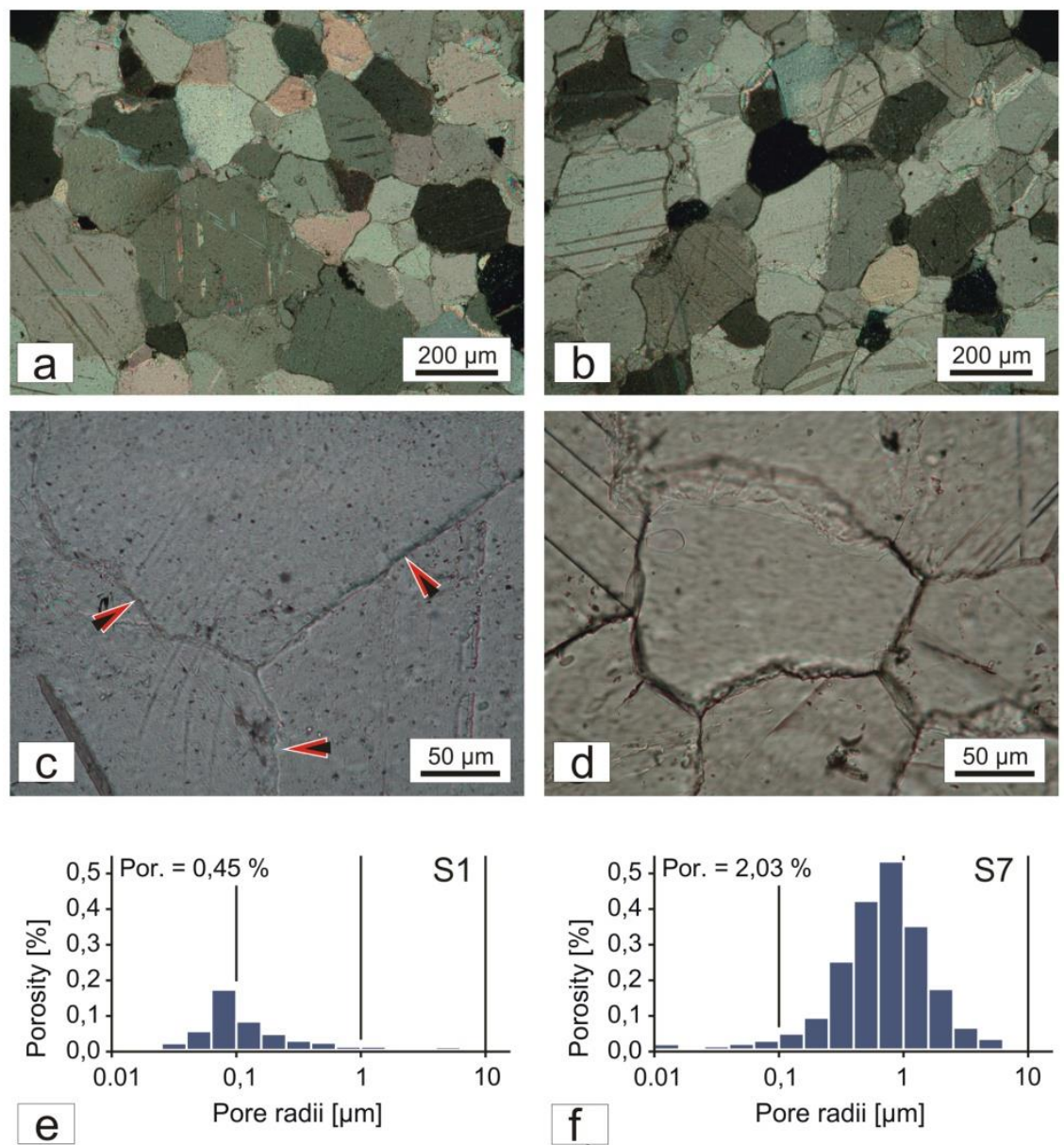

Fig. 1.5 Representative thin section images of (a) slightly deformed Carrara marble and (b) strongly deformed Carrara marble; (a, b) overview (crossed polarizers) and (c,d) details of the grain boundaries;

(e) pore radii distribution of slightly deformed Carrara marble $(\mathbf{f})$ pore radii distribution of strongly deformed Carrara marble. Shown in $(\mathbf{e}, \mathbf{f})$ is the percent of the porosity in each pore size range. The total porosity is shown in the insert (modified from Siegesmund et al. 2008).

Thermal expansion anisotropy degrades calcitic marbles more than dolomitic marbles, and the degradation is more severe if the marbles have straight grain boundaries, e.g., Weiss et al. (2002), Siegesmund et al. (2000), Luque et al. (2011), Shushakova et al. (2012).

Many fabric parameters influence this thermal degradation, notably, lattice preferred orientation (LPO), shape preferred orientation (SPO), grain size, grain-boundary toughness, grain-to grain misorientation (Widhalm et al. 1996, Tschegg et al. 1999, Siegesmund et al. 2000, Zeisig et al. 2002, Weiss et al. 2002; 2003; 2004b, Saylor et al. 2007, Siegesmund et al. 2008, Shushakova et al. 2011, Shushakova et al. 2012) and marble composition (Royer-Carfagni 1999, Siegesmund et al.2000), as well as the 
single-crystal properties of the rock forming minerals. Additionally, as has already been mentioned, the type of grain boundaries is an important factor that determines the behavior of marbles during thermal tests. Simple grain boundaries indicate a lower binding energy between them and interlobate grain boundaries reflect higher binding energy between grains (see Siegesmund et al. 2000, Alnæs et al. 2004, Grelk et al. 2004). Microstructure-based finite-element simulations were used by Weiss et al. (2002; 2003; 2004b), Saylor et al. (2007), Wanner et al. (2010), Shushakova et al. (2011), and Shushakova et al. (2012) to provide excellent insight into the influence of crystal texture (lattice preferred orientation) and grain-neighbor misorientation configurations on the microstructural strain energy and stresses affecting thermal degradation. The thermal expansion behavior of marbles was modeled with a good coincidence to real experiments (Zeisig et al. 2002, Luque et al. 2011).

The goal of the present thesis is to establish the influence of fabric parameters on the marble degradation phenomena caused by thermal expansion and to predict the material behavior based on the rock fabric data. Two dimensional finite-element simulations (the object-oriented finite element analysis of microstructures (OOF), developed at the National Institute of Standards and Technology (USA)), EBSD technique, and thermal expansion measurements under dry and water-saturated conditions are applied. The work consists of four case studies. In the first and second case studies artificial microstructures and modeled textures are used. The third and fourth case studies consider the real marble samples.

The first case study (chapter 4 ) is focused on the elucidation of the synergistic influence of shape fabric (e.g., SPO) and crystal texture (e.g., LPO) on factors, such as the stored elastic strain energy density and microstructural stresses, that influence marble degradation. Microstructure-based finite-element simulations are used to explore a wide range of modeled SPO and LPO. In order to define the dependence of marble degradation on SPO and LPO the extremes of shape fabric are examined: an equiaxed and an elongated microstructure with an intermediate case that is a mixture of the two extremes. Extremes of crystal texture are considered: from a random orientation distribution function (ODF) to ODFs that are crystallographically textured at 20 and 40 times a random ODF. Additionally, the directionality of the LPO with respect to the SPO 
is examined. The influence of the content of calcite and dolomite in marble on degradation phenomena is elucidated.

In the second case study (chapter 5) the influence of rock's fabric on propensity and extent of microcracking in marble structures is investigated, and the relation of the degradation to microstructural indicators is established. Two-dimensional finite-element simulations are used to elucidate microcracking initiation and propagation in calcitic and dolomitic marbles. The influence of fabric parameters include: extremes of crystallographic texture, a random orientation distribution function (ODF) and crystallographic texture 20 times a random ODF; three morphological types of microstructures; different grain sizes; various grain-boundary toughness; and different marble composition.

In the third case study (chapter 6) eight different well-known marbles with various fabric parameters were selected for a study of their thermal-elastic behavior. Microstructurebased finite-element simulations in combination with electron microscopy (EBSD technique), and experimental measurements of the thermal expansion behavior were used to elucidate the influence of rock fabrics on marble degradation. The finite-element simulations used to determine the thermal-elastic responses of the marbles. Electron backscatter diffraction (EBSD) measurements were used to determine the microstructures and the crystallographic orientations of grains of the marble samples. Additionally, the directional dependence of the thermal expansion was computed with the MTEX software using the crystal texture measured by EBSD. The results are compared with the experimental data and numerical simulations.

In the fourth case study (chapter 7 ) the volume extension index (decay index) of marble was developed. This index reflects the relative volume change on the basis of the knowledge of thermal dilatation under dry and wet conditions. An assessment of marble stability was done for the investigated marble samples. 
Fabric parameters: terminology

\section{Fabric parameters: terminology}

\subsection{Marble composition}

Marble is a metamorphic rock formed from limestone by pressure and heat in the earth crust due to geological processes and consists predominately of calcite and dolomite. Additionally, some impurities could be present, such as quartz, feldspars, phyllosilicates, epidote or amphiboles. Since marble is considered to be a monomineralic rock, its physical properties will be defined by the properties of main rock forming minerals calcite or dolomite. Their single-crystals constants and the crystalline coefficients of thermal expansion are given in Table 2.1. Calcite and dolomite are minerals of trigonal symmetry.

Table 2.1 The single-crystal elastic constants, $\boldsymbol{C}_{i j}$, in GPa (Bass 1995) and the crystalline coefficients of thermal expansion, $\boldsymbol{\alpha}_{i j}$, in $10^{-6} \mathrm{~K}^{-1}$ for calcite (Kleber 1959) and dolomite (Reeder and Markgraf 1986).

\begin{tabular}{|c|c|c|c|c|c|c|c|c|c|}
\hline Material & $\mathbf{C}_{\mathbf{1 1}}$ & $\mathbf{C}_{\mathbf{1 2}}$ & $\mathbf{C}_{\mathbf{1 3}}$ & $\mathbf{C}_{\mathbf{1 4}}$ & $\mathbf{C}_{\mathbf{1 5}}$ & $\mathbf{C}_{\mathbf{3 3}}$ & $\mathbf{C}_{\mathbf{4 4}}$ & $\boldsymbol{\alpha}_{\mathbf{1 1}}$ & $\boldsymbol{\alpha}_{\mathbf{3 3}}$ \\
\hline Calcite & 144.0 & 53.9 & 51.1 & -20.5 & 0 & 84.0 & 33.5 & -6.0 & 26.0 \\
\hline Dolomite & 205 & 70 & 57.4 & -19.5 & 13.7 & 113.0 & 39.8 & 6.0 & 26.0 \\
\hline
\end{tabular}

Both minerals show a pronounced anisotropy in their coefficients of thermal expansion. Calcite expands in one direction along c-axis upon heating, while contracting along the a-axis; and upon cooling the dilation is in the opposite direction (Fig. 2.1). Dolomite has positive values for the coefficients of thermal expansion, however, by different amounts, and thus expands or contracts in all directions upon heating or cooling, respectively (Fig.2.2). Due to the large anisotropy in the coefficients of thermal expansion of both minerals $\left(32 \times 10^{-6} \mathrm{~K}^{-1}\right.$ for calcite and $20 \times 10^{-6} \mathrm{~K}^{-1}$ for dolomite) residual stresses develop between the adjacent grains upon changes of temperature, either an increase or a decrease. Dolomite with its smaller thermal expansion anisotropy should be more resistance to the deterioration in spite of its stiffer elastic behavior. 


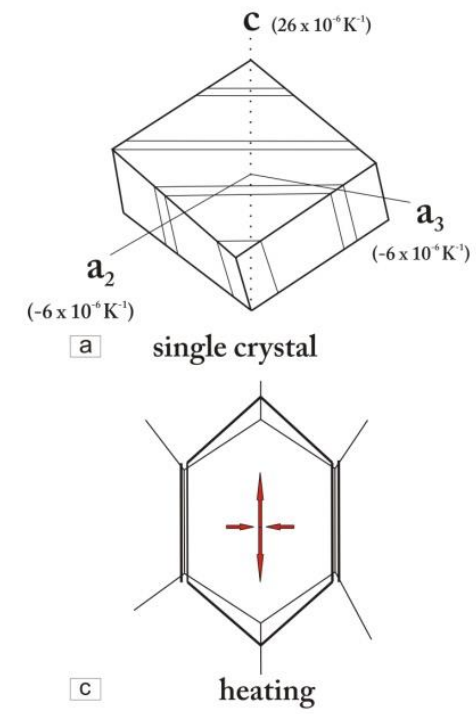

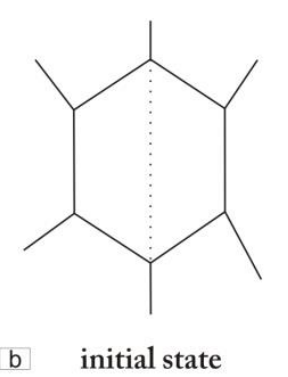

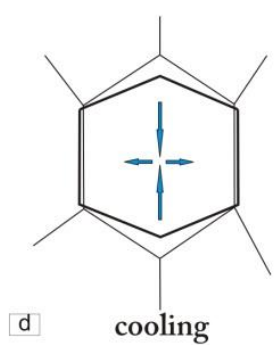

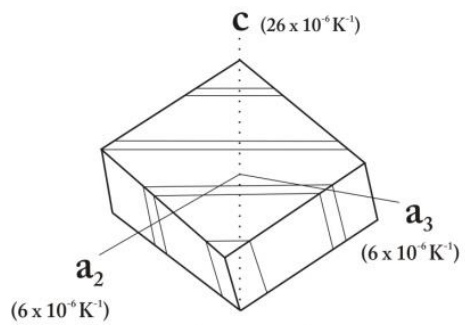

a single crystal

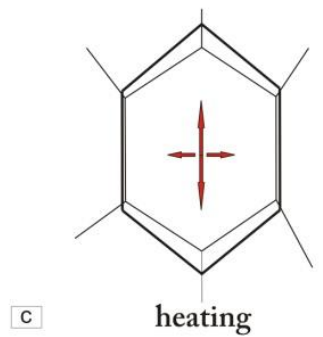

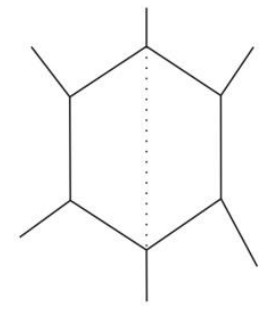

b initial state

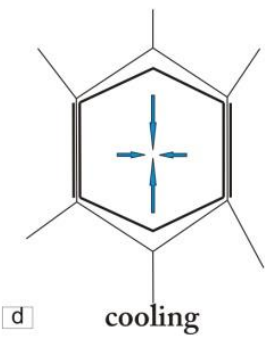

Fig. 2.1 The illustration of calcite thermal behavior. (a) Anisotropy of thermal expansion coefficients of Fig. 2.2 The illustration of dolomite thermal behavior. (a) Anisotropy of thermal expansion crystal, (b) initial state of crystal in idealized marble coefficients of crystal, (b) initial state of crystal in matrix, (c) expansion of c-axis and contraction of aidealized marble matrix, (c) expansion of c-axis axes upon heating, (d) expansion of a-axes and contraction of $\mathrm{c}$-axis upon cooling (modified after and expansion of a-axes upon heating, (d) Steiger and Charola 2011 (from Siegesmund et al. upon cooling. 2004 and Luque 2010)).

\subsection{Shape preferred orientation (SPO)}

Fabric elements of marbles form during ongoing tectonic processes. In general, fabric is related to particular strain parameters, though these relationships are often not straightforward (Means, 1976). Fabric elements themselves may consist of foliations, lineations, or lattice preferred orientations (Passchier and Trouw, 1996). Calcite and dolomite are the principal mineral components in marble and their deformation mechanisms and slip systems influence strongly the formation of its fabric (Koch, 2006).

A foliation is any layered fabric in a rock. Often, layers are thought of as planar, but in fact, in deformed rocks, the layering is more commonly curvi-planar. The planar fabric itself can be due to platy minerals elongated in a single direction, or planar discontinuities due to deformation or original compositional layering in the rock, usually in the case of metasediments (Borradaile et al., 1982). 
Fabric parameters: terminology

A lineation is any fabric best represented by a line, where a fabric element is much more strongly pronounced in one direction than any other. Linear features can develop due to intersections of two planar features with one another or due to tectonic stretching or preferred alignment of neo-formed minerals (Passchier and Trouw, 1996).

The foliation could be produced by oblate grains (Fig. 2.3a) and lineation by prolate grains (Fig. 2.3b) (Ruedrich 2003). Shape preferred orientation defines the anisotropic spatial distribution of the short and long axes of crystals (Siegesmund and Török 2011).

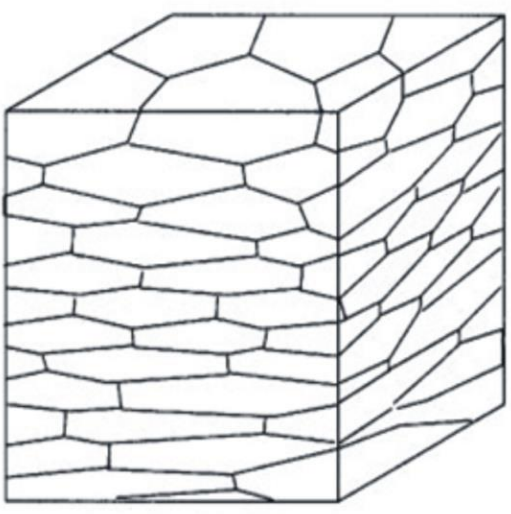

a

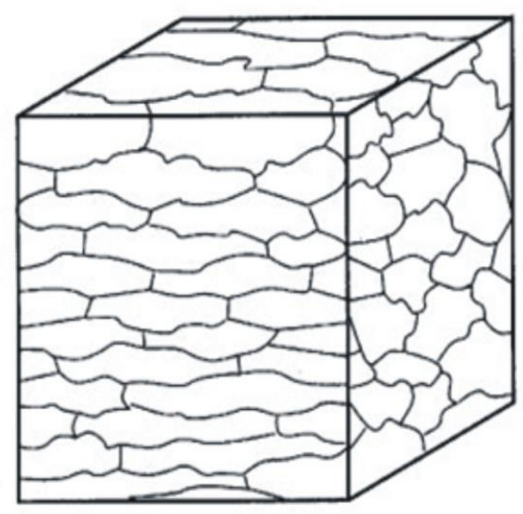

b

Fig. 2.3 The schematic illustration of (a) foliation and (b) lineation (after Ruedrich (2003) from Passchier and Trouw (1996)).

Myriad shape preferred orientations (SPO) and lattice preferred orientations (LPO) are observed for calcite and dolomite in limestone and marble. Both minerals are easily deformable at low temperatures, as is known from natural examples and from laboratory deformation studies (e.g., Leiss and Molli 2003). SPO is common in calcite and dolomite and mainly results via plastic deformation. Nonetheless, recrystallization and graincoarsening can reset the grain shapes to an equiaxed fabric (Shelley 1993, Bukhard 1993, Ferrill 1998).

\subsection{Lattice preferred orientation (LPO)}

Lattice preferred orientation (LPO) may also be formed during deformation. LPO is the result of intracrystalline plasticity, and when present, it will also determine directionally 
dependent, physical and mechanical properties of a rock (Siegesmund and Török 2011). LPO is sometimes referred to as "micro-fabric".

LPO is usually represented by lower hemisphere, stereographic projection of poles to crystallographic planes. Undeformed rocks show no preferred crystallographic orientations of any planes and as a result, the plot of poles covers the entire hemispheric projection evenly. Deformed rocks show strong preferred orientation, resulting in different concentrations of poles according to the type of deformation the rock has undergone (see Fig.2.4).
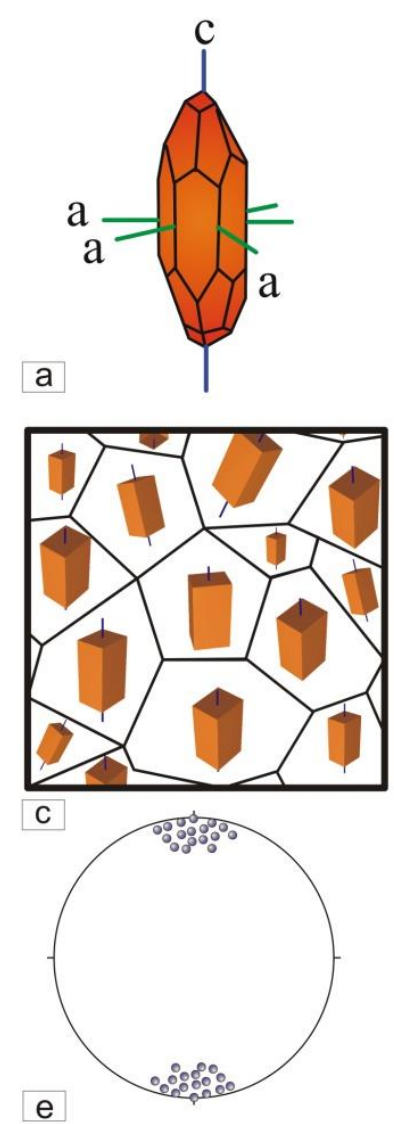

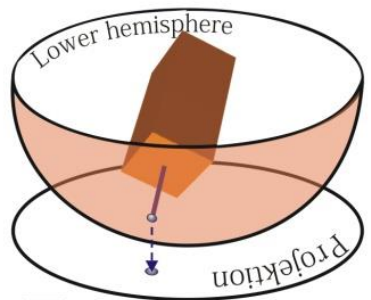

b
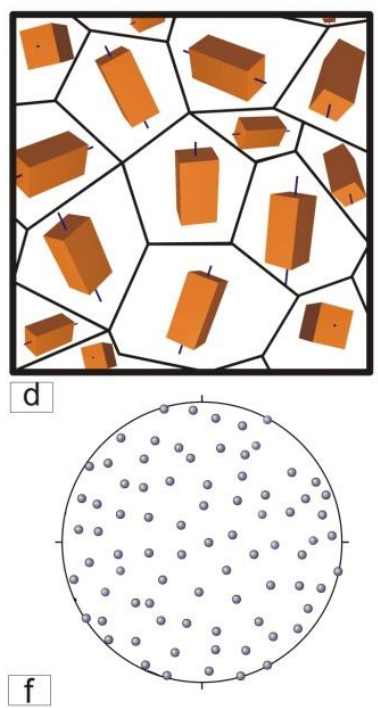

Fig. 2.4 Illustration of LPO in marble: (a) calcite single crystal, (b) the projection of position of c-axis in a Schmidt net, (c) the preferred orientation of crystals, (d) randomly oriented crystals, (e) pole points of caxis showing the small clusters characterize strong texture, (f) pole points of c-axis scattering over the whole pole figure represent random texture (from Siegesmund and Török 2011).

As is the case for most rock-forming minerals, LPO for calcite strongly depends on the active slip systems, and on the geometry and symmetry of the flow pattern. This results in a LPO geometry that is similar to the strain geometry (Kern and Wenk 1983; Wenk et 
al. 1987; Shelley 1993; Passchier and Trouw 1996). For example, in uniaxial compression, calcite develops a LPO with the c-axes close to the shortening direction and at a high angle to foliation, i.e., c-axes have a maximum around the compression axis. In constriction a c-axes-girdle develops perpendicular to an a-axis.

Leiss and Ullemeyer (1999) described fundamental calcite and dolomite texture types as c-axis and a-axis fiber type, or overlapping of these two texture types. Later Leiss and Molli (2003) found one more type of texture, called high-temperature texture in natural marbles of Carrara. Fiber-texture characterizes as texture with axial symmetry and could be defined as a single crystal rotation around a specific axis (Leiss and Ullemeyer 1999). In the c-axis fiber texture the rotation axis is c-axis, which results in a single c-axis-maximum and an a-axis-distribution on a girdle. In the a-axis fiber texture one of the a-axes is rotation axis, that results in a single a-axis-maximum and c-axisarrangement on a girdle. High-temperature texture type is characterized by a double maximum of the c-axis with a bisecting line normal to the share plane and the-axis distribution displays an adequate broad a-axis maximum normal to the shear direction (Leiss and Molli 2003). All texture types are shown in Fig. 2.5.

c (006)
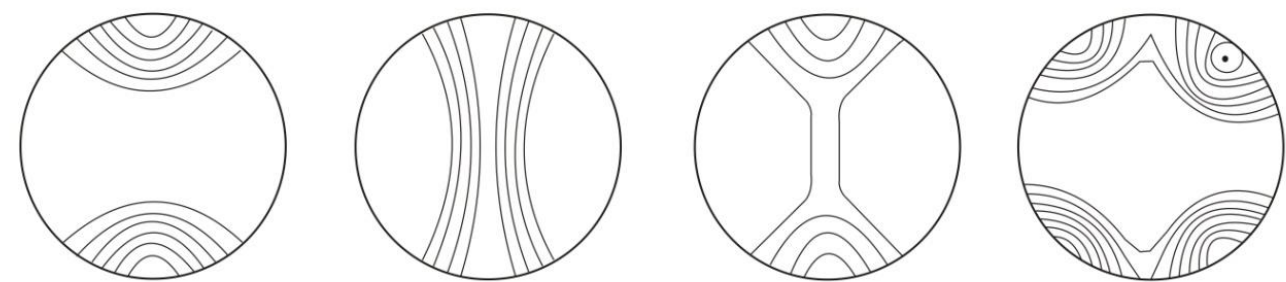

a (110)
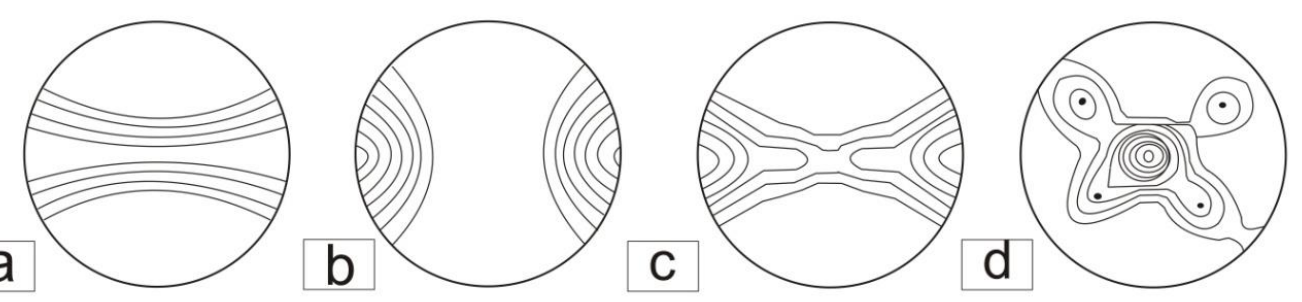

Fig. 2.5 Schematic illustration of pole figures of c-axis and a-axis of typical marble texture types: (a) caxis fiber type, (b) a-axis fiber type, (c) intermediate fiber type, (d) high-temperature texture type (modified after Koch 2006 and Leiss and Molli 2003). 
Fabric parameters: terminology

\subsection{Grain size}

Grain size is important rock fabric that gives information about the nature of rock formation. Moreover, grain size distribution controls the frequency and distribution of grain boundaries (Ruedrich 2003). The following terminology to describe grain size was used (Table 2.2).

Table 2.2 Classification of grain size for rocks (modified after Koch 2006 from Wimmenauer 1985).

\begin{tabular}{|cc|}
\hline Designation & Grain diameter, mm \\
Very fine-grained & $0.01-0.1$ \\
Fine-grained & $0.1-0.3$ \\
Small-grained & $0.3-1.0$ \\
Medium-grained & $1.0-3.3$ \\
Coarse-grained & $3.3-10$ \\
\hline
\end{tabular}

The size distribution of grains could be classified as equigranular (or equiaxed), when grains have more or less equal size; inequigranular, if distribution of different grain sizes is presented; and seriate, this is the case of gradation of fine- to coarse-grained distribution (Passchier and Trouw 1996).

\subsection{Grain boundary configuration}

Grain boundary geometry in rocks may be polygonal, when grain boundaries are straight, and interlobate, in the case of irregular, lobate grain boundaries (Moore 1970). A polygonal grain boundary configuration is the result of a geological process known as static recrystrallisation. This is a post-deformation mechanism that reduces grain boundary area and hence free energy along grain boundaries to a minimum (Passchier and Trouw 1996).

In combination with grain size distribution the classification of shape of grain aggregates follows (Fig. 2.6). 


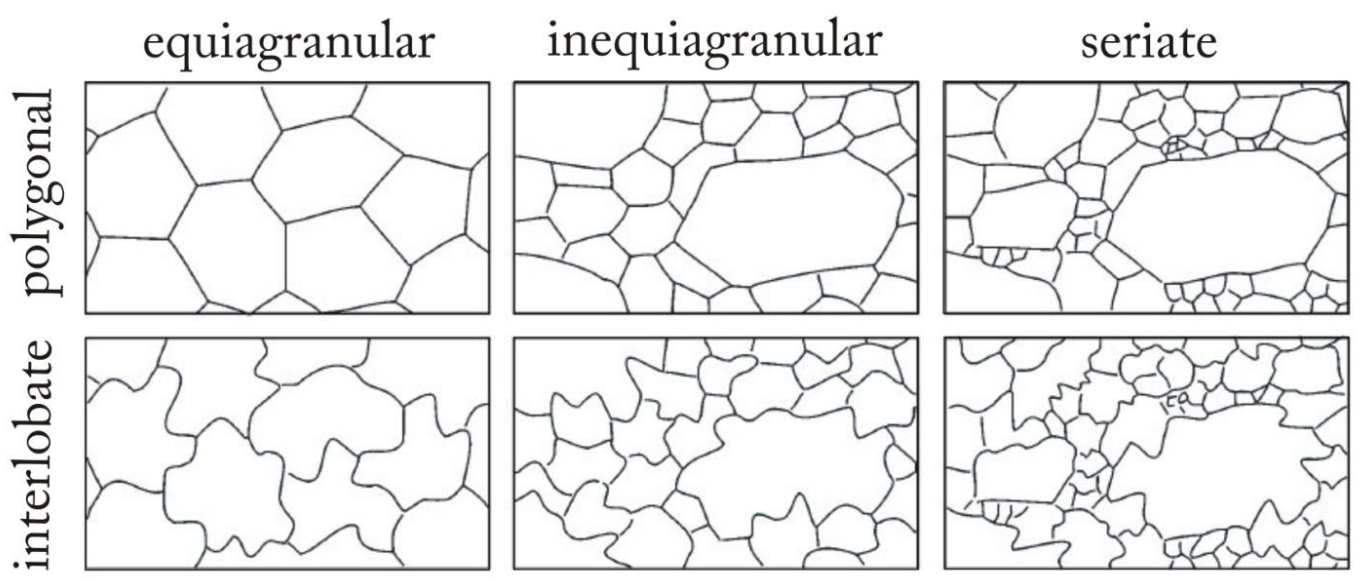

Fig. 2.6 Classification of fabric for the shape of grains and grain aggregates (after Ruedrich 2003 from Passchier and Trouw 1996).

\subsection{Microcracks}

Microcracks are another common fabric element in marble, and can be formed during different geological processes and under various conditions. There are three general classes of microcracks based on their position within rock (see Fig. 2.7): intergranular (microcracks occur along grain boundaries), intragranular microcracks which appear within the mineral grains and transgranular microcracks those cut more than one grain (Kranz 1983). Three different classes of microcracks based on their state are distinguished: open (usually the youngest crack generation, has significant influence on the material behavior (Vollbrecht et al. 1993)); mineralized cracks (microcracks formed during later mineralization) are classified into "healed" (microcracks which are filled with the same material as the host grain), and "sealed" (microcracks those are filled with a foreign material). Microcracks could form complex networks and afterwards with crack growth lead to formation of macroscopic fractures (Siegesmund and Török 2011).
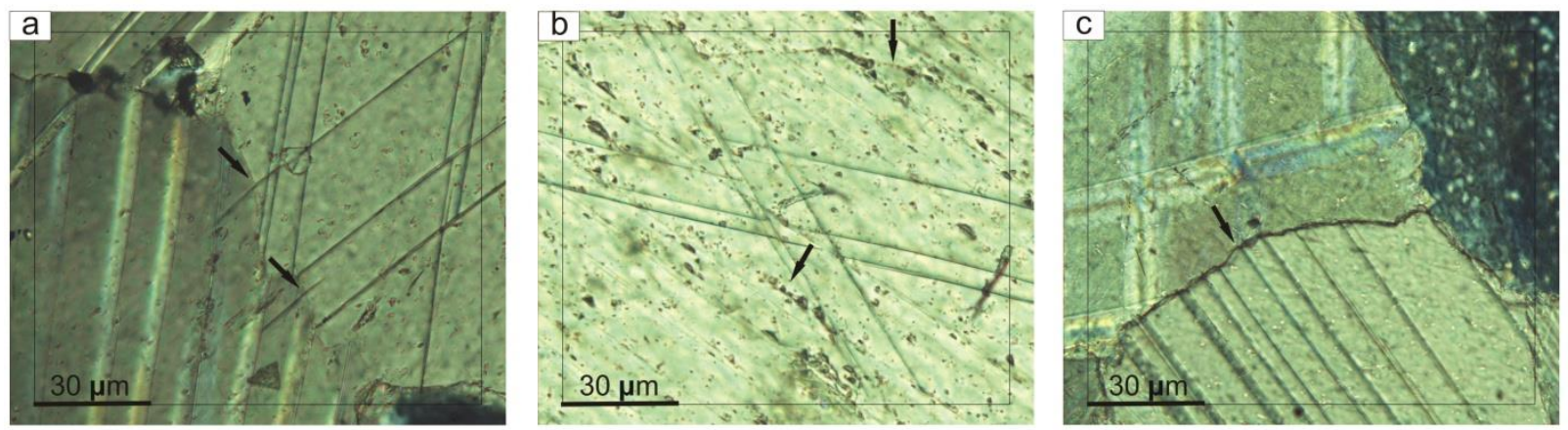

Fig. 2.7 Thin section images of Lasa marble: (a) transgranular opened microcracks in XY plane (b) intragranular partly "healed" with calcite microcracks in YZ plane, (c) intergranular partly "sealed" with hematite microcracks in XY plane. Black arrows indicate the location of microcracks. 
Methods and materials

\section{Methods and materials}

\subsection{OOF approach}

The microstructure-based finite-element approach used here is based on the ObjectOriented Finite Element program OOF developed at the National Institute of Standards and Technology (Langer et al. 2001). The OOF software is in the public domain. Executables, source code, and manuals are available at the website: http://www.nist.gov/msel/ctcms/oof/. The OOF1 software was used here.

OOF consists of two programs: ppm2oof and oof. The program ppm2oof involves a twostep procedure: the identifying microstructural features and creating a finite element mesh from these features. The purpose of the first step is to assign the material type to each pixel and then to combine pixels to pixelgroups (for instance, each grain represents a pixelgroup). The second step is used to create a finite element mesh. There are two principally different methods: adaptive meshing and simple meshing. The first method based on the subdividing triangles and movement of the nodes to conform to the microstructure (Carter et al. 1998, Langer et al. 2001, Chawla et al. 2003). In the second method every pixel in the microstructure is divided into two triangular elements. Both methods have advantages and disadvantages. In adaptive meshing if the mesh is too coarse, there is not high enough accuracy for the triangular mesh to accurately reproduce the rock fabric adequately (Weiss et al. 2002). Simple mesh creates too many elements when large homogeneous regions can be discretized more coarsely. Moreover, the extremely large number of mesh elements would have required much more computer resources that are available. Both meshing types were applied in the present thesis for different purposes. An example of adaptive mesh is shown in Fig. 3.1.

The ppm2oof program was designed to be a front-end for the actual finite element program oof (Carter et al. 2003). It creates a specialized data file including the mesh (goof), which is used as the starting point for oof for further computational simulations. After the thermo-elastic properties and orientations are assigned to each pixelgroup, and boundary conditions with temperature differential are set, the matrix equation $\mathrm{Kx}=\mathrm{f}$ is solved by oof, where $\mathrm{K}$ is a stiffness matrix, $\mathrm{f}$ is a vector of external and thermal forces and $x$ is the degrees of freedom being solved (Carter et al. 2003). The matrix equation is solved when the norm of $\mathrm{Kx}-\mathrm{f}$ is less than the chosen tolerance times the norm of $f$. Tolerance and number of iterations should be specified as well. 
More detailed presentation of matrix equation can be described as following (Reid et al. 2009):

$$
\begin{aligned}
& \sigma_{j}=\sum_{i} C_{i j} \varepsilon_{i} \text { (generalized Hook's law) } \\
& \nabla \sigma_{j}=f_{j}
\end{aligned}
$$

where $\varepsilon_{i}$ is the strain, $C_{i j}$ is the elastic stiffness tensor, $\sigma_{j}$ is the stress and $f_{j}$ is an applied force.

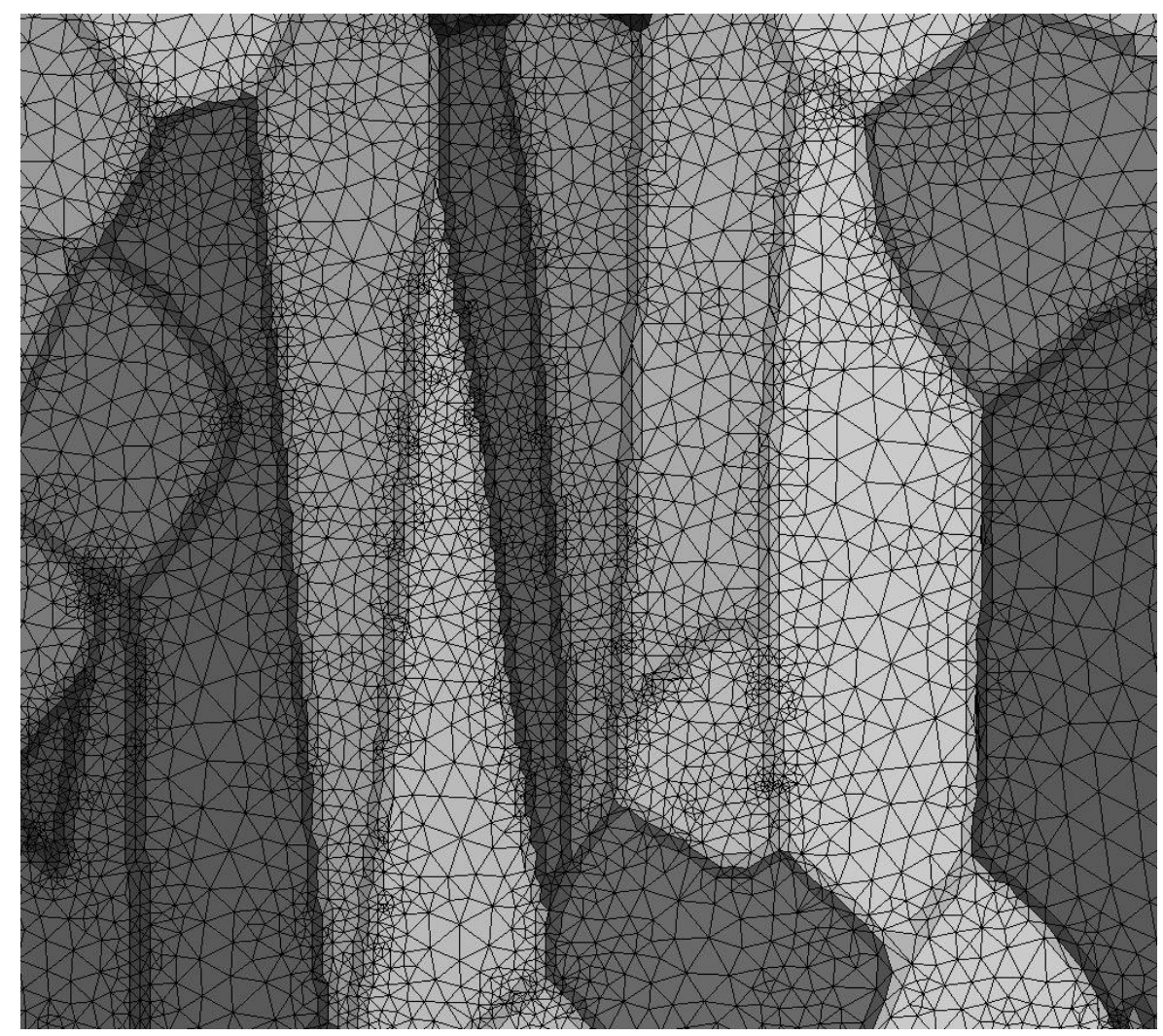

Fig. 3.1 Small region of the complete adaptive mesh of microstructure with mixed of equiaxed and elongated SPO.

Material properties in OOF are given in three-dimensional form and after assigning them to microstructure they are reduced to two-dimensional form by specifying plane stress or plane strain (Reid et al. 2009). OOF can compute strains, stresses, thermal distortions and display the results. 
To calculate the strain the conjugate gradient algorithm (Press et al. 2002) is used to determine the strain $\varepsilon$ for each element. The total elastic strain energy could be found as:

$$
E=\frac{1}{2}\left[C_{i j}\left(\varepsilon_{i}-\varepsilon_{i}^{T}\right)\left(\varepsilon_{j}-\varepsilon_{j}^{T}\right)\right]^{l} \Delta A^{l}
$$

where $C_{i j}$ is a stiffness tensor at each element, $\varepsilon_{i}^{T}$ is the thermal misfit strain at each element and $\Delta A$ is the element area. The repeated indices $i, j$ are summed from 1 to 6 , and superscript index I is summed over the elements (Saylor et al. 2007). To visualize elastic strain energy, where $\varepsilon_{i}$ is the calculated strain for each element and has six components, the element strain energy density was used (Saylor et al. 2007):

$$
U=\frac{1}{2}\left(\varepsilon_{i}-\varepsilon_{i}^{T}\right) C_{i j}\left(\varepsilon_{j}-\varepsilon_{j}^{T}\right)
$$

Additionally, for each element the stress tensor is calculated and could be displayed in Cartesian coordinates, i.e., $\left(\sigma_{x x}, \sigma_{x y}, \sigma_{x z} ; \sigma_{y y}, \sigma_{y z} ; \sigma_{z z}\right)$. Three eigenvalues from this tensor can be found $\left(\sigma_{\min }, \sigma_{\text {mid }}, \sigma_{\max }\right)$ and represent the minimum, middle and maximum principal stresses, respectively. The simulations performed in the present thesis are plane stress and two-dimensional and hence $\sigma_{z z}=\sigma_{x z}=\sigma_{y z}=0$, and $\sigma_{\max }=0$ corresponds to a state of in-plane compression, i.e., $\sigma_{\min }$ and $\sigma_{\text {mid }}$ are negative. Thus, the maximum principal stress ranges from 0 to some tensile value and can never be negative.

To simulate microcracking in OOF, a Griffith-like algorithm was implemented. The Griffith criterion based on the balance between mechanical and surface energy. It states that a crack will propagate when the total surface energy required to propagate the crack can be supplied by the elastic energy stored in the body (Carter et al. 2003). Element's elastic properties are mutated when element reaches the critical energy density which equals to

$$
e_{c}=\frac{4 \gamma_{s}}{\sqrt{A_{e} \pi}}
$$

where $\gamma_{s}$ is surface energy and $A_{e}$ is element area (Zimmermann et al. 2001, Galal Yousef et al. 2005). 
Elements, which are mutated (cracked), are actually elements that reduce their moduli anisotropically to simulate a crack. The amount of surface area generated by mutation has to be estimated (Carter et al. 2003).

\subsection{EBSD technique}

In order to obtain data from real marble samples for OOF simulations Electron backscatter diffraction (EBSD) technique was applied. EBSD is texture analyzing technique of scanning electron microscope (SEM), where the SEM is equipped with a EBSD detector. The detector is a digital camera with CCD chip which is illuminated by the phosphor screen. The phosphor transforms the diffracted electrons into light appropriate for the CCD camera to record (Maitland and Sitzman 2006). For an EBSD measurement a polished sample (cylinder $20 \mathrm{~mm} \times 15 \mathrm{~mm}$ ) is placed in the SEM chamber at a titled angle ( $70^{\circ}$ from horizontal) towards to EBSD detector. With an electron beam point on the sample surface electron diffraction occurs and EBSP (electron backscatter diffraction pattern) is produced from this point. EBSP is uniquely defined when diffracted electrons form Kikuchi bands (when Bragg condition is satisfied), which are detected by the EBSD software and correspond to the lattice diffracting planes. When the band location is defined (by Hough transform), the software relates these locations to the corresponding crystal orientation, since angles between bands represent angles between lattice planes (Dingley and Randle 1992).

Once the EBSP is solved, its phase, xy position of measured grid, orientation and other values are recorded. EBSD data collection is analyzed and converted by the Oxford Instruments HKL Channel 5 program, which includes different tools to create microstructural map and pole figures from the EBSD data. In the microstructure grains are colored according to their measured crystallographic orientation represented by three Euler angles. Euler angles were converted to a red, green and blue color and combined into a single RGB color per pixel by Tango-mapping (HKL Technology CHANNEL 5 Manual). Similar colors in microstructural map indicate similar orientations of grains. The schematic illustration of obtaining grain orientations and microstructure via EBSD is shown in Fig. 3.2. 


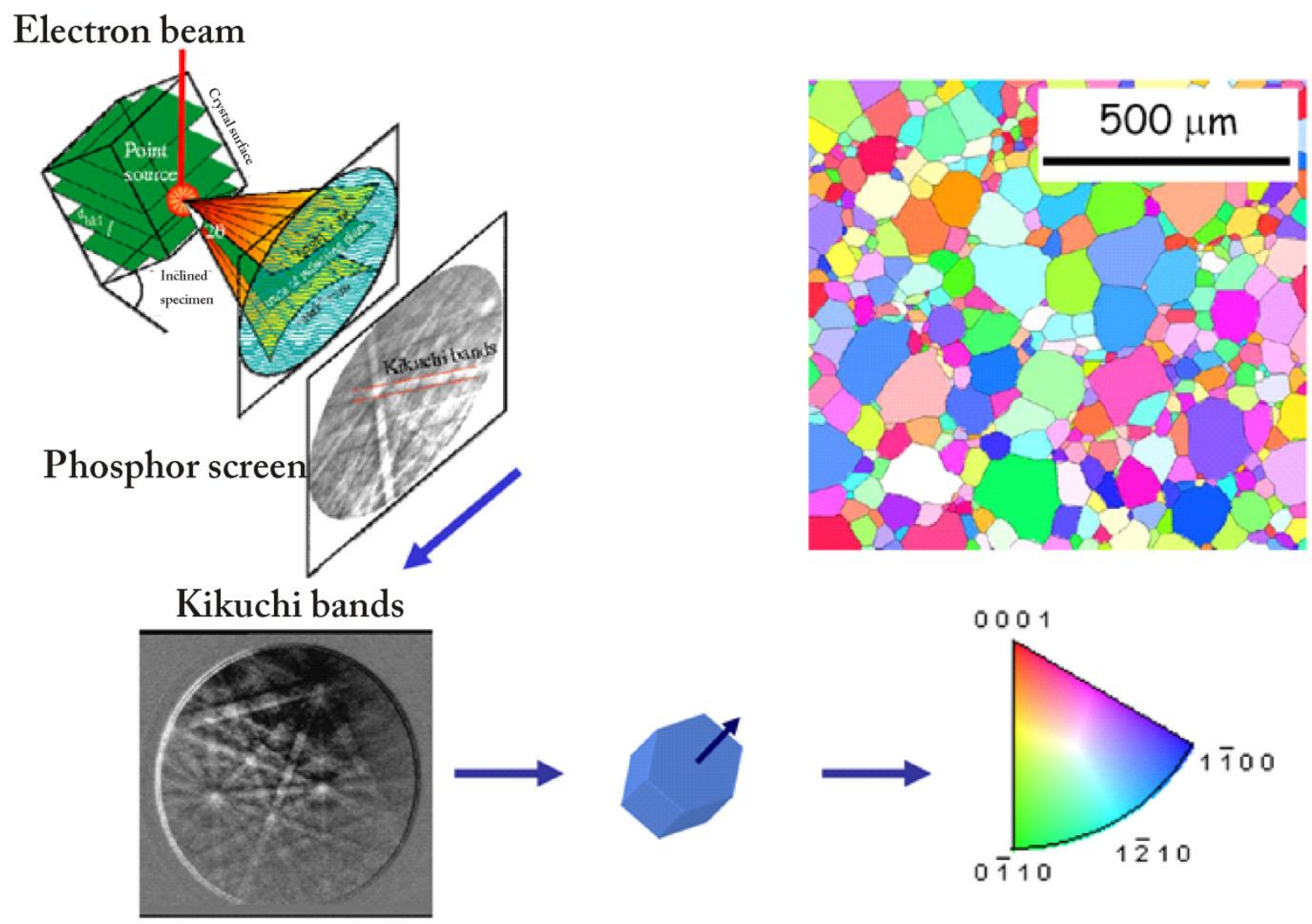

Fig. 3.2 The schematic illustration of obtaining grain orientations and microstructure via EBSD technique.

3.3 Thermal expansion measurements under dry and water-saturated conditions

The temperature fluctuations and the presence of water are the main external factors that lead to marble deterioration. To replicate temperature changes observed in nature on building stones, thermal expansion measurements were performed in the temperature range $20^{\circ} \mathrm{C}$ to $90^{\circ} \mathrm{C}$ using a pushrod dilatometer with a rate of increase $1^{\circ} \mathrm{C} /$ min to ensure thermal equilibration of the specimen (Strohmeyer 2003, Koch and Siegesmund 2004). The three main components of the dilatometer are (i) the specimen holder in a climate chamber; (ii) the heating unit; and (iii) the displacement register (Fig. 3.3). The displacement sensors are able to determine length changes of $\pm 1 \mu \mathrm{m}$. Thus, a final residual strain of about $0.02 \mathrm{~mm} / \mathrm{m}$ could be resolved for sample with a length of 50 $\mathrm{mm}$. A quartz glass sample was used to calibrate the dilatometer. 


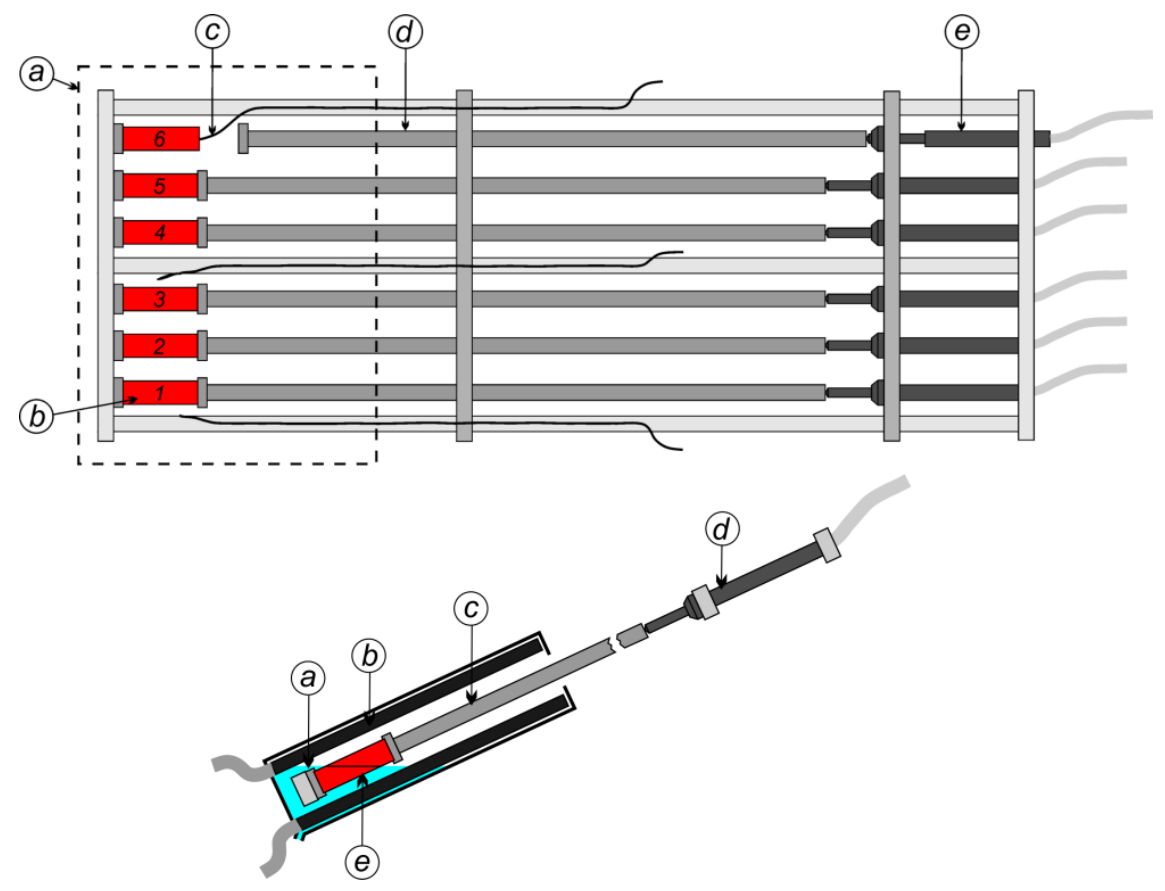

Fig. 3.3 Overview of the pushrod dilatometer. At the top: (a) position of the climate chamber, (b) specimen cylinder, (c) temperature sensor, (d) quartz glass pushrod, (e) displacement sensor. At the bottom: (a) water level, (b) heat exchanger copper plate, (c) quartz glass pushrod, (d) displacement sensor, (e) specimen cylinder (after Koch and Siegesmund 2004 from Strohmeyer 2003).

The experimental setup allows the thermal dilatation of up to six samples to be measured simultaneously at same conditions. For thermal expansion measurements the six specimens were cut in the X-, Y-, Z-, XY-, XZ-, and YZ- directions for each marble type (Fig. 3.4). The dilatometry samples were cylinders $15 \mathrm{~mm}$ in diameter and $50 \mathrm{~mm}$ in length.

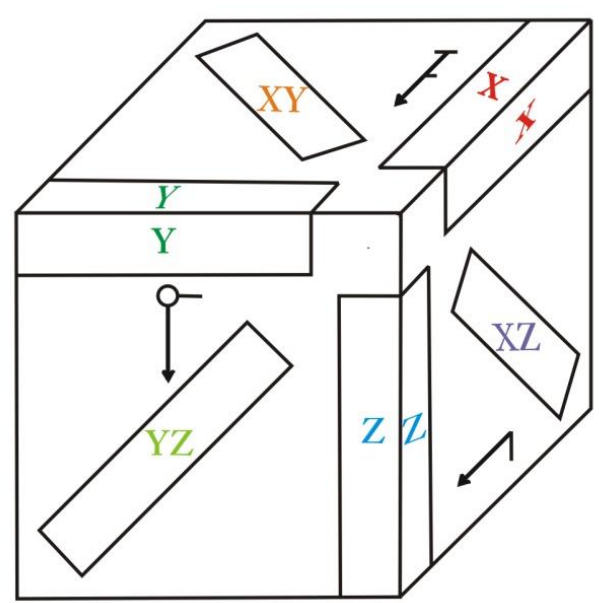

Fig. 3.4 The choice of cut directions for thermal expansion measurements. X-direction corresponds to lineation and Z-direction is perpendicular to a foliation of sample. 
The thermal expansion coefficient $\left(\alpha_{\text {expt }}\right)$ which describes the specific length change under the considered temperature interval is determined by the following equation:

$$
\alpha_{\text {expt }}=\frac{\Delta l}{l_{0} \cdot \Delta T}
$$

Where $\Delta l=\left[l\left(90^{\circ} \mathrm{C}\right)-l\left(20^{\circ} \mathrm{C}\right)\right]$ is the sample length change, $l_{0}=l\left(20^{\circ} \mathrm{C}\right)$ is the original sample length, and $\Delta T$ is the temperature differential. The usual units of the coefficients of thermal expansion here are $10^{-6} \mathrm{~K}^{-1}$. The residual strain $\varepsilon_{r}$ (in $\mathrm{mm} / \mathrm{m}$ ) is determined as the ratio between the sample length change $\Delta l$ after the certain number of complete heating-cooling cycles and the initial length of the sample $l_{0}$ :

$$
\varepsilon_{r}=\frac{\Delta l}{l_{0}}
$$

The investigated marble samples were heated from $20{ }^{\circ} \mathrm{C}$ to $90{ }^{\circ} \mathrm{C}$ and then cooled to the initial temperature of $20^{\circ} \mathrm{C}$, each cycle lasts 14 hours and 20 minutes. Four repeating heating-cooling cycles were performed for investigated marble samples (Fig. 3.5).

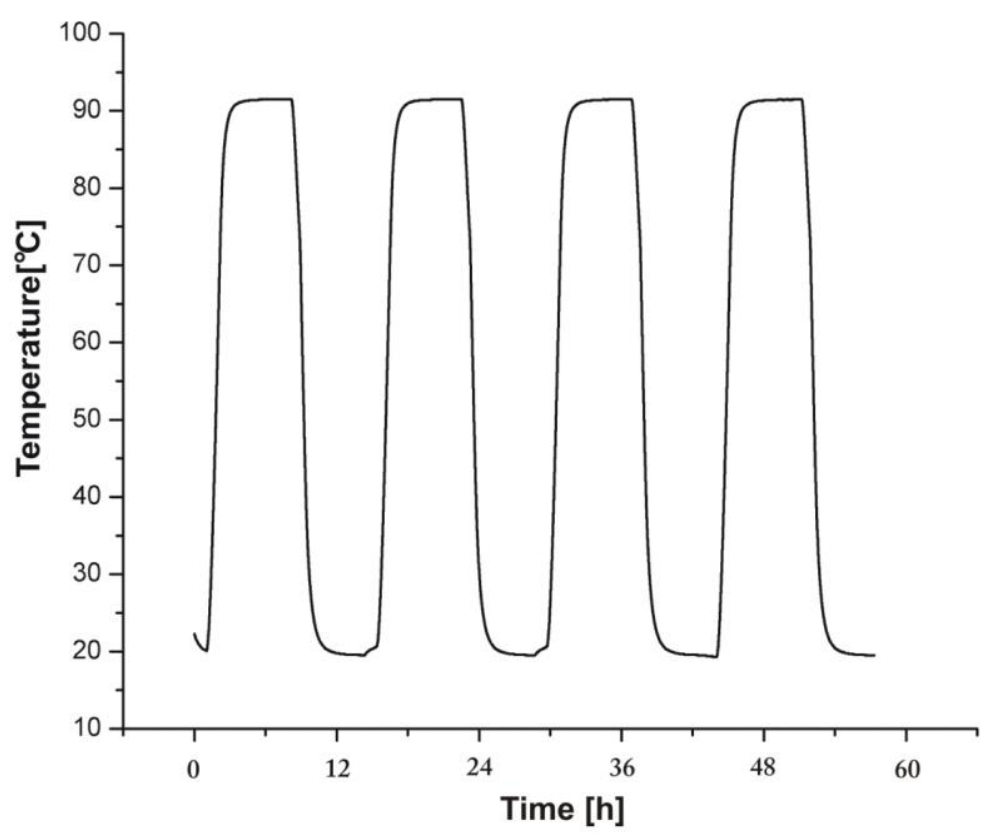

Fig. 3.5 Temperature as a function of time. Four heating-cooling cycles were performed at a rate of $1{ }^{\circ} \mathrm{C} / \mathrm{min}$. 
Previous studies (Siegesmund et al. 2000, Zeisig et al. 2002) have shown that distinct marble groups can be distinguished according to their thermal dilation and residual strain behavior under thermal treatment. The four types after Siegesmund et al. (2004) are used to classify the marbles investigated here. They are: (a) isotropic thermal expansion with small or no residual strain; (b) anisotropic thermal expansion with small or no residual strain; (c) isotropic thermal expansion with a residual strain; and (d) anisotropic thermal expansion with residual strain (Fig. 3.6).
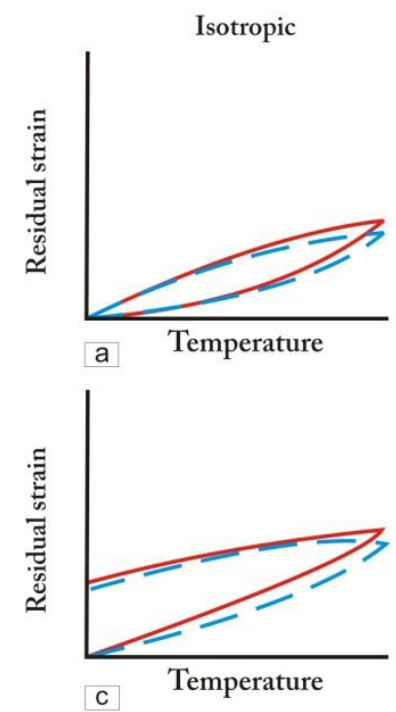
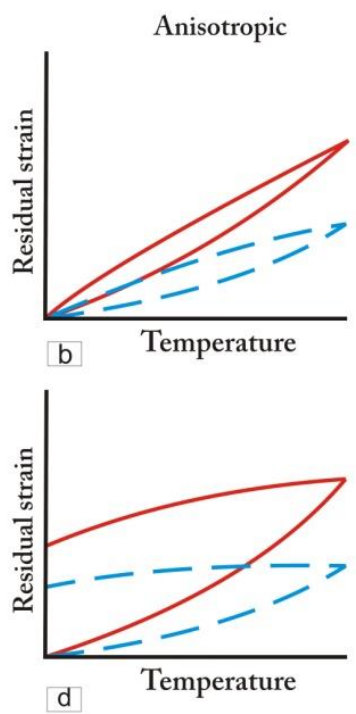

Fig. 3.6 Representation of four typical types of thermal behavior marble: (a) isotropic thermal expansion with small or no residual strain; (b) anisotropic thermal expansion with small or no residual strain; (c) isotropic thermal expansion with a residual strain; (d) anisotropic thermal expansion with residual strain (after Siegesmund et al. 2004).

In repetitive heating-cooling under dry conditions significant inelastic residual strain appears only after the first thermal cycle (Sage et al. 1988, Widhalm et al. 1996, Siegesmund et al. 2000, Koch and Siegesmund 2004, Siegesmund et al. 2008). The presence of water enhances the residual strain. Thereby, the moisture content after a thermal treatment has a certain impact on the degradation rate of material. Thus, thermal expansion measurements were carried out under water-saturated conditions as well. The setup was inclined at an angle of $25^{\circ}$ and the sample chamber was filled with demineralised water as the half of the sample was dipped in water. Then samples were heated up to $90{ }^{\circ} \mathrm{C}$ and for eight hours the temperature was held until the water evaporates in the sample chamber. Afterwards already dry samples were cooled to 20 ${ }^{\circ} \mathrm{C}$. Before beginning of new heating cycle the sample chamber was filled with water (Koch 2006). Each cycle lasts 19 hours and 20 minutes. For investigated marble samples seven heating-cooling cycles under wet conditions were performed. 


\subsection{Artificial microstructures and modeled texture}

\subsubsection{Extremes of SPO}

The two-dimensional artificial rock microstructures were generated by a nucleation and growth algorithm (Ito and Fuller 1993; Miodownik et al. 1999; Saylor et al. 2004; Saylor et al. 2007), using the Microstructure Builder program from Carnegie Mellon University by Saylor. Circular or elliptical seeds were used to give the extremes in shape fabric. For circular (isotropic) seeds the simulated equiaxed microstructure is a Voronoi tessellation (see Fig. 3.7a). For elongated elliptical seeds the simulated microstructure is elongated. By giving directionality to the seeds, in this case along the $y$-axis, the textured shape fabric (or SPO) shown in Fig. 3.7c is obtained. Using a mixture of the two types of seeds, the mixed shape fabric shown in Fig. 3.7b is obtained.
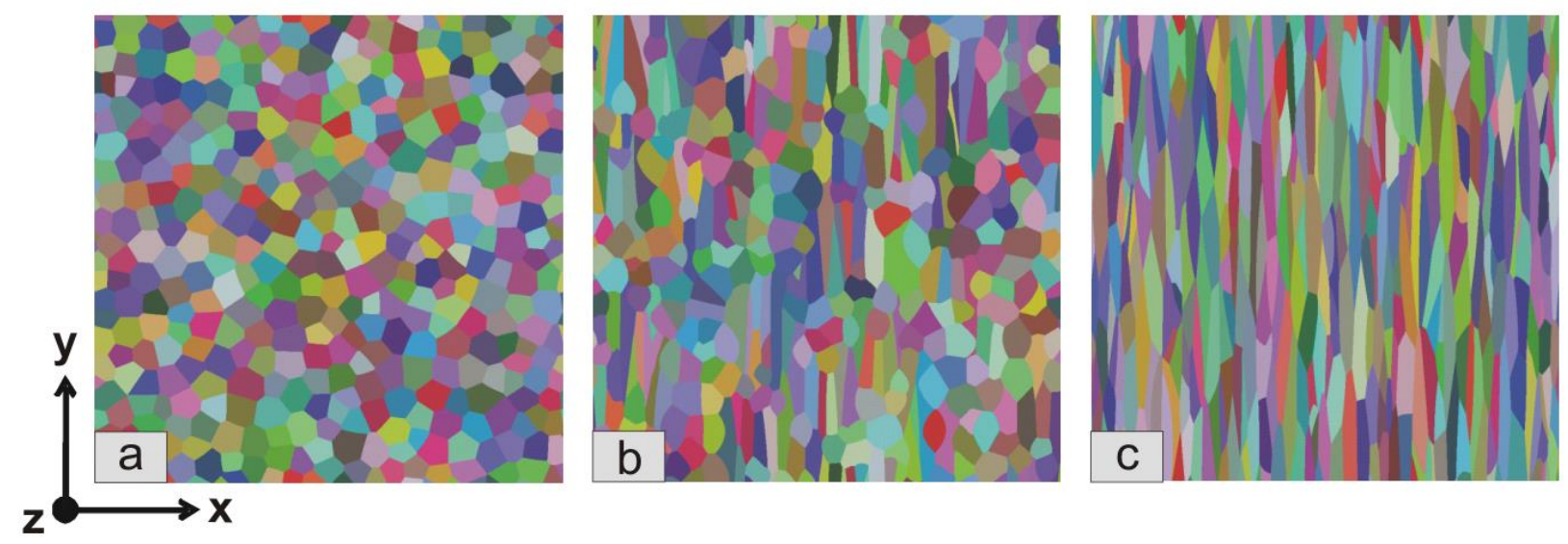

Fig. 3.7 The three microstructures used in the simulations to vary shape fabric: (a) an equiaxed microstructure; (b) a mixed microstructure with shape fabric from the two extremes; and (c) an elongated grain shape microstructure. The number of grains in each microstructure, respectively, are 382 grains, 347 grains, and 312 grains. The coordinate systems used to describe the results is also indicated in the figure.

The microstructural images have a resolution of $1000 \times 1000$ pixels. The number of grains in the equiaxed, mixed, and elongated microstructures, respectively, are 382 grains, 347 grains, and 312 grains. Accordingly, the average grain size increases with shape fabric from 2617.8 pixels per grain for the equiaxed microstructure to 2881.8 pixels per grain for the mixed microstructure to 3205.1 pixels per grain for the elongated microstructure. This of course assumes that the simulation cell size in absolute units is the same size. 
The coordinate system shown in Fig. 3.7 is used to describe the results: the $\boldsymbol{y}$ direction is parallel to the SPO; the $\boldsymbol{x}$ direction is perpendicular to the SPO and in the plane of the microstructure; and the $\boldsymbol{z}$ direction is perpendicular to the SPO and out of the plane of the microstructure.

\subsubsection{Extremes of LPO}

Orientation distribution functions (ODFs) with LPOs were generated a via March Dollase fiber-texture distribution (Dollase 1986; Blendell et al. 2004). Given a texture direction and the crystallographic axes to be textured, in this case the crystallographic c-axes, the cumulative fraction of $c$-axis orientations within a cone of half angle $\theta$ about the texture direction is given by:

$$
P(M, \theta)=1-\cos (\theta) / \sqrt{\cos ^{2}(\theta)+M \sin ^{2}(\theta)}
$$

where $M$ is a parameter characterizing the degree of texture. The probability distribution function is given by $\partial P(M, \theta) / \partial \theta=f(M, \theta) \sin \theta$, where

$$
f(M, \theta)=M /\left[\cos ^{2}(\theta)+M \sin ^{2}(\theta)\right]^{3 / 2}
$$

gives the multiple of a random distribution (MRD) at that value of $\theta$.

If $M=1, f(M=1, \theta)=1$, and the distribution is random. If $M>1$, one has fiber texture in a cone of half angle $\theta$ (the c-axis fiber types considered here). The maximum MRD occurs at $\theta=0$, and is equal to $M$.

Three ODFs (or three LPOs) were considered: a random ODF (i.e., $M=1$ ); an ODF with fiber-texture that is 20 time random (i.e., $M=20$ ); and an ODF with fiber-texture that is 40 time random (i.e., $M=40$ ). For brevity in labeling the simulation results, the three LPOs are denoted as $\mathbf{M 1}, \mathbf{M} 20$, and $\mathbf{M} 40$, respectively. For all cases the half-angle $\theta$ of the cone containing the crystal c-axis was selected from the March-Dollase distribution described by Eq. (3.10) below. Using a random number between 0 and 1 for the cumulative probability $P$, the polar angle of the orientation is given by:

$$
\theta=\arccos \left(\sqrt{\frac{M(1-P)^{2}}{1+(M-1)(1-P)^{2}}}\right)
$$


The two azimuthal angles describing the crystal orientations, $\varphi$ and $\omega$, are selected randomly from the interval 0 to $2 \pi$.

Representative pole figures for the three ODFs considered here are shown in Fig. 3.8. The fiber texture is along the North-South direction in these figures, but variants are considered where texture direction is rotated with respect to the SPO. The pole figures show the individual poles of the crystallographic c-axis for each grain in the microstructure. The contour lines are select MRD contours from the March-Dollase distribution, from which the orientations were chosen. The distributions become more textured as the maximum MRD in the March-Dollase function (i.e., $M$ ) varies from 1 (untextured) to 40 (highly textured).
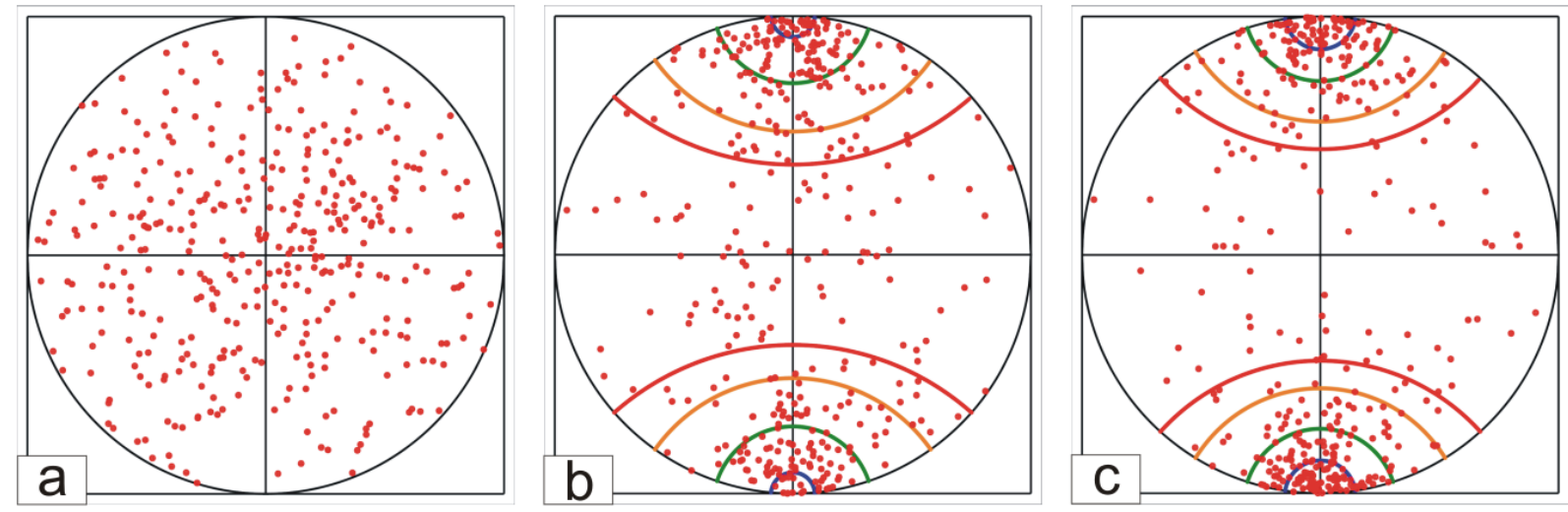

Fig. 3.8 Representative pole figures showing the individual poles of the crystallographic c-axis for each grain in the microstructure. In (a) the orientations were chosen from a random ODF. In (b) the orientations were chosen from a March-Dollase ODF with fiber texture along the North and South pole that is 20 times random. In (c) the orientations were chosen from a March-Dollase ODF with fiber texture along the North and South pole that is 40 times random. For both (b) and (c) the contour lines correspond to multiple random distribution (MRD) from the March-Dollase distribution function of 16 (blue), 4 (green), 1 (orange) and $1 / 2$ (red). 


\subsection{Marble samples}

\subsubsection{Microfabric}

To investigate the influence of rock fabric on marble decay eight various marble types were selected (Table 3.1). These marble types have been used as ornamental stones and exterior and interior cladding both in the past and in the present. They have different compositions, i.e., calcitic and dolomitic, vary in grain size from $75 \mu \mathrm{m}$ to $1.75 \mathrm{~mm}$ and exhibit diverse texture types, notably weak texture, strong texture, girdle texture and high-temperature texture.

Table 3.1 Marble types, locations, and select fabric parameters.

\begin{tabular}{|cccc|}
\hline Marble & Location & Composition & Average grain size \\
Thassos [Th] & Greece & Dolomitic & $1.75 \mathrm{~mm}$ \\
Lasa [LA] & Italy & Calcitic & $1 \mathrm{~mm}$ \\
Grechisches Volakas & Greece & Calcitic & $75-100 \mu \mathrm{m}$ \\
{$[\mathrm{G}]$} & Austria & Calcitic & $1.25 \mathrm{~mm}$ \\
Sölk [SK] & Austria & Calcitic & $1-1.5 \mathrm{~mm}$ \\
Wachau [W] & Calcitic & $200-300 \mu \mathrm{m}$ \\
Arabescato Altissimo & Italy & Calcitic & $150 \mu \mathrm{m}$ \\
Carrara [AA] & & & \\
Bianco Carrara [BC] & Italy & Calcitic & $200-800 \mu \mathrm{m}$ \\
High-Temperature & Italy & & \\
Carrara (HT) & & & \\
\hline
\end{tabular}

The microfabric analysis is based on microstructures that were obtained by EBSD measurements. According to classification in the Table 2.2 and in Fig. 2.6 Grechisches Volakas is very-fine-grained marble with inequigranular-polygonal fabric. The Arabescato Altissimo (AA) and Bianco Carrara $(B C)$ are fine-grained marbles and show nearly equigranular straight grain boundaries (i.e., a foam structure). High-Temperature Carrara (HT) marble shows inequigranular-polygonal grain boundaries, and the grain size varies from $200 \mu \mathrm{m}$ to $800 \mu \mathrm{m}$. Lasa is a small-grained marble with inequigranularinterlobate structure. While Wachau and Sölk marbles are medium-grained and exhibit seriate-interlobate and inequigranular-interlobate grain boundaries, respectively. Dolomitic marble Thassos exhibits the largest grain size and has equigranularinterlobate fabric. The microfabrics are presented in Fig. 3.9. 

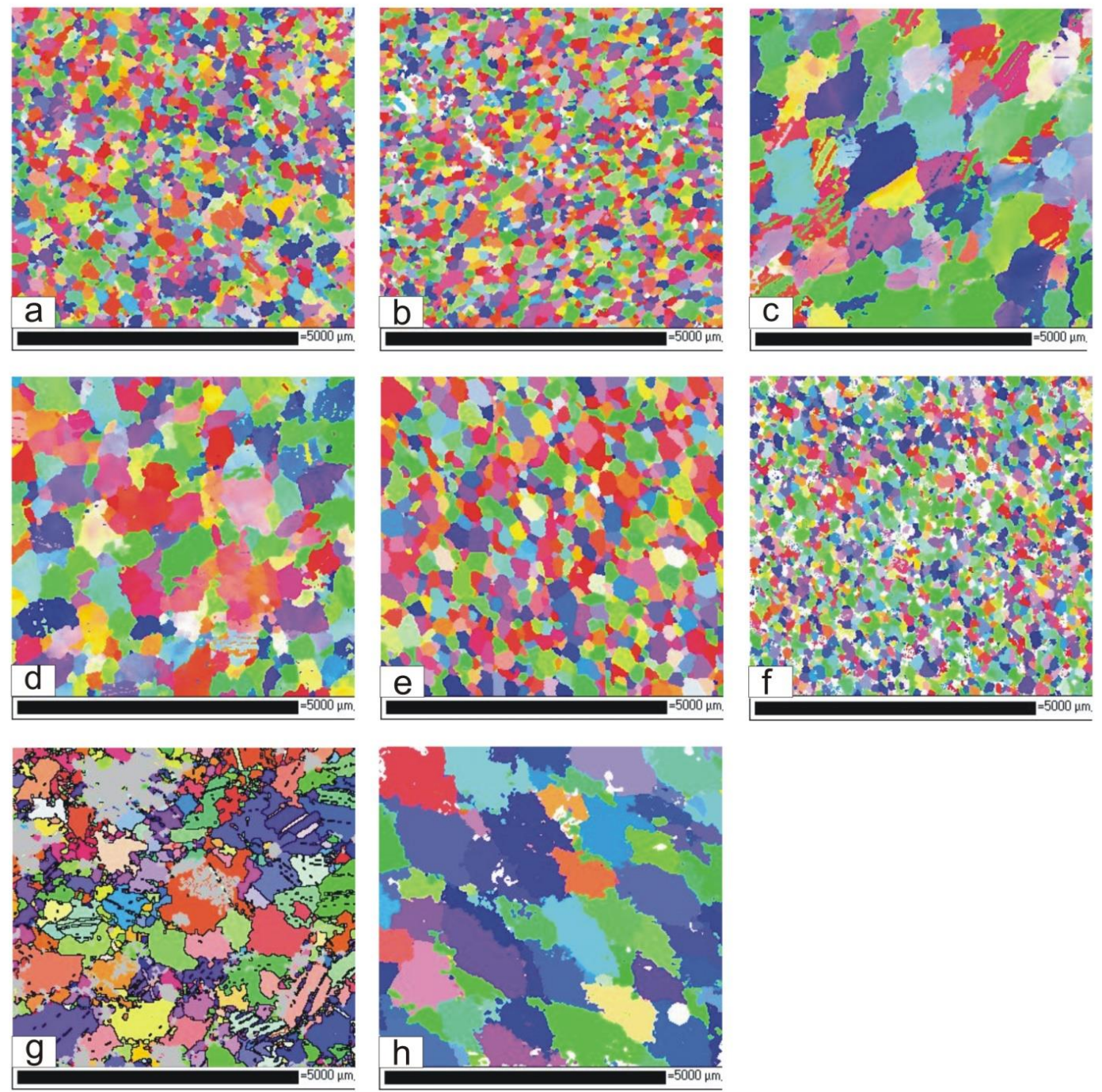

Fig. 3.9 Marble microfabric: (a) Arabescato Altissimo (AA) marble; (b) Bianco Carrara (BC) marble; (c) Sölk (SK) marble; (d) Lasa (LA) marble; (e) High-Temperature Carrara (HT) marble; (f) Grechisches Volakas (G) marble; (g) Wachau (W) marble; (h) Thassos (Th) marble. The microfabric is shown as a cropped selection (305 x 285 pixels) from microstructures obtained by EBSD in XZ plane of marble samples.

\subsubsection{Crystal texture}

To elucidate the influence of the texture on the thermal-elastic response, pole figures for each marble sample were generated using the EBSD HLK Channel 5 software. Four typical types of marble texture were observed: (a) weak texture (e.g., AA, BC marbles); (b) strong texture (e.g., SK, W, Th, G marbles); (c) girdle texture (e.g., LA marble); and high-temperature texture (e.g., HT marble). The $\{001\}$ pole figures of AA, SK, LA, HT marbles illustrate the different texture types (Fig. 3.10). 


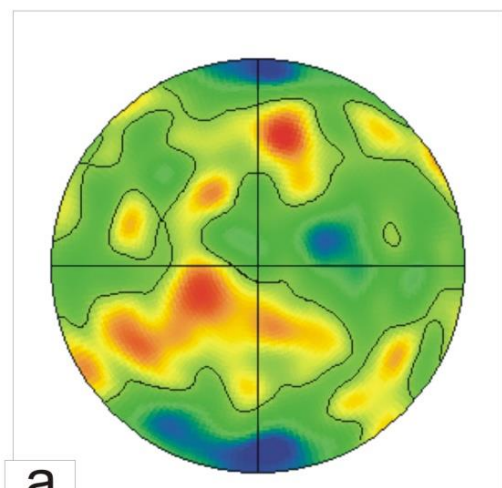

a

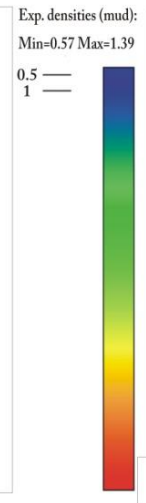

b
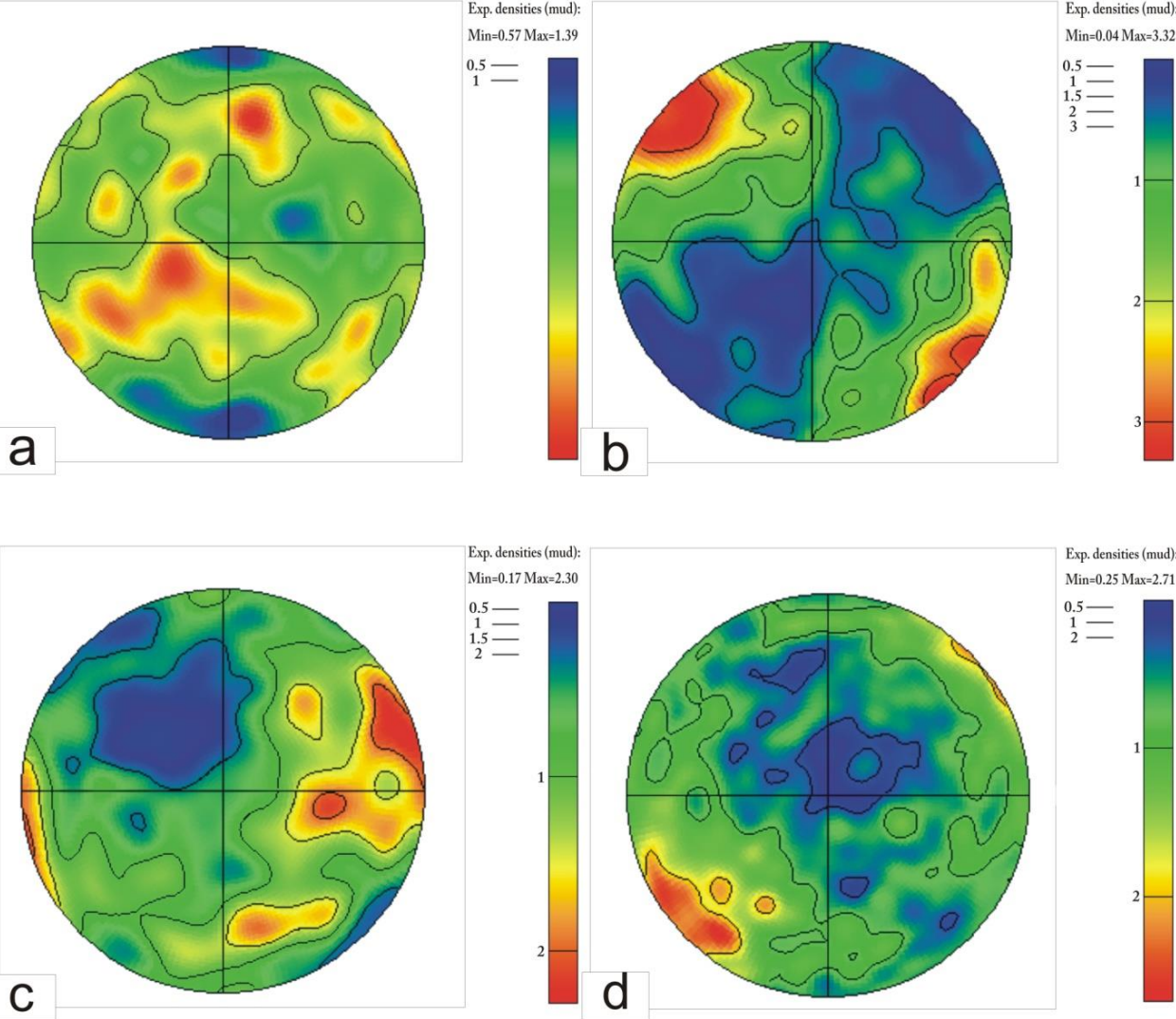

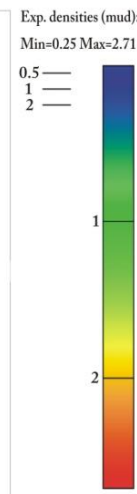

Fig. 3.10 \{001\} Pole figures from the EBSD HLK Channel 5 software for marble samples in XZ planes: (a) Arabescato Altissimo Carrara marble (weak texture); (b) Sölk marble (strong texture); (c) Lasa marble (girdle texture); (d) High-Temperature Carrara marble (high-temperature texture).

Carrara marbles $A A$ and $B C$ show weak c-axis fiber texture with a maximum of the multiples of random distribution (MRD) of 1.39 and 1.33, respectively. Sölk marble exhibits c-axis fiber type and shows a strong c-axis maximum of 3.32 MRD. Two other types of texture were observed by EBSD measurements. The c-axis of Lasa marble show a girdle distribution, while a naturally deformed Carrara marble (HT) exhibits a high-temperature texture. Grechisches Volakas marble and Thassos marble exhibit caxis fiber texture with a c-axis maximum of MRD of 3.63 and 7.6, respectively. The texture type of Wachau marble was found by Zeisig et al. (2002) and determined as a strong c-axis fiber texture. 
Influence of shape fabric and crystal texture on marble degradation phenomena: simulations

\section{Influence of shape fabric and crystal texture on marble degradation phenomena: simulations}

4.1 Microstructural simulations: simulation design

To investigate the influence of shape fabric and crystal textures on marble decay extremes of SPO (Fig. 3.7) and LPO (Fig. 3.8) were considered. Both the LPO and the SPO have directionality. For textured microstructures there are three possible relations between them. Since here the SPO is always aligned along the $y$-axis, these three relations are specified by the orientation of the LPO. The designations $\boldsymbol{x}, \boldsymbol{y}$, and $\boldsymbol{z}$, are used to correspond to the c-axes having fiber texture along $x$-axis (in plane and perpendicular to the shape fabric), $\boldsymbol{y}$-axis (parallel to the shape fabric), and $\boldsymbol{z}$-axis (out of plane and perpendicular to the shape fabric), respectively.

The simulation design matrix has $3 \times 3 \times 3$ or 27 variables. The three SPOs are: an equiaxed microstructure; a mixed microstructure; and an elongated microstructure. The three LPOs are: a random ODF; an ODF with fiber-texture that is 20 time random; and an ODF with fiber-texture that is 40 time random. The last three variables are the directionality of the LPO fiber texture with respect to the SPO. These directional conditions are: crystal fiber texture perpendicular to the SPO, but in the plane of the microstructure; crystal fiber texture parallel to the SPO; and crystal fiber texture perpendicular to the SPO, but out of the plane of the microstructure. For the random ODF these 3 directional conditions are equivalent and are not distinct. Accordingly, there are only 21 unique configurations specified by shape fabric, crystal texture, and directionality of the LPO with respect to the SPO. For each of these 21 cases five different, independent sets of orientations, or replications, were generated. Thus, 105 microstructural configurations for each of the investigated marble composition, i. e., for calcitic, dolomitic and a mixed content of calcite $(50 \%)$ and dolomite $(50 \%)$ marbles, served as the basis for the finite-element simulations.

Briefly, a uniform $200 \times 200$ mesh of 80000 right triangular elements was positioned on the $1000 \times 1000$ pixel microstructure. Then an adaptive meshing algorithm was used to align the nodes of inhomogeneous elements (i.e., those which overlapped two or more grains) with the grain boundaries. The resulting finite-element meshes consisted of 80000 triangular elements, which have an average area of $12.50 \pm 3.80$ pixels per element for the equiaxed microstructure, $12.50 \pm 3.74$ pixels per element for the mixed 
Influence of shape fabric and crystal texture on marble degradation phenomena: simulations

microstructure, and $12.50 \pm 3.66$ pixels per element for the elongated microstructure The element size distribution was kept relatively uniform so that microstructural statistics over the microstructure are more meaningful.

After the finite-element mesh was generated, thermophysical properties of calcite or dolomite (according to which marble composition (calcite or dolomite) was being considered) were assigned to the elements. The single-crystal values for the coefficients of thermal expansion (Kleber 1959) and the elastic stiffness coefficients (Bass 1995) are given in Table 2.1. The crystallographic orientations of each grain were selected from the appropriate ODF, as described above, and were from threedimensional distributions.

Upon heating or cooling from a stress free state, the misorientation between neighboring grains and the associated thermal expansion anisotropy result in thermal misfit strains. These strains in turn give rise to internal residual stresses, which are computed by the finite element method. The temperature change used here was a temperature increase of $+100{ }^{\circ} \mathrm{C}$ (i.e., heating). All of the finite-element simulations used two-dimensional elasticity with a plane-stress assumption, thereby simulating a free surface.

Effective polycrystalline in-plane coefficients of thermal expansion coefficient were computed by measuring the relative dimensional changes of the simulation microstructure and dividing by the temperature change. These effective values represent only the contribution to the thermal expansion (or contraction) from the elastic thermal misfit strains. If microcracking occurs, for example in a real microstructure, or if it is included in the simulations, an additional expansion will occur, which is independent of whether the temperature change is heating or cooling. The total thermal expansion (or contraction) is the sum of the elastic thermal expansion (contraction) and the microcracking expansion. 
Influence of shape fabric and crystal texture on marble degradation phenomena: simulations

4.2 Results and discussion

4.2.1 Elastic strain energy density

The elastic strain energy density, $\boldsymbol{U}$ (eq. 3.4), is a key indicator of potential microcracking sites in a microstructure, as it provides the surface energy necessary to create the fracture surfaces of the microstructural cracks. Accordingly, to elucidate factors related to marble degradation from microcracking phenomena, the influence of shape fabric and crystallographic texture on the elastic strain energy density were studied by microstructural simulations. Variables observed were (i) the average elastic strain energy density for the microstructure and (ii) the variation of the strain energy density throughout the microstructure, as characterized by the standard deviation of the strain energy density distribution.

\subsubsection{Elastic strain energy density: influence of SPO}

Firstly, results for calcitic marbles will be discussed. The influence of shape fabric on the elastic strain energy density, as characterized by the three SPO types (equiaxed, mixed, and elongated), is minimal when the crystallographic texture is random (i.e., $\boldsymbol{M}=1$, or no LPO). See $\mathbf{M} 1$ in Fig. 4.1. The average strain energy density shows a small decrease from $31.5 \pm 0.7 \mathrm{~kJ} \cdot \mathrm{m}^{-3}$ for the equiaxed microstructure to $29.8 \pm 2.1 \mathrm{~kJ} \cdot \mathrm{m}^{-3}$ for the mixed microstructure and to $28.3 \pm 1.5 \mathrm{~kJ} \cdot \mathrm{m}^{-3}$ for the elongated microstructure. The variation represents the standard deviation over the five simulation replications using five different random ODFs.

The variation of the strain energy density within the microstructure, microstructural standard deviation, similarly shows little dependence on shape fabric for random crystallographic texture. The microstructural standard deviation of the strain energy density distribution increases from $29.7 \pm 0.8 \mathrm{~kJ} \cdot \mathrm{m}^{-3}$ for the equiaxed microstructure, to $30.3 \pm 2.0 \mathrm{~kJ} \cdot \mathrm{m}^{-3}$ for the mixed microstructure, and to $30.8 \pm 1.1 \mathrm{~kJ} \cdot \mathrm{m}^{-3}$ for the elongated microstructure. Again, the variation is the standard deviation from the five simulation replications of the random ODF.

Note that the variation of the strain energy density within the microstructure is as large as the average strain energy density. The frequency distributions of strain energy density throughout the microstructure is essentially a decreasing function with the 
Influence of shape fabric and crystal texture on marble degradation phenomena: simulations

largest fraction of strain energy densities in the microstructure, as discretized by the finite elements, lying at low values. The upper tail of the frequency distribution of strain energy density is expected to be characteristic of the propensity for microcracking. However, a measure of this upper tail, i.e., the strain energy density at $90 \%$ cumulative probability, essentially mimics the average strain energy density, so it is not reported here separately.

When the LPO has fiber texture that has a maximum value of 20 times random, i.e., $\boldsymbol{M}=20$, the strain energy density shows a significant dependence on the shape fabric. Moreover, this dependence is strongly influenced by the direction of the LPO with respect to the SPO. See M20 in Fig. 4.1. For the equiaxed microstructure there is no SPO. Thus, the strain energy density values should statistically be the same whether the crystal texture is along the $\boldsymbol{x}$ - or the $\boldsymbol{y}$-directions. This is observed to be the case. However, for the mixed and the elongated microstructures the strain energy density value is significantly larger when the c-axis crystal texture is aligned with the SPO, i.e., the $\boldsymbol{y}$ direction. In contrast, when the c-axis crystal texture is perpendicular to the SPO, i.e., the $\boldsymbol{x}$ direction, the strain energy density value decreases with shape fabric. When the c-axis crystal texture is out of the plane of the simulation, i.e., the $\boldsymbol{z}$ direction, the strain energy density values are smaller and exhibit only a minor dependence.

However, the variation of the strain energy density, as characterized by the microstructural standard deviation, increases with increasing shape fabric for all three directions of the LPO ( $\boldsymbol{x}, \boldsymbol{y}$ and $\boldsymbol{z}$ ) and is the largest for the elongated microstructure. Furthermore, the microstructural variation is substantially larger than the average value, and the standard deviation of these standard deviation values increases with increasing fabric shape. See Fig. 4.1. 
Influence of shape fabric and crystal texture on marble degradation phenomena: simulations
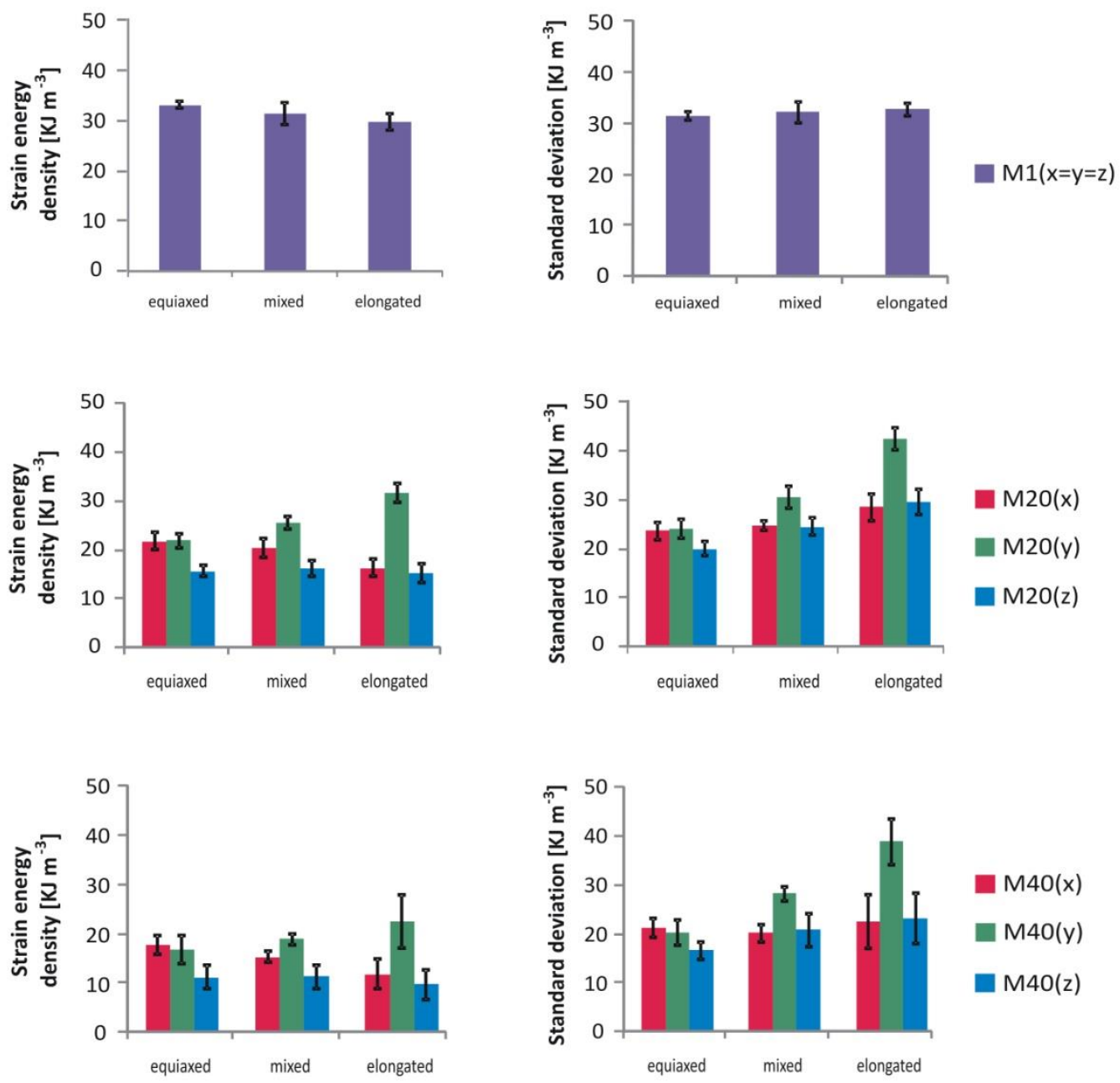

Fig. 4.1 Elastic strain energy density and its microstructural standard deviation (the square root of its variance throughout the microstructure) for calcitic marbles as a function of SPO and LPO for a temperature change of $+100{ }^{\circ} \mathrm{C}$. The different LPOs, or crystal texture ODFs, are denoted as M1, M20 and M40, respectively corresponding to a March-Dollase parameter $\boldsymbol{M}$ of 1,20 , and 40 for the distribution from which the orientations were chosen. The errors bars show the standard deviation from 5 independent replications of the ODF. Three directions for the LPOs were observed: $\boldsymbol{x}, \boldsymbol{y}$ and $\boldsymbol{z}$, corresponding to the c-axes having fiber texture along $\boldsymbol{x}$-, $\boldsymbol{y}$-, and $\boldsymbol{z}$-axis, respectively.

When the LPO has fiber texture that has a maximum value of 40 times random, i.e., $M=40$, the strain energy density exhibits a similar dependence with shape fabric and LPO to that of M20, but slightly smaller. See M40 in Fig. 4.1. However, the standard deviation of these standard deviation values is larger than that of M20, i.e., there is more variation in the five replications of the ODF. 


\subsubsection{Elastic strain energy density: influence of LPO}

With one exception, as the crystal texture increases from untextured or random $(\boldsymbol{M}=1)$ to a high degree of fiber texture $(\boldsymbol{M}=40)$, the average strain energy density and its microstructural variation (the microstructural standard deviation) decrease. Thus, in most cases increased LPO or crystal texture reduces the propensity for microstructural microcracking.

The one exception is for an elongated microstructure when the crystallographic c-axis texture is aligned parallel with the SPO direction (i.e., the crystalline c-axes are aligned along the shape fabric $y$ direction). For this combination of LPO and SPO the average strain energy density first increases with crystal texture from $28.3 \pm 1.5 \mathrm{~kJ} \cdot \mathrm{m}^{-3}$ for $\boldsymbol{M}=1$ to $30.8 \pm 1.8 \mathrm{~kJ} \cdot \mathrm{m}^{-3}$ for $\boldsymbol{M}=20$ and then decrease with further crystal texture to $21.7 \pm 5.3 \mathrm{~kJ} \cdot \mathrm{m}^{-3}$ for $\boldsymbol{M}=40$. Similarly, the microstructural standard deviation of the strain energy density distribution increases with crystal texture from $30.8 \pm 1.1 \mathrm{~kJ} \cdot \mathrm{m}^{-3}$ for $\boldsymbol{M}=1$ to $41.4 \pm 2.1 \mathrm{~kJ} \cdot \mathrm{m}^{-3}$ for $\boldsymbol{M}=20$ and then decrease to $37.4 \pm 4.5 \mathrm{~kJ} \cdot \mathrm{m}^{-3}$ for $\boldsymbol{M}=40$. The reason for this phenomenon is that several elongated grains per chance are crystallographically misoriented with respect to the average LPO. Initially, the elastic strain energy from these misaligned grains dominate the strain energy density distribution, giving rise both to more microstructural variation and to a slight increase in the average value. With increasing crystalline texture alignment, the effect diminishes. However, the phenomenon, which is described further in the section on microstructural stress maps, is probably unrealistic for two reasons. First, the crystal texture is probably correlated with the shape texture, so these misoriented grains are not highly probable. Second, typical LPOs for calcite marbles are such that the c-axes are aligned perpendicular to the SPO, i.e., the crystalline c-axes are aligned along the shape fabric $\boldsymbol{x}$ or $\boldsymbol{z}$ directions (e.g., Leiss and Ullemeyer 1999).

\subsubsection{Maximum principal stress: influence of SPO}

The dependence of the maximum principal stress and its microstructural standard deviation on the SPO and the LPO is essentially the same that for the elastic strain energy density. Fig. 4.2 shows the average maximum principal stress and the microstructural standard deviation for the microstructure configurations investigated in 
Influence of shape fabric and crystal texture on marble degradation phenomena: simulations

this study. The error bars represent the standard deviation for the five replications of the ODF.

For the random ODFs (M1 in Fig. 4.2) there is slight but insignificant decrease in the maximum principal stress with shape fabric: $34.7 \pm 0.4 \mathrm{MPa}$ for the equiaxed fabric; $33.1 \pm 1.1 \mathrm{MPa}$ for the mixed fabric; and $30.5 \pm 0.9 \mathrm{MPa}$ for the elongated fabric. For the textured ODFs (M20 and M40 in Fig. 4.2) the values for the $\boldsymbol{x}$ and $\boldsymbol{y}$ directions are statistically equivalent for the equiaxed fabric, and respectively, show decreases and increases with shape fabric that are similar to those for the strain energy density.
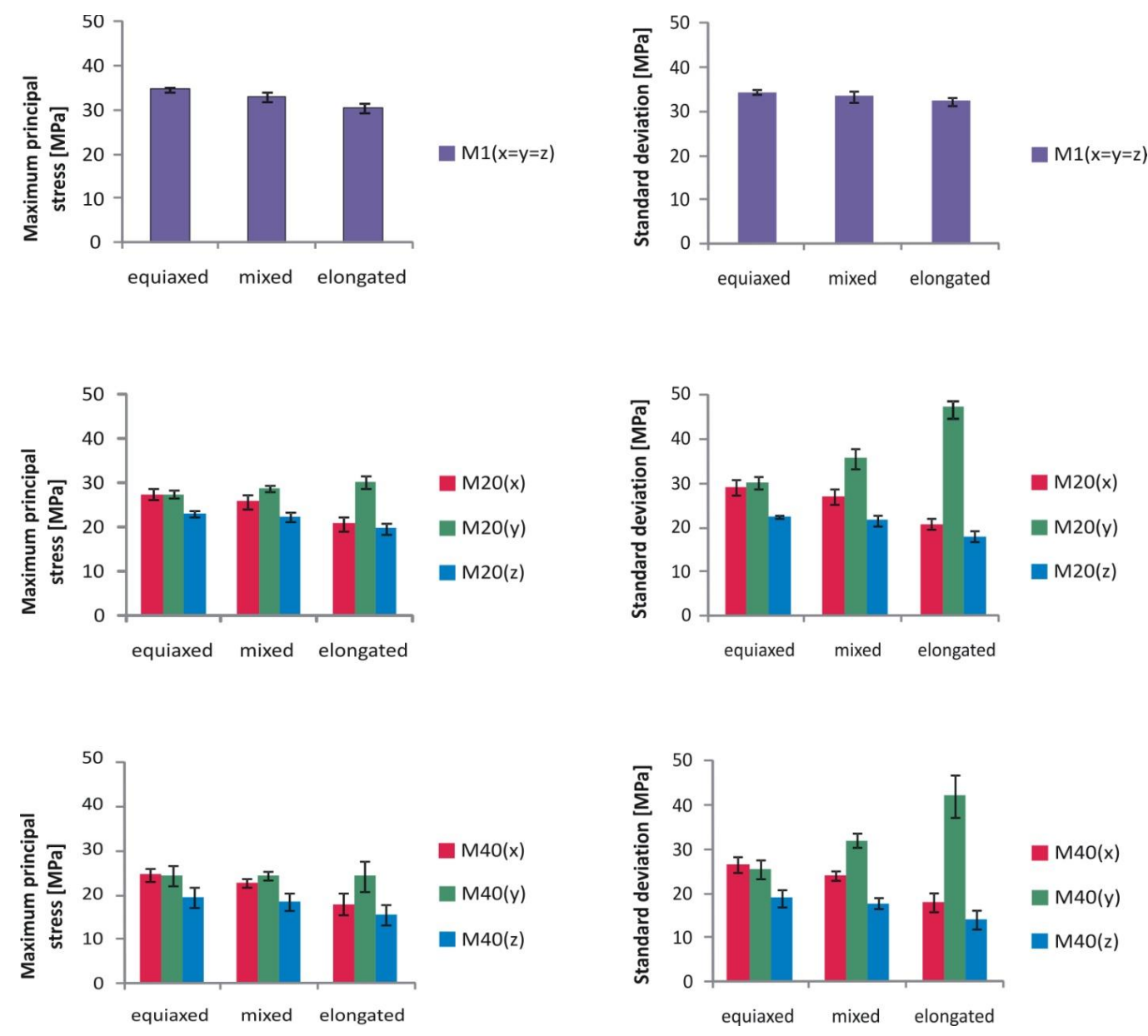

Fig. 4.2 Maximum principal stress and its microstructural standard deviation (the square root of its variance throughout the microstructure) for calcitic marbles as functions of SPO and LPO for a temperature change of $+100^{\circ} \mathrm{C}$. The different LPOs, or crystal texture ODFs, are denoted as M1, M20 and $M 40$, respectively corresponding to a March-Dollase parameter $M$ of 1,20 , and 40 for the distribution from which the orientations were chosen. The errors bars show the standard deviation from 5 independent replications of the ODF. Three directions for the LPOs were observed: $\boldsymbol{x}, \boldsymbol{y}$ and $\boldsymbol{z}$, corresponding to the c-axes having fiber texture along $\boldsymbol{x}$-, $\boldsymbol{y}$-, and $\boldsymbol{z}$-axis, respectively. 
Influence of shape fabric and crystal texture on marble degradation phenomena: simulations

The most significant variation with shape fabric is seen for the M20 microstructural standard deviation when the crystal texture is parallel to the shape texture (the $\boldsymbol{y}$ direction): $29.9 \pm 1.5 \mathrm{MPa}$ for the equiaxed fabric; $35.4 \pm 2.1 \mathrm{MPa}$ for the mixed fabric; and $47.2 \pm 1.6 \mathrm{MPa}$ for the elongated fabric. As in the discussion for the strain energy density, this phenomenon may be unrealistic. For the highly textured ODFs (M40) all values are decreased from the M20 values.

\subsubsection{Maximum principal stress: microstructural maps}

Spatial variations of the maximum principal stress are shown in Fig. 4.3 for the three shape fabrics, the three degree of crystallographic texture, and the three directions of LPO with respect to SPO. The stress values are shown with a thermal scale that ranges from black (0 MPa) to red-orange (125 MPa) to white ( $\geq 250 \mathrm{MPa})$. Each of the 27 microstructural maps shows the results for one of the five replications of the ODFs for that configuration. However, as the results for the $\boldsymbol{M}=1$ rows are for a random ODF, the maps in Fig. 4.3a, 4.3b, and 4.3c for each shape fabric of this row are statistically equivalent. Similarly, but now due to the equiaxed fabric, the maps in Fig. 4.3a and Fig. 4.3b for the equiaxed fabric column are statistically equivalent. Comparing these equivalent maps, one can see the variations that arise from the different ODFs and from the different equiaxed fabric directions. These variations are reflected quantitatively by the standard deviations of the maximum principal stress values (the error bars in Fig. 4.2). Similar variations occur for the other replications of the ODFs for $\boldsymbol{M}=20$ and $\boldsymbol{M}=40$ that are not reflected in Fig. 4.3. The statistical variation between replications of the ODFs is not to be confused with the microstructural standard deviation, shown in Fig. 4.2 (and in Fig. 4.1 for the strain energy density). The microstructural standard deviation represents the standard deviation of the maximum principal stress values (or strain energy density values) within a single microstructural configuration.

For random crystal texture $(\boldsymbol{M}=1)$ the overall range of the maximum principal stress values does not change significantly with SPO. However, the patterns in the stress maps reflect the shape fabric. For the equiaxed fabric, and to some extent for the mixed fabric, the stress patterns show the network structure described by Wanner et al. (2010). This structure of a high-stress network surrounding low-stresses regions (the darker regions in Fig. 4.3) develops due to neighborhoods of grains having similar 
crystallographic orientations, thereby locally minimizing the thermal expansion anisotropy misfit strains. This network structure persists for microstructure with increasing in-plane LPO (i.e., for $\boldsymbol{M}=20$ and $\boldsymbol{M}=40$, when the crystal texture is along the $\boldsymbol{x}$ or the $\boldsymbol{y}$ direction, i.e., in-plane).

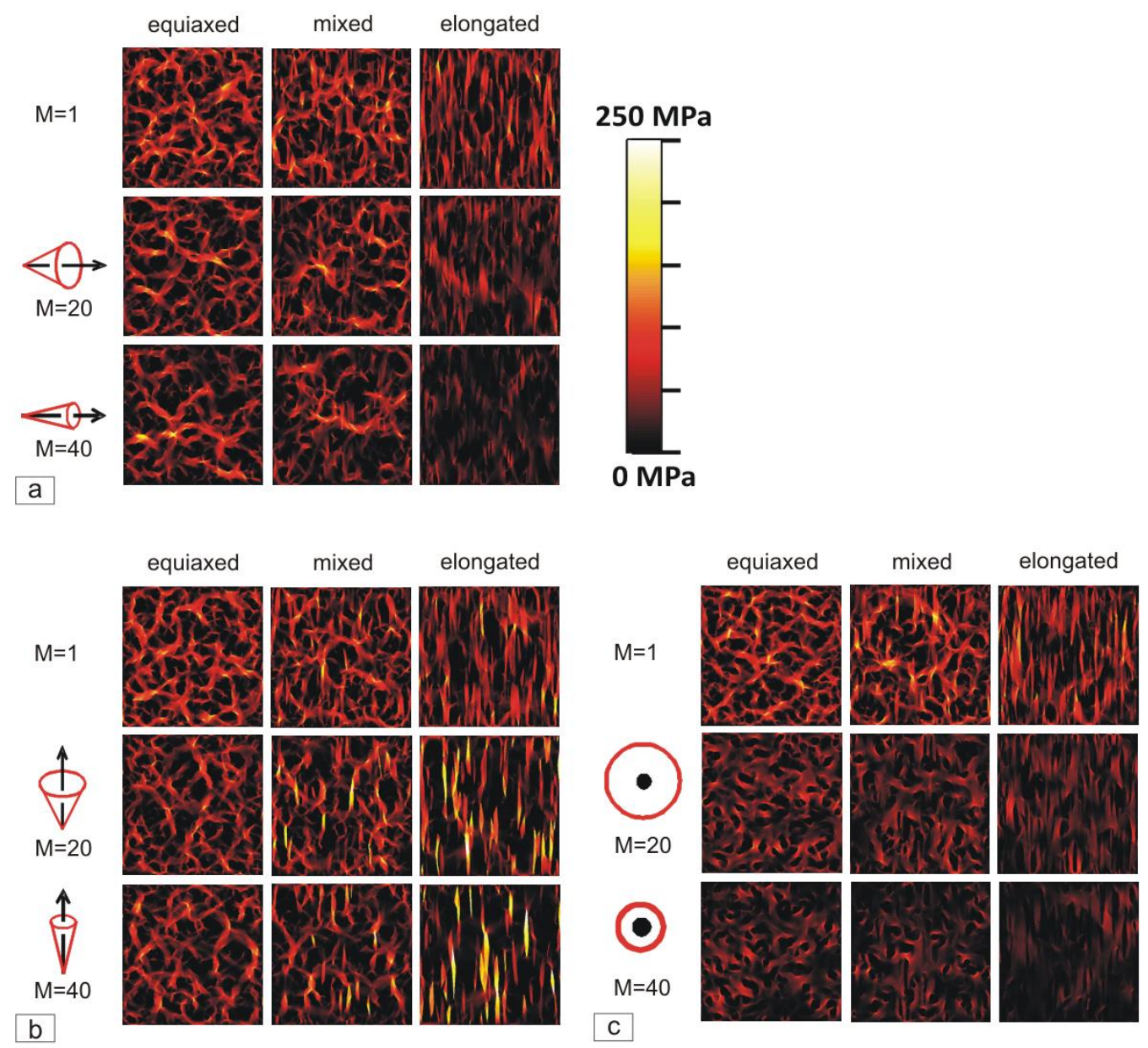

Fig. 4.3 Microstructural maps showing the spatial dependence of the maximum principal stress for the three shape fabrics and the three degree of crystallographic texture in calcitic marble: (a) the crystal texture is perpendicular to the shape fabric direction and in the plane of the microstructure (c-axes are textured along the $x$-direction); (b) the crystal texture is parallel to the shape fabric direction (the c-axes are textured along the $y$-direction); and (c) the crystal texture is perpendicular to the shape fabric direction and out of the plane of the microstructure (the c-axes are textured along the $z$-direction). Stresses are shown with a thermal scale that ranges from black ( $0 \mathrm{MPa})$ to red-orange $(125 \mathrm{MPa})$ to white $(\geq 250$ $\mathrm{MPa})$.

For increasing in-plane crystal texture $(\boldsymbol{M}=20$ and $\boldsymbol{M}=40)$ and SPO, the regions with relatively high maximum principal stress decrease when the crystal texture is perpendicular to the SPO, i.e., in the $\boldsymbol{x}$ direction (see Fig. 4.3a). This is the typical LPO 
Influence of shape fabric and crystal texture on marble degradation phenomena: simulations

for calcite marbles (e.g., Leiss and Ullemeyer 1999). Hence, the propensity for microcracking should decrease for calcite marbles with increasing LPO and SPO.

In contrast, when the crystal texture is parallel to the SPO, i.e., in the $y$ direction, the regions with relatively high maximum principal stress increase noticeably for increasing LPO and SPO (see Fig. 4.3b). This observation is apparently counter to the results in Fig. 4.2, where the average value of maximum principal stress for the elongated fabric initially remains constant and then decreases as $\boldsymbol{M}$ increases from 1 to 20 to 40 . The explanation is in the microstructural standard deviation of the maximum principal stress, which increases as $\boldsymbol{M}$ increases from 1 to 20 , and only slightly decreases as $\boldsymbol{M}$ increases further from 20 to 40 . This observation is related to the same phenomenon described above for the strain energy density. By random chance several of the elongated grains are crystallographically misoriented with respect to the general LPO. Namely, these grains have large values of the fiber texture angle $\boldsymbol{\theta}$, which is not in concord with the expected probability distribution. Accordingly, the long direction of these grains has a low coefficient of thermal expansion (a value somewhat greater than that of the basal plane, i.e., $-6.0 \times 10^{-6} \mathrm{~K}^{-1}$ ), while the textured matrix, in which they lay, has an average coefficient of thermal expansion in that direction that is somewhat less than that of the c-axis, i.e., $26.0 \times 10^{-6} \mathrm{~K}^{-1}$. Thus, on heating the long direction of these misoriented grain contracts, or only slightly expands, in a direction where the remainder of the microstructure is greatly expanding. Hence, these misoriented elongated grains have large axial tension. Therefore, even though the average value of maximum principal stress for the elongated fabric initially remains constant with crystal texture and then decreases, these microstructures could have a greater propensity for microcracking, since fracture is determined by the extremes in the distribution, not by the mean.

The stress state of these grains is seen better in Fig. 4.4, where the stress components in the $\boldsymbol{x}$ and $\boldsymbol{y}$ directions, $\boldsymbol{\sigma}_{\boldsymbol{x} \boldsymbol{x}}$ and $\boldsymbol{\sigma}_{\boldsymbol{y} \boldsymbol{y}}$, respectively, are shown along with the maximum principal stress. The thermal scale for the stress components $\sigma_{x x}$ and $\sigma_{y y}$ ranges from black ( $\leq-250 \mathrm{MPa})$ to red-orange $(0 \mathrm{MPa})$ to white $(\geq+250 \mathrm{MPa})$. The thermal scale for the maximum principal stress is the same as that for Fig. 4.3. From Fig. 4.4a, when the crystalline c-axis is textured perpendicular to the SPO direction, grains with a relatively 
Influence of shape fabric and crystal texture on marble degradation phenomena: simulations

high value of the maximum principal stress, the yellow-colored grains, are aligned along the crystal texture direction better than the average value. Thus, upon heating they contract more (or expand less) than the average. Hence, these well-aligned elongated grains have moderate axial tension. On the other hand, highly misaligned grains, the red- and black-colored grains, have large axial compression. For plane-stress simulations, the maximum principal stress for a region with in-plane biaxial compression is the zero out-of-plane stress, $\boldsymbol{\sigma}_{\mathbf{z z}}$. Thus, the highly misaligned grains are not apparent in the maximum principal stress microstructural maps.

From Fig. 4.4b, when the crystalline c-axis is texture parallel to the SPO direction, the effect of misaligned grains, as described above, is more striking. Clearly, the grains with large values of the maximum principal stress also have large values of $\sigma_{y y}$. The fact these highly stressed grains were actually very misoriented was validated for select grains by noting the misorientation angle $\boldsymbol{\theta}$ of these grains and by computing the direction of the maximum principal stress. So, while the average value of the maximum principal stress decreases with LPO, the few misoriented grains with large axial tension results in a large variance for the maximum principal stress distribution and hence, the large value of the microstructural standard deviation seen in Fig. 4.2 for $M 20(y)$ and $\mathrm{M} 40(\boldsymbol{y})$.

The very different character of the microstructural maps for the maximum principal stress when the crystal texture is out of the plane of the microstructure can be seen in Fig. 4.3c. These patterns result from the near isotropic in-plane properties that result from this type of crystal texture. Nonetheless, the patterns in the stress maps still reflect the shape fabric. Additionally, the magnitude of the maximum principal stress is reduced from that in Fig. 4.3a and Fig. 4.3b.

These observations clearly show that both grain shape fabric and crystal texture have significant impact on the maximum principal stresses that arises in calcite microstructure due to temperature changes, and hence, on the propensity for microcracking. 

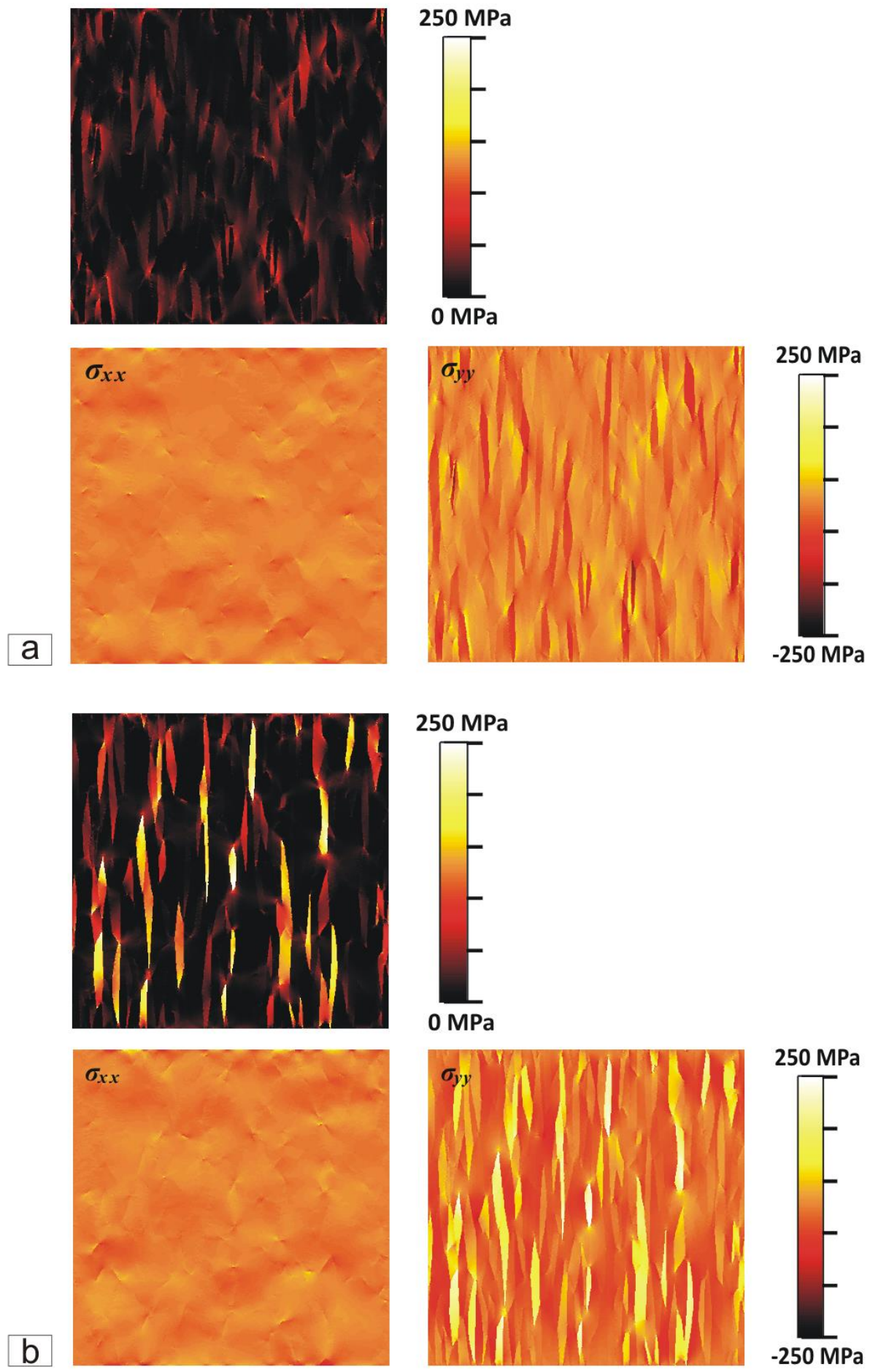

Fig. 4.4 Microstructural maps of the stress tensor components $\sigma_{x x}$ and $\sigma_{y y}$ and the maximum principal stress for the elongated shape fabric in calcitic marble, which has large $(\boldsymbol{M}=40)$ in-plane crystal texture (a) perpendicular to the shape fabric (along the $x$ directions) and (b) parallel to the shape fabric (along the $y$ direction). The stress tensor components are shown with a thermal scale that ranges from black ( $\leq-$ $250 \mathrm{MPa}$ ) to red-orange (0 MPa) to white $(\geq+250 \mathrm{MPa})$. The thermal scale for the maximum principal stress is the same as that for Fig. 4.3. 
Influence of shape fabric and crystal texture on marble degradation phenomena: simulations

4.2.6 Influence of marble composition: dolomitic marbles and marbles with the mixed content of calcite $(50 \%)$ and dolomite (50\%)

Elastic strain energy density and maximum principal stress were computed for dolomitic marbles and marbles with the mixed content, i.e., $50 \%$ of calcite and $50 \%$ of dolomite. The results for dolomitic marbles revealed that the elastic strain energy density of dolomite is approximately two times smaller than those of calcite (compare Fig. 4.1 and Fig. 4.5). However, the maximum principal stress values of the two minerals did not show a significant difference, values of dolomitic marbles are slightly smaller. Microstructural maps showing the spatial dependence of the maximum principal stress for dolomitic marbles are presented in Fig. 4.6. The same observations concerning the influence of SPO, LPO and directionality of the LPO fiber texture with respect to the SPO are found for dolomitic marbles.

The values of strain energy density and maximum principal stress of mixed content of calcite $(50 \%)$ and dolomite $(50 \%)$ marbles are slightly larger than those of calcitic marbles (Fig. 4.7). The different behavior in comparison to pure calcitic or dolomitic marbles is observed when c-axis aligns parallel to z-direction. The values are predominantly larger than those when $c$-axis aligns parallel to $x$ - and $y$-direction (exception is still for elongated microstructure with 20 times random texture). Such results are expectable because in structures with mixture of calcite and dolomite the additional contraction of crystals now is presented in the plane of microstructure since these two minerals have negative and positive coefficients of thermal expansion parallel to a-axes. The influence of LPO is significant, while influence of SPO is not pronounced (Fig. 4.7). 

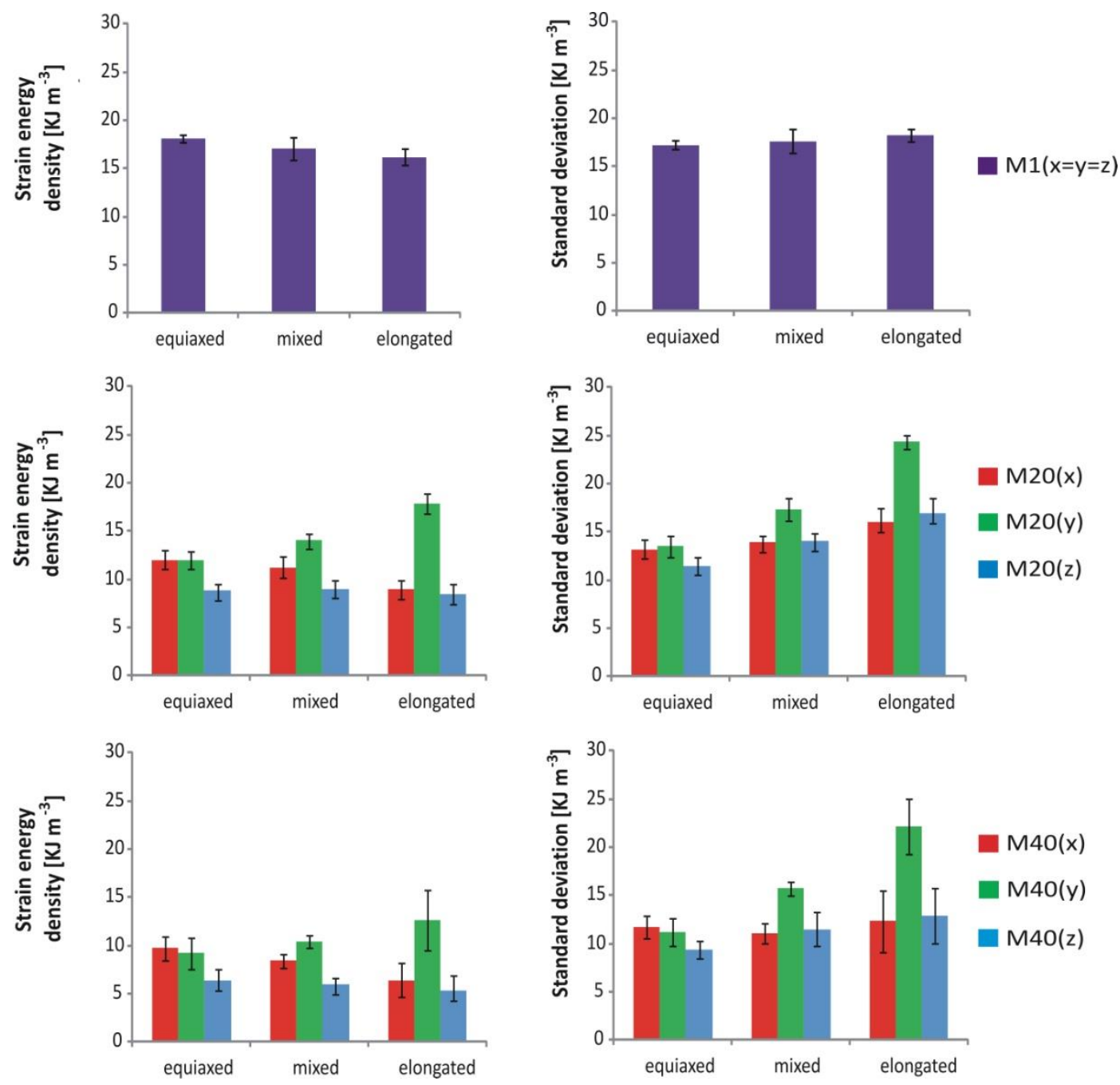

Fig. 4.5 Elastic strain energy density and its microstructural standard deviation (the square root of its variance throughout the microstructure) for dolomitic marbles as a function of SPO and LPO for a temperature change of $+100{ }^{\circ} \mathrm{C}$. The different LPOs, or crystal texture ODFs, are denoted as M1, M20 and M40, respectively corresponding to a March-Dollase parameter $\boldsymbol{M}$ of 1,20 , and 40 for the distribution from which the orientations were chosen. The errors bars show the standard deviation from 5 independent replications of the ODF. Three directions for the LPOs were observed: $\boldsymbol{x}, \boldsymbol{y}$ and $\boldsymbol{z}$, corresponding to the c-axes having fiber texture along $\boldsymbol{x}$-, $\boldsymbol{y}$-, and $\boldsymbol{z}$-axis, respectively. 

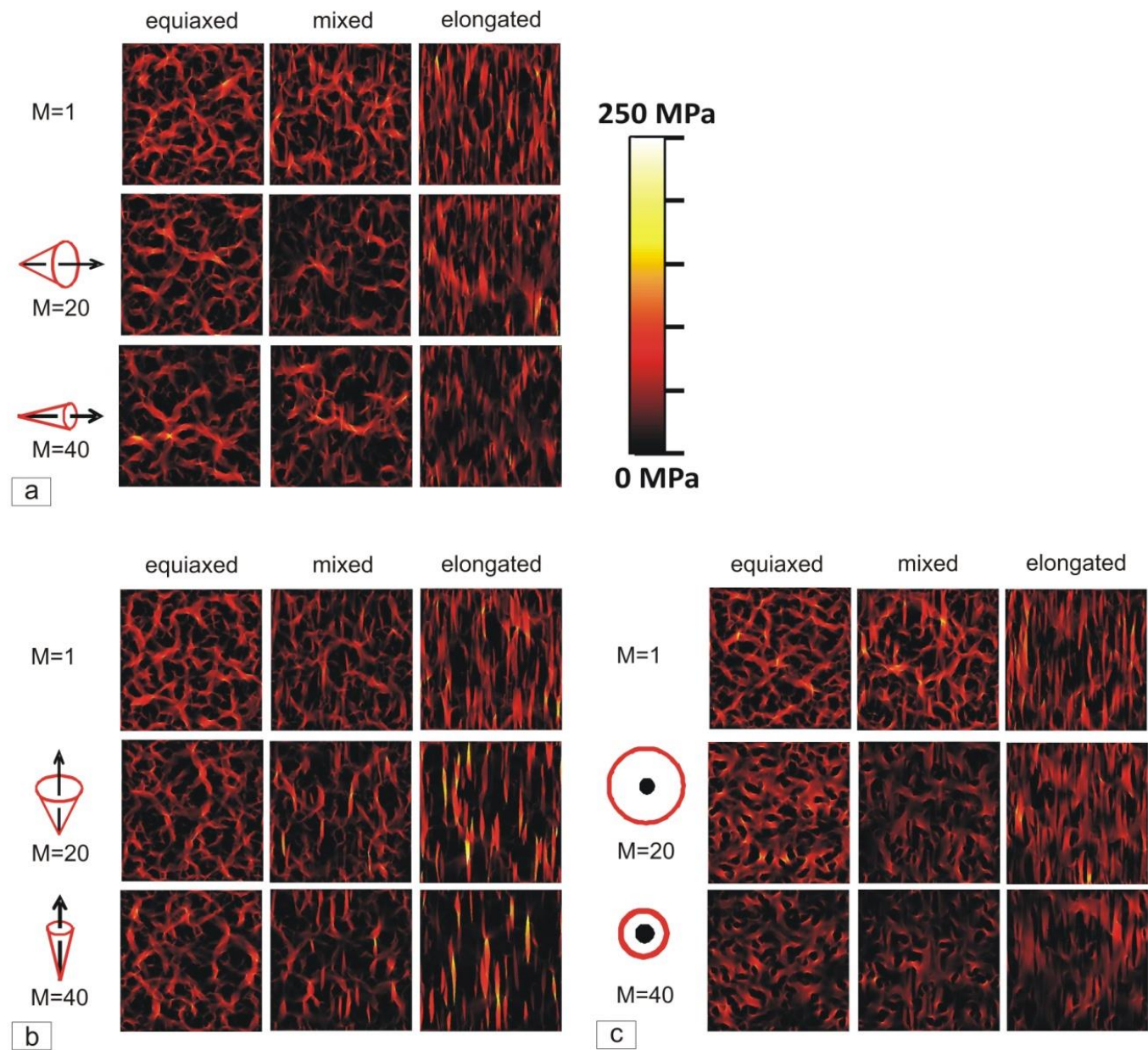

Fig. 4.6 Microstructural maps showing the spatial dependence of the maximum principal stress for the three shape fabrics and the three degree of crystallographic texture in dolomitic marbles: (a) the crystal texture is perpendicular to the shape fabric direction and in the plane of the microstructure (c-axes are textured along the $\boldsymbol{x}$-direction); (b) the crystal texture is parallel to the shape fabric direction (the c-axes are textured along the $\boldsymbol{y}$-direction); and (c) the crystal texture is perpendicular to the shape fabric direction and out of the plane of the microstructure (the $c$-axes are textured along the $\boldsymbol{z}$-direction). Stresses are shown with a thermal scale that ranges from black $(0 \mathrm{MPa})$ to red-orange $(125 \mathrm{MPa})$ to white $(\geq 250$ $\mathrm{MPa})$. 

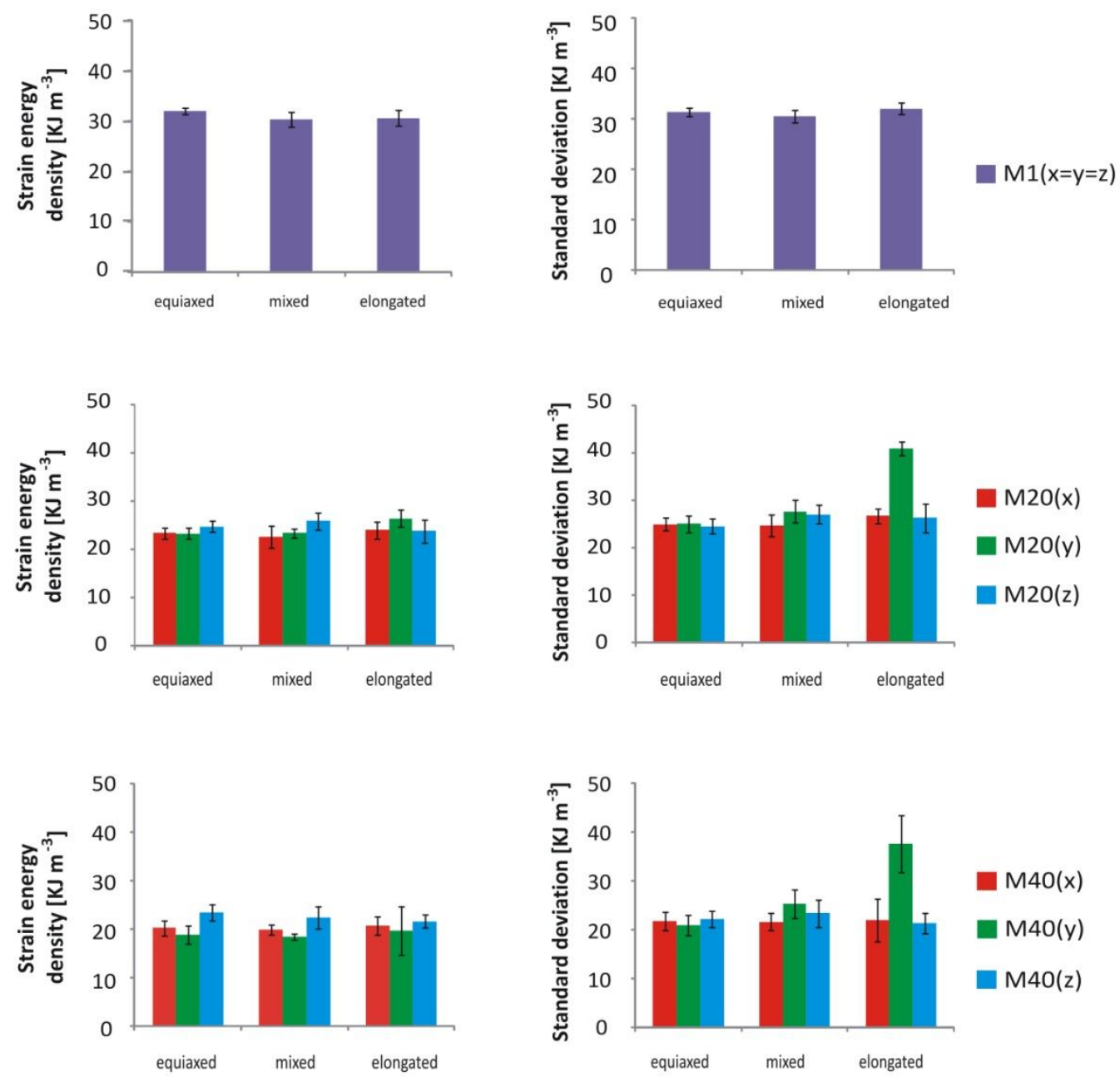

Fig. 4.7 Elastic strain energy density and its microstructural standard deviation (the square root of its variance throughout the microstructure) as a function of SPO and LPO for a temperature change of $+100{ }^{\circ} \mathrm{C}$ for marbles with the mixed content of calcite (50\%) and dolomite (50\%). The different LPOs, or crystal texture ODFs, are denoted as M1, M20 and M40, respectively corresponding to a March-Dollase parameter $\boldsymbol{M}$ of 1,20, and 40 for the distribution from which the orientations were chosen. The errors bars show the standard deviation from 5 independent replications of the ODF. Three directions for the LPOs were observed: $\boldsymbol{x}, \boldsymbol{y}$ and $\boldsymbol{z}$, corresponding to the c-axes having fiber texture along $\boldsymbol{x}$-, $\boldsymbol{y}$-, and $\boldsymbol{z}$-axis, respectively.

\subsubsection{Coefficient of thermal expansion}

For a given simulation configuration and a given temperature change, the effective coefficient of thermal expansion coefficient in the $\boldsymbol{x}$ direction, $\boldsymbol{\alpha}_{\boldsymbol{x}}{ }^{\text {eff }}$, is computed from the relative displacement change of the right and left sides of the microstructure. Similarly, the effective coefficients of thermal expansion coefficient in the $\boldsymbol{y}$ direction, $\boldsymbol{\alpha}_{\boldsymbol{y}}{ }^{\text {eff }}$, are computed from the relative displacement change of the top and bottom of the 
Influence of shape fabric and crystal texture on marble degradation phenomena: simulations

microstructure. The results of these measurements for the various combinations of SPO, degrees of LPO, and the directional relationships between them for calcitic and dolomitic marbles are given in Table 4.1. The uncertainty estimates represent the standard deviation from the five independent replications of the ODF.

Table 4.1. The effective coefficients of thermal expansion in the $\boldsymbol{x}$-and $\boldsymbol{y}$-directions, $\boldsymbol{\alpha}_{\boldsymbol{x}}{ }^{\text {eff }}$ and $\boldsymbol{\alpha}_{\boldsymbol{y}}{ }^{\text {eff }}$, in units of $10^{-6}{ }^{\circ} \mathrm{K}^{-1}$ for the three shape fabrics (equiaxed, mixed, and elongated), the three degrees of LPO (M1, M20, and M40), and the three directions of crystallographic texture with respect to SPO (denoted by $\boldsymbol{c}$-X ,

$\boldsymbol{c}-\boldsymbol{y}$, and $\boldsymbol{c}-\boldsymbol{z}$ for when the c-axes are align along $\boldsymbol{x}$-, $\boldsymbol{y}$ - and $\boldsymbol{z}$-direction, respectively) for calcitic and dolomitic marbles.

\begin{tabular}{|c|c|c|c|c|c|c|c|c|c|c|}
\hline & \multicolumn{3}{|c|}{ equiaxed } & \multicolumn{3}{|c|}{ mixed } & \multicolumn{3}{|c|}{ elongated } \\
\hline & & $c-x$ & $c-y$ & $c-z$ & $c-x$ & $c-y$ & $c-z$ & $c-x$ & $c-y$ & $c-z$ \\
\hline \multicolumn{11}{|c|}{ Calcite } \\
\hline \multirow{2}{*}{ M1 } & $a_{x}^{e f f}$ & $4.1 \pm 0.6$ & $4.1 \pm 0.6$ & $4.1 \pm 0.6$ & $4.0 \pm 0.5$ & $4.0 \pm 0.5$ & $4.0 \pm 0.5$ & $4.1 \pm 0.8$ & $4.1 \pm 0.8$ & $4.1 \pm 0.8$ \\
\hline & $a_{y}^{e f f}$ & $4.1 \pm 0.6$ & $4.1 \pm 0.6$ & $4.1 \pm 0.6$ & $4.0 \pm 0.5$ & $4.0 \pm 0.5$ & $4.0 \pm 0.5$ & $4.1 \pm 0.8$ & $4.1 \pm 0.8$ & $4.1 \pm 0.8$ \\
\hline & & & & & & & & & & \\
\hline \multirow{2}{*}{ M20 } & $a_{x}^{e f f}$ & $17.0 \pm 0.5$ & $-2.2 \pm 0.1$ & $-1.9 \pm 0.4$ & $17.0 \pm 0.8$ & $-1.9 \pm 0.3$ & $-1.6 \pm 0.5$ & $17.5 \pm 0.8$ & $-1.8 \pm 0.6$ & $-1.8 \pm 0.6$ \\
\hline & $a_{y}^{e f f}$ & $-2.0 \pm 0.4$ & $17.0 \pm 0.5$ & $-2.2 \pm 0.2$ & $-1.9 \pm 0.5$ & $16.5 \pm 0.8$ & $-2.2 \pm 0.6$ & $-2.3 \pm 0.5$ & $16.4 \pm 1.0$ & $-2.2 \pm 0.5$ \\
\hline & & & & & & & & & & \\
\hline \multirow{2}{*}{ M40 } & $a_{x}^{e f f}$ & $19.2 \pm 1.0$ & $-3.1 \pm 0.5$ & $-3.0 \pm 0.4$ & $19.6 \pm 0.5$ & $-3.1 \pm 0.4$ & $-3.0 \pm 0.2$ & $20.0 \pm 1.1$ & $-3.2 \pm 0.5$ & $-2.9 \pm 0.7$ \\
\hline & $a_{y}^{e f f}$ & $-3.1 \pm 0.4$ & $19.2 \pm 1.0$ & $-3.0 \pm 0.5$ & $-3.2 \pm 0.2$ & $19.3 \pm 0.6$ & $-3.2 \pm 0.4$ & $-3.3 \pm 0.6$ & $19.2 \pm 1.3$ & $-3.6 \pm 0.4$ \\
\hline \multicolumn{11}{|c|}{ Dolomite } \\
\hline \multirow{2}{*}{ M1 } & $a_{x}^{e f f}$ & $12.2 \pm 0.4$ & $12.2 \pm 0.4$ & $12.2 \pm 0.4$ & $12.2 \pm 0.4$ & $12.2 \pm 0.4$ & $12.2 \pm 0.4$ & $12.2 \pm 0.6$ & $12.2 \pm 0.6$ & $12.2 \pm 0.6$ \\
\hline & $a_{y}^{e f f}$ & $12.2 \pm 0.4$ & $12.2 \pm 0.4$ & $12.2 \pm 0.4$ & $12.2 \pm 0.4$ & $12.2 \pm 0.4$ & $12.2 \pm 0.4$ & $12.2 \pm 0.6$ & $12.2 \pm 0.6$ & $12.2 \pm 0.6$ \\
\hline & & & & & & & & & & \\
\hline \multirow{2}{*}{$M 20$} & $a_{x}^{e f f}$ & $20.5 \pm 0.3$ & $8.3 \pm 0.1$ & $8.5 \pm 0.2$ & $20.5 \pm 0.5$ & $8.4 \pm 0.2$ & $8.7 \pm 0.3$ & $20.8 \pm 0.5$ & $8.6 \pm 0.3$ & $8.6 \pm 0.4$ \\
\hline & $a_{y}^{e f f}$ & $8.3 \pm 0.2$ & $20.5 \pm 0.3$ & $8.3 \pm 0.1$ & $8.4 \pm 0.3$ & $20.2 \pm 0.5$ & $8.3 \pm 0.2$ & $8.1 \pm 0.3$ & $20.1 \pm 0.6$ & $8.2 \pm 0.3$ \\
\hline & & & & & & & & & & \\
\hline \multirow{2}{*}{ M40 } & $a_{x}^{\text {eff }}$ & $21.9 \pm 0.6$ & $7.7 \pm 0.3$ & $7.8 \pm 0.3$ & $22.1 \pm 0.3$ & $7.7 \pm 0.3$ & $7.8 \pm 0.1$ & $22.3 \pm 0.7$ & $7.7 \pm 0.3$ & $7.9 \pm 0.4$ \\
\hline & $a_{y}^{e f f}$ & $7.7 \pm 0.3$ & $21.9 \pm 0.6$ & $7.8 \pm 0.3$ & $7.7 \pm 0.2$ & $21.9 \pm 0.4$ & $7.6 \pm 0.2$ & $7.6 \pm 0.4$ & $21.7 \pm 0.7$ & $7.4 \pm 0.2$ \\
\hline
\end{tabular}

A distribution-averaged coefficient of thermal expansion tensor in the sample reference frame can also be computed from the crystal coefficient of thermal expansion tensor and the March-Dollase probability distribution function. First the crystal coefficient of thermal expansion tensor is rotated to the sample reference frame using the orientational relationship described by the polar angle, $\boldsymbol{\theta}$, and the two azimuthal angles, $\boldsymbol{\varphi}$ and $\boldsymbol{\omega}$. Then, the rotated tensor is averaged over all polar angles and all azimuthal angles weighted by the March-Dollase probability distribution function, $\boldsymbol{f}(\boldsymbol{M}, \boldsymbol{\theta}) \sin (\boldsymbol{\theta})$, where $\boldsymbol{f}(\boldsymbol{M}, \boldsymbol{\theta})$ is given by Eq. (3.9). 
Influence of shape fabric and crystal texture on marble degradation phenomena: simulations

The tensor values, thus computed for calcite, both parallel and perpendicular to the texture direction are given by:

$$
\begin{array}{lll}
M=1 & \alpha^{\text {eff }}{ }_{\text {parallel }}=\alpha^{\text {eff }} \text { perpendicular }_{1}=4.67 \times 10^{-6} \mathrm{~K}^{-1} \\
M=20 & \alpha^{\text {eff }}{ }_{\text {parallel }}=17.29 \times 10^{-6} \mathrm{~K}^{-1} & \alpha^{\text {eff }}{ }_{\text {perpendicular }}=-1.64 \times 10^{-6} \mathrm{~K}^{-1} \\
M=40 & \alpha^{\text {eff }}{ }_{\text {parallel }}=19.40 \times 10^{-6} \mathrm{~K}^{-1} & \alpha^{\text {eff }}{ }_{\text {perpendicular }}=-2.70 \times 10^{-6} \mathrm{~K}^{-1}
\end{array}
$$

The tensor values computed for dolomite are given by:

$$
\begin{array}{lll}
M=1 & \alpha^{\text {eff }}{ }_{\text {parallel }}=\alpha_{\text {perpendicular }}^{\text {eff }}=12.67 \times 10^{-6} \mathrm{~K}^{-1} \\
M=20 & \alpha^{\text {eff }}{ }_{\text {parallel }}=20.6 \times 10^{-6} \mathrm{~K}^{-1} & \alpha_{\text {perpendicular }}^{\text {eff }}=8.7 \times 10^{-6} \mathrm{~K}^{-1} \\
M=40 & \alpha^{\text {eff }}{ }_{\text {parallel }}=21.8 \times 10^{-6} \mathrm{~K}^{-1} & \alpha^{\text {eff }}{ }_{\text {perpendicular }}=8.1 \times 10^{-6} \mathrm{~K}^{-1}
\end{array}
$$

As more crystal texture develops going from a random ODF $(\boldsymbol{M}=1)$ to a highly textured ODF $(\boldsymbol{M}=40)$, the effective coefficient of thermal expansion tensor approaches the single-crystal tensor. The change of sign in $\alpha^{\text {eff }}$ perpendicular from an expansion (a positive value) to a contraction (a negative value) for calcite occurs at approximately $\boldsymbol{M}=8.30$. Note, however, that the volume coefficient of thermal expansion, given by the trace of the thermal expansion tensor, is independent of crystal texture (i.e., $\boldsymbol{M}$ ) and is equal to $14.0 \times 10^{-6} \mathrm{~K}^{-1}$ for calcite and $38 \times 10^{-6} \mathrm{~K}^{-1}$ for dolomite.

The effective coefficients of thermal expansion in Table 4.1 show a strong dependence on the degree of LPO (i.e., $\boldsymbol{M}$ ) and on the directional relationship between the thermal expansion tensor and the crystal texture direction (i.e., parallel or perpendicular), but only show a minor influence on the shape fabric for both minerals, calcite and dolomite. The dependence of the simulation results on the degree of LPO agrees well with that computed for the distribution-averaged coefficient of thermal expansion. Several minor deviations are apparent, however, which are not fully understood at present. The lack of dependence on shape fabric was unexpected. One might have expected the shape fabric to have had a significant influence on the effective thermal expansion when combined with crystalline texture. For example, elongated grains aligned in the crystalline texture direction might have had more of an effect that an ensemble of equiaxed grains. Simulation results seem to show that this is not the case. However, as mentioned above, these effective values represent only the contribution to the thermal expansion or contraction from the elastic thermal misfit strains. If microcracking occurs, an additional expansion will occur, which may depend on shape fabric and any synergy between shape fabric and crystal texture. 
Influence of shape fabric and crystal texture on marble degradation phenomena: simulations

\subsection{Summary and conclusions}

The elastic strain energy density and maximum principal stress are important microstructural properties for predicting microcrack formation. Spatial regions where these two microstructural properties are large are expected to indicate regions in the microstructure with a propensity for microcracking. Microstructure-based finite-element simulations were used to elucidate not only these spatial regions, but also the average values of these thermal-elastic responses and their microstructural standard deviations, i.e., the standard deviation of their spatial distributions. This finite element approach is considered an excellent tool for elucidating influences of the rock's fabric and crystal texture on the thermal-elastic behavior of marbles.

Significant observations are:

- For random crystallographic texture, i.e., no LPO, shape fabric did not have a significant influence on either the average values or the microstructural standard deviation of the thermal-elastic responses. While not necessarily surprising, this observation was not expected. There is, however, spatial dependence to the stress networks that form. These networks of high strain energy density and maximum principal stress mimic the SPO, so this spatial dependence may have an influence on microcrack formation.

- With equiaxed shape fabric, increasing degrees of LPO generally lead to a reduction in the microstructural stresses and the stored elastic strain energy. This effect was expected since crystallographic texture reduces the misfit strains from the thermal expansion anisotropy. As expected, there is minor influence of the direction of the crystal texture, since statistically there is no directionality to the grain fabric.

- LPO in combination with a mixed or elongated shape fabric can synergistically lead to significant effects, which have a strong directional dependence.

- When the LPO is aligned parallel with the SPO direction, the thermal-elastic responses increase markedly with shape fabric that observed for calcitic and dolomitic marbles, while for marbles with the mixed content of calcite $(50 \%)$ and dolomite $(50 \%)$ such increasing is not significant. The responses with crystal texture are more complex, but essentially either remain constant, increase slightly and then decrease, or decrease. More significantly, however, 
is the increase of the microstructural standard deviations of these responses, indicating wide microstructural variation of these responses. These microstructural variations are clearly apparent in the microstructural response maps.

- When the LPO is aligned perpendicular to the SPO direction, the thermalelastic responses remain constant or decrease with shape fabric and decrease with crystal texture. The microstructural standard deviations of the strain energy density increase with shape fabric and decrease with crystal texture. The microstructural standard deviations of the maximum principal stress decrease with both shape fabric and crystal texture. Generally, microstructures with this combination of shape fabric and crystal texture will have less of a tendency to microcrack, particularly as the crystal texture increases.

- When the LPO is aligned perpendicular to the SPO direction and out of the plane of the simulation, the in-plane thermal-elastic responses are nearly isotropic, and are reduced in magnitude accordingly.

- Even though microstructures with aligned LPO and SPO features give the largest thermal-elastic responses and microstructural variability, this response may not be significant for several reasons. First, if the crystal texture is correlated with the shape texture, these misoriented grains may not be probable. Second, this LPO is less often reported for marbles. And third, this combination of LPO and SPO would lead to transgranular microcracking perpendicular to the elongated direction of the grains, i.e., axial segmentation of these grains. Such microcracking would therefore depend on a low fracture energy cleavage plane, which may not be the case.

- Marble composition has significant influence on the thermal-elastic response. Dolomitic marbles are supposed to be more resistance to microcracking since they show two times smaller values of elastic strain energy density, which is a main precursor of microcracking. However, the presence of dolomite in calcitic marble can lead to increasing of the thermal-elastic responses since dolomite crystals produce the additional contraction with calcite crystals. 
Microcracking in calcite and dolomite marble: microstructural influences and effects on properties

\section{Microcracking in calcite and dolomite marble: microstructural influences and effects on properties}

5.1 Input parameters

Two-dimensional hypothetical rock microstructures (Fig. 3.7) were used as input micrographs for the finite-element simulations in order to investigate microcracking initiation and propagation in marble structures.

When fracture is included as a phenomenon in finite-element simulations, the material now has a length scale (namely, the fracture surface energy divided by an elastic modulus), by which to measure grain size. Heretofore (e.g., chapter 4), outputs from microstructure-based simulations (e.g., elastic strain energy density and maximum principal stress) were independent of grain size; the only units being those of strain energy density $\left(\mathrm{kJ} \cdot \mathrm{m}^{-3}=10^{-6} \mathrm{GPa}\right)$ or stress (GPa). Now, grain size, or equivalently, the size of the microstructural image, is important as it influences the parameter that is input into the simulation for the fracture surface energy. Accordingly, we introduce grain size as an important fabric, or microstructural parameter. We consider here three grain sizes: $200 \mu \mathrm{m} ; 1 \mathrm{~mm}$; and $2 \mathrm{~mm}$. However, due to the complexity of three SPOs in the present simulations (e.g., two different grain distributions in the mixed microstructure and non-equiaxed grains in the elongated microstructure), a better dimensional metric is the size of the microstructural image. Thus, the grain diameters for equiaxed grains and the grain widths for elongated grains were measured for a representative number of grains in each SPO microstructure. Using an average of these values to compute a nominal average grain size, the size of the microstructure was adjusted to give the three nominal average grain sizes. For a nominal average grain size of $1 \mathrm{~mm}$, the size of the micrograph for the equiaxed and the mixed microstructure is $16.13 \mathrm{~mm} \times 16.13 \mathrm{~mm}$, and the size for the elongated microstructure is $13.89 \mathrm{~mm} \times 13.89 \mathrm{~mm}$. Similarly, when the nominal average grain size is $200 \mu \mathrm{m}$ and $2 \mathrm{~mm}$, the sizes of the micrographs (edge lengths), respectively, are $3.125 \mathrm{~mm}$ and $31.25 \mathrm{~mm}$ for the equiaxed and mixed microstructure, and $2.778 \mathrm{~mm}$ and $27.78 \mathrm{~mm}$ for the elongated microstructure.

Two different types of LPO were generated using $\boldsymbol{M}$ values of 1 and 20 (see Fig. $3.8 a, b)$. 
Typical LPOs for marbles, as described in Leiss and Ullemeyer (1999), are textured with the c-axes perpendicular to the SPO. Accordingly, while there are many ways to align LPO with respect to SPO (e.g., three mutually orthogonal idealized configurations were considered in chapter 4), in the current simulations we have aligned the c-axes perpendicular to the shape fabric and out of plane, i.e., parallel to the $\boldsymbol{z}$ direction.

\subsection{Finite-element simulations}

An adaptive meshing algorithm was used to create a finite-element mesh with a grainboundary phase that has the same thermal-elastic properties and orientations as the host grains, but with a different fracture toughness, i.e., the grain-boundary toughness, Yig. The final mesh consisted of 140,358 triangular elements for the equiaxed microstructure; 207,208 triangular elements for the mixed microstructure; and 163,668 elements for the elongated microstructure.

After creating the mesh, thermal-elastic properties were assigned to the grains and to the grain boundaries according to which marble composition (calcite or dolomite) was being considered. The single crystal elastic constants for both minerals, $\boldsymbol{C}_{i j}$, (Bass 1995) and the crystalline coefficients of thermal expansion for calcite (Kleber 1959) and dolomite (Reeder and Markgraf 1986) were used (see Table 2.1).

Thirty unique configurations specified by SPO, LPO, grain size, grain-boundary toughness and marble composition were used in the simulations. Three different sets of orientations were generated for the calcite microstructures with equiaxed, mixed and elongated grains, random and twenty times random texture, a nominal grain size of $1 \mathrm{~mm}$, and a grain-boundary toughness of $40 \%$ of that for the grains. For other microstructural configurations only one replication of the ODF was used in the simulations. Thus, with replications, 42 configurations were used as the basis for the finite-element simulations.

Strain energy density and maximum principal stress were calculated for all microstructure configurations on heating and cooling by $50{ }^{\circ} \mathrm{C}$. Simulations were done with and without allowing microcracking to occur. 
Microcracking in calcite and dolomite marble: microstructural influences and effects on properties

The fracture surface energy of single crystals is typically of order $0.3 \mathrm{Jm}^{-2}$ to $1.1 \mathrm{Jm}^{-2}$ (Becher and Freiman 1978, White et al. 1988). Accordingly, in the present simulations the crystalline or grain fracture toughness, $\boldsymbol{V}_{x t a l}$, for both calcite and dolomite was assumed to be $0.5 \mathrm{Jm}^{-2}$, and isotropic. Little is known about experimental values for the grain-boundary toughness. Accordingly, to examine the influence of the intergranular fracture resistance, the grain-boundary toughness was assumed to be $40 \%$ and $20 \%$ of $V_{x t a l}$, thus the fracture resistance energy of the grain boundaries was $\boldsymbol{V}_{i g}=0.2 \mathrm{Jm}^{-2}$ and $\boldsymbol{V}_{i g}=0.1 \mathrm{Jm}^{-2}$, respectively. For simulations of microcrack initiation and crack propagation a Griffith-type fracture criterion was used. This criterion is based on the energy balance between mechanical and surface energy (Griffith 1921). How it is implemented in OOF is described in section 3.1. Since the elastic constants input into OOF have units of GPa, the fracture surface energy has units of GPa times the size of the microstructure. Thus, by varying the input value of the fracture surface energy, one can vary the size of the microstructure, and hence, the nominal average grain size, as discussed above.

Fracturing in OOF is accomplished by reducing the directional elastic moduli (both the tensile and shear moduli) across the fracture plane by multiplicative factors (Carter et al. 1998; Zimmerman et al. 2001; Galal Yousef et al. 2005). Multiplicative factors were chosen to be $1 \times 10^{-6}$ and $2 \times 10^{-6}$ in this study.

The finite-element simulations used two-dimensional elasticity with a plane-stress assumption, thereby simulating a free surface.

\subsection{Results and discussion}

\subsubsection{Effect of SPO and LPO}

The influence of SPO and LPO are illustrated for a calcitic marble with a nominal grain size of $1 \mathrm{~mm}$ and a grain-boundary toughness of $40 \%$ of the single crystal toughness. Nonetheless, the results are general for all compositions and grain sizes. The results for this configuration are averaged over three replications of orientations (i.e., the ODFs) for the LPO distribution. For the equiaxed microstructure with a random $\operatorname{ODF}(\boldsymbol{M}=1)$ the onset of microcracking on heating occurs at an average temperature change of $\Delta \mathrm{T}=15 \pm 2{ }^{\circ} \mathrm{C}$. For the mixed grain microstructure microcracking commences at $\Delta \mathrm{T}=16 \pm 1^{\circ} \mathrm{C}$, while for the elongated microstructure microcracking commences at 
$\Delta T=20 \pm 2^{\circ} \mathrm{C}$. The elastic strain energy density and the maximum principal stress were monitored during heating and cooling for temperature step changes of $1^{\circ} \mathrm{C}$ for both cracked and uncracked samples. The uncracked simulations are those for which the microcracking algorithm was not activated. The thermal-elastic response values are plotted for the temperature interval from $10^{\circ} \mathrm{C}$ to $50^{\circ} \mathrm{C}$ during heating and from $-10^{\circ} \mathrm{C}$ to $-50^{\circ} \mathrm{C}$ during cooling (see Fig. 5.1). The strain energy density and the maximum principal stress for the cracked state show a strong dependence on SPO for random crystallographic texture.
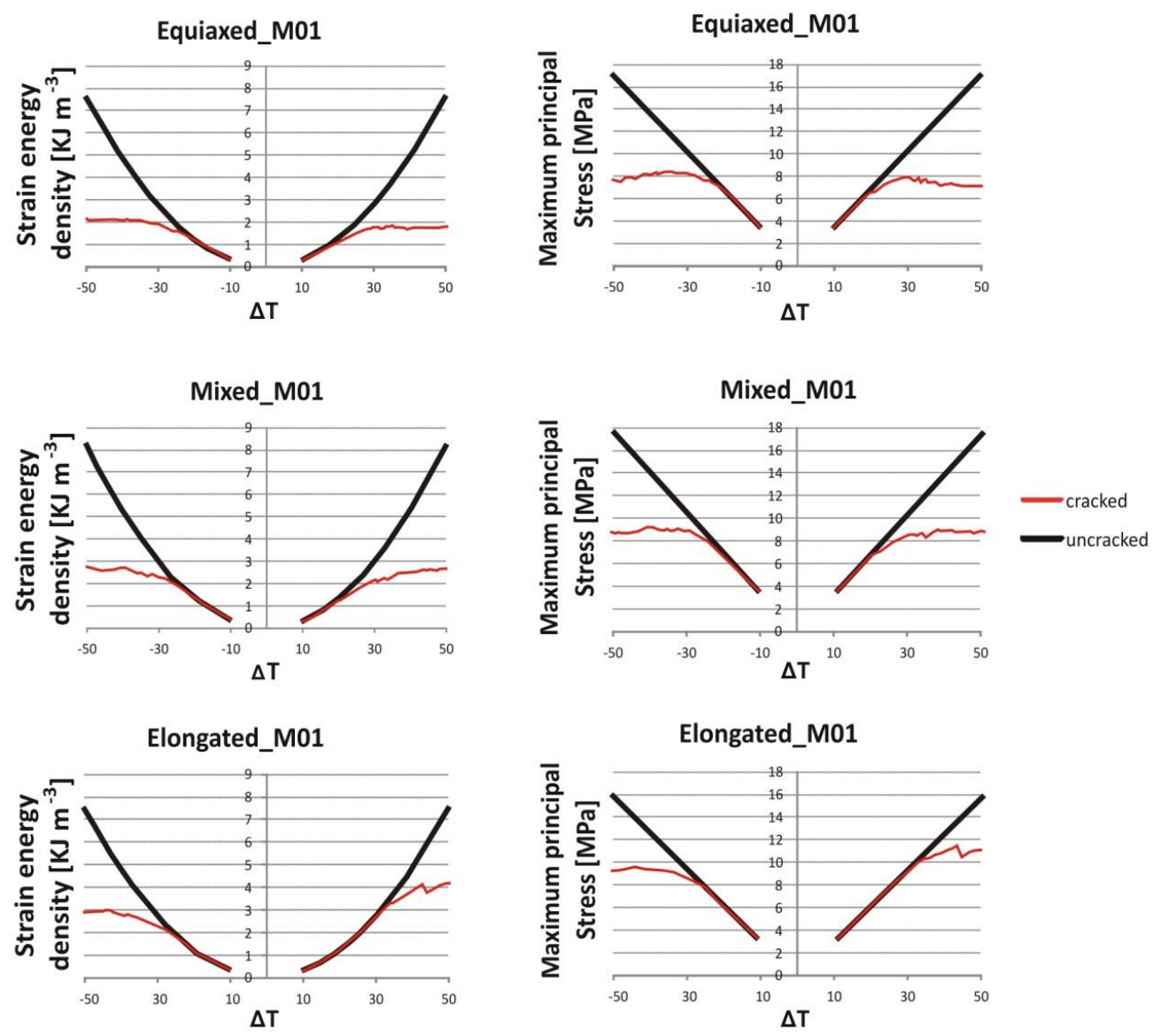

Fig. 5.1 Representative responses (a single replication of a random ODF) of the elastic strain energy density and the maximum principal stress for microcracked (red) and unmicrocracked (black) idealized marble microstructures versus the temperature change from the unstressed state. Results are shown for three idealized calcitic microstructures (equiaxed grains, a mixture of equiaxed and elongated grains, and elongated grains) with a nominal grain size of $1 \mathrm{~mm}$ and random texture, denoted as M01.

Microcracking in simulations with a highly textured LPO $(\boldsymbol{M}=20)$ commences at a larger temperature increment from the unstressed state compared to the simulations with no texture, i.e., a random ODFs $(\boldsymbol{M}=1)$. The equiaxed microstructure begins to microcrack 
at average of $\Delta \mathrm{T}=18 \pm 1{ }^{\circ} \mathrm{C}$, while the microstructure with mixed shape fabric starts to crack at $\Delta \mathrm{T}=18 \pm 4^{\circ} \mathrm{C}$, and the elongated microstructure commences to crack at an even higher temperature differential of $\Delta \mathrm{T}=23 \pm 4{ }^{\circ} \mathrm{C}$. The strain energy density and maximum principal stress for the fabric parameters are plotted in Fig. 5.2. A significant influence of SPO on the response of the cracked microstructures is observed upon heating; upon cooling the responses are similar.
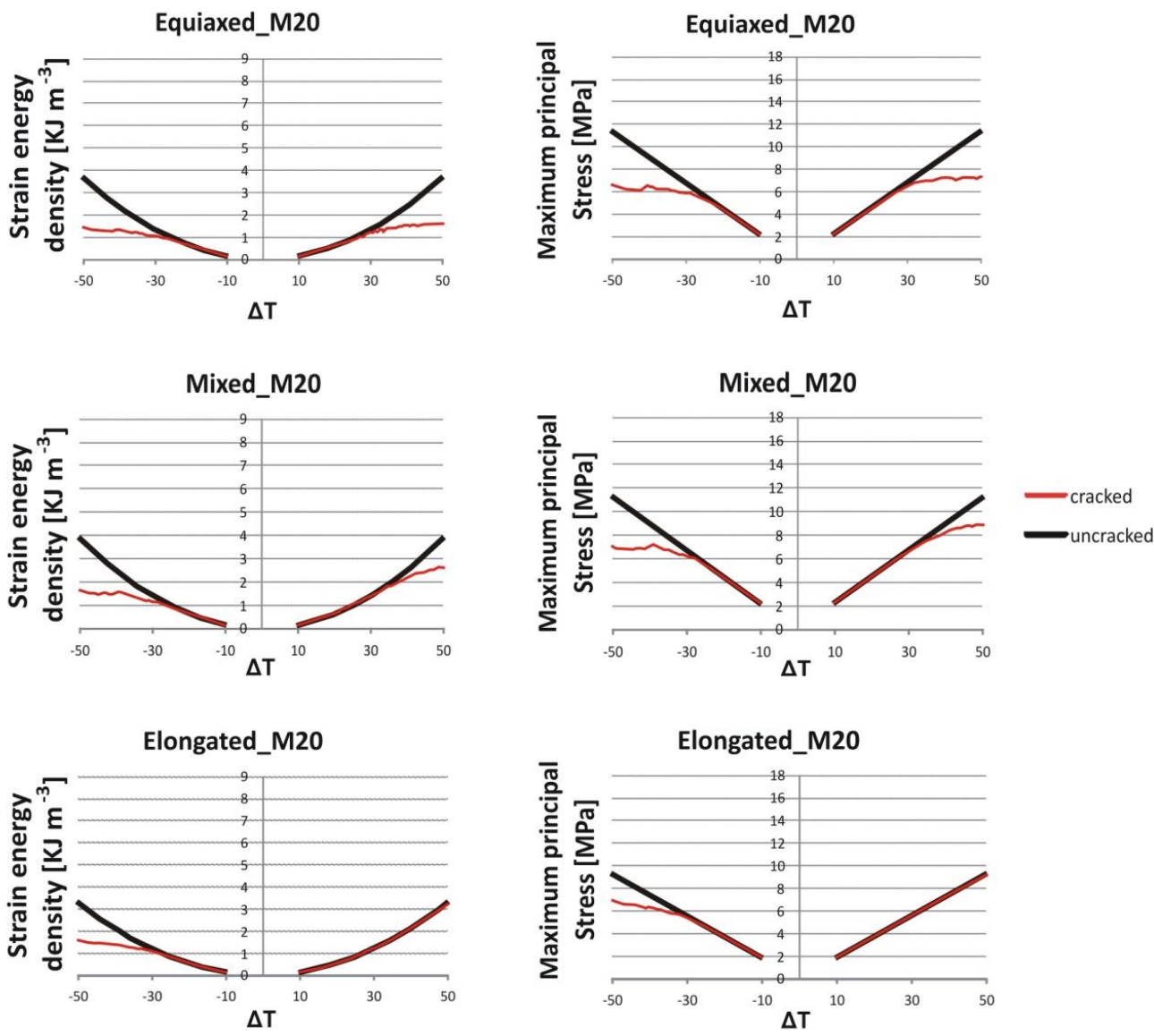

Fig. 5.2 Representative responses (a single replication of a textured ODF) of the elastic strain energy density and the maximum principal stress for microcracked (red) and unmicrocracked (black) idealized marble microstructures versus the temperature change from the unstressed state. Results are shown for three idealized calcitic microstructures (equiaxed grains, mixture of equiaxed and elongated grains, and elongated grains) with a nominal grain size of $1 \mathrm{~mm}$ and crystallographic texture that is twenty times random texture (denoted as M20).

The decrement in elastic strain energy density on microcracking (i.e., the difference between the strain energy density of the uncracked state and the cracked state) is the largest in the equiaxed microstructure with random texture (see Fig. 5.3). Since elastic strain energy is converted to fracture surface energy on microcracking, this result would 
suggest more microcracking in the equiaxed microstructure with random texture. To verify this conjecture, the averaged percentage of microcracked elements from three replications of the ODF are shown in Fig. 5.4 for a temperature change of $50{ }^{\circ} \mathrm{C}$ in both heating and cooling. The greatest extent of microcracking is observed in the equiaxed microstructure with random texture upon cooling (i.e., $9.1 \pm 0.3 \%$ of the total area at $\Delta T=-50^{\circ} \mathrm{C}$ ). This is closely followed by the same microstructure upon heating (i.e., $7.8 \pm 0.2 \%$ at $\Delta \mathrm{T}=+50{ }^{\circ} \mathrm{C}$ ). In the mixed grain-type microstructure only $7.2 \pm 0.5 \%$ of whole area is microcracked upon cooling and $5.9 \pm 0.3 \%$ upon heating. Even fewer microcracks are observed in the elongated microstructure: $6.8 \pm 1.3 \%$ and $4.0 \pm 0.6 \%$ upon cooling and heating, respectively. In all microstructures more microcracking is observed upon cooling, than upon heating. The asymmetry is shown in Fig. 5.5 for an elongated-grain microstructure with random texture. An apparent reason for this asymmetry can be explained as following. If the long axis of a grain is perchance aligned along the c-axis, upon heating it would be in compression. And, upon cooling, it would be in tension. A similar phenomenon would occur for equiaxed grains, but would not be so pronounced. Therefore, one would expect a SPO effect.

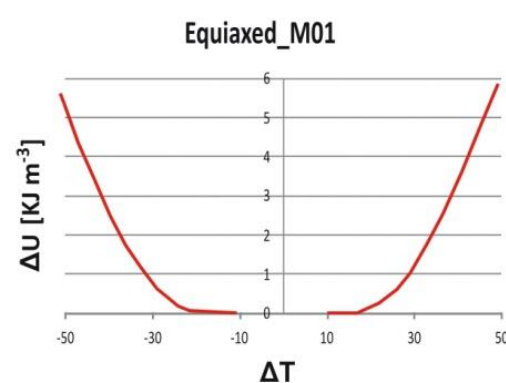

$\Delta \mathrm{T}$

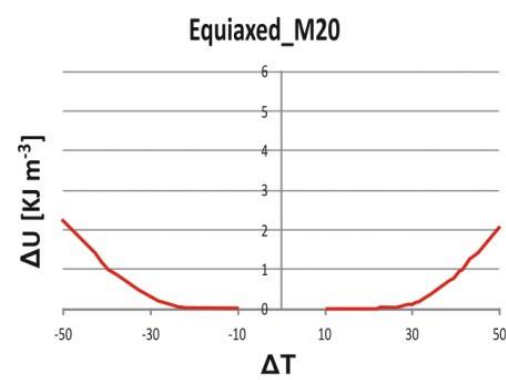

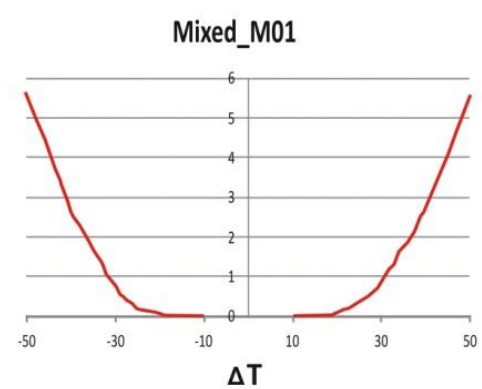

Mixed_M20

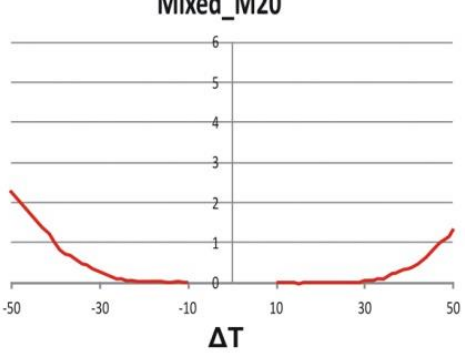

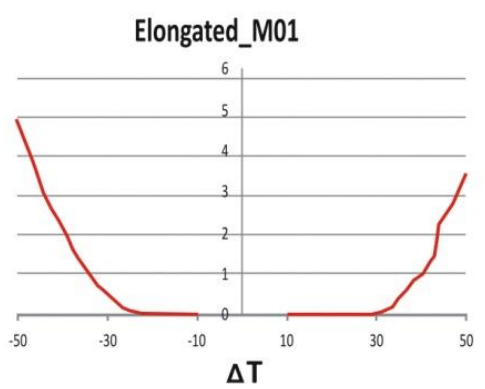

$\Delta \mathrm{T}$

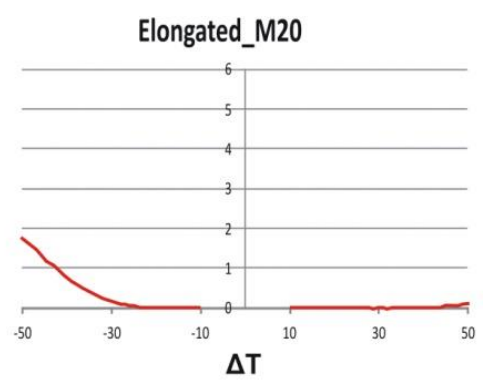

Fig. 5.3 The decrement in the elastic strain energy density between the unmicrocracked and the microcracked states of idealized calcitic marble microstructures with a nominal grain size of $1 \mathrm{~mm}$. Results are shown for random crystallographic texture (denoted M01) and a texture that is twenty times random (denoted as M20). 
When the crystallographic texture is twenty times random, the least amount of microcracking is observed in the elongated grain-type microstructure upon heating. Only $0.3 \pm 0.1 \%$ of the total area microcracks for a temperature change of $\Delta \mathrm{T}=+50{ }^{\circ} \mathrm{C}$. In contrast, cooling the same microstructure results in $2.8 \pm 0.4 \%$ of the total area microcracking for a temperature change of $\Delta T=-50^{\circ} \mathrm{C}$. In the mixed grain-type microstructure the amount of microcracking is $2.2 \pm 0.4 \%$ and $3.4 \pm 0.3 \%$ of the total area upon heating and cooling, respectively. For the highly textured material the most amount of microcracking is observed in the equiaxed microstructure with $3.8 \pm 0.1 \%$ of whole area upon heating and $4.0 \pm 0.2 \%$ upon cooling (See Fig. 5.4). The influence of SPO on the degree of microcracking is quite apparent upon heating: there is a sevenfold increase in microcracking when changing from the elongated grain-type to the mixed grain-type microstructure. Upon cooling, the amount of microcracking is greater, but does not increase as significantly with decreasing SPO (only about $20 \%$ for each grain-type change).

M01

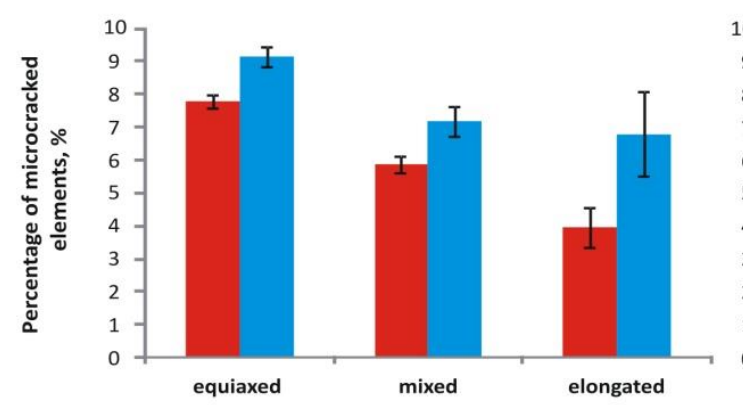

M20

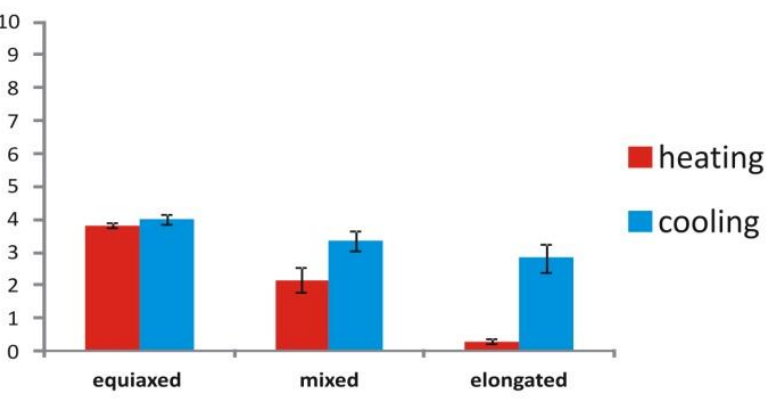

Fig. 5.4 Averaged percentage of microcracked elements from three replications of the ODF for the three idealized calcitic marble microstructures with a nominal grain size of $1 \mathrm{~mm}$ and random texture (denoted as M01) and texture that is twenty times random (denoted as M20). Results are for a temperature change of $+50^{\circ} \mathrm{C}$ (denoted as heating) and $-50^{\circ} \mathrm{C}$ (denoted as cooling). The error bars represent one standard deviation.

The amount of stored elastic strain energy of the uncracked state, as measured by the strain energy density, decreased approximately twofold with increasing LPO. However, the amount of stored strain energy of the cracked state decreased only slightly with increasing LPO (Fig. 5.1 and Fig. 5.2). Accordingly, the decrement in elastic strain energy (Fig. 5.3) and the percentage of microcracked area (Fig. 5.4) both decrease 

approximately by $60 \%$ with increasing LPO. Fig. 5.6 provides visualization of the onset and degree of microcracking and of the influence of SPO and LPO.
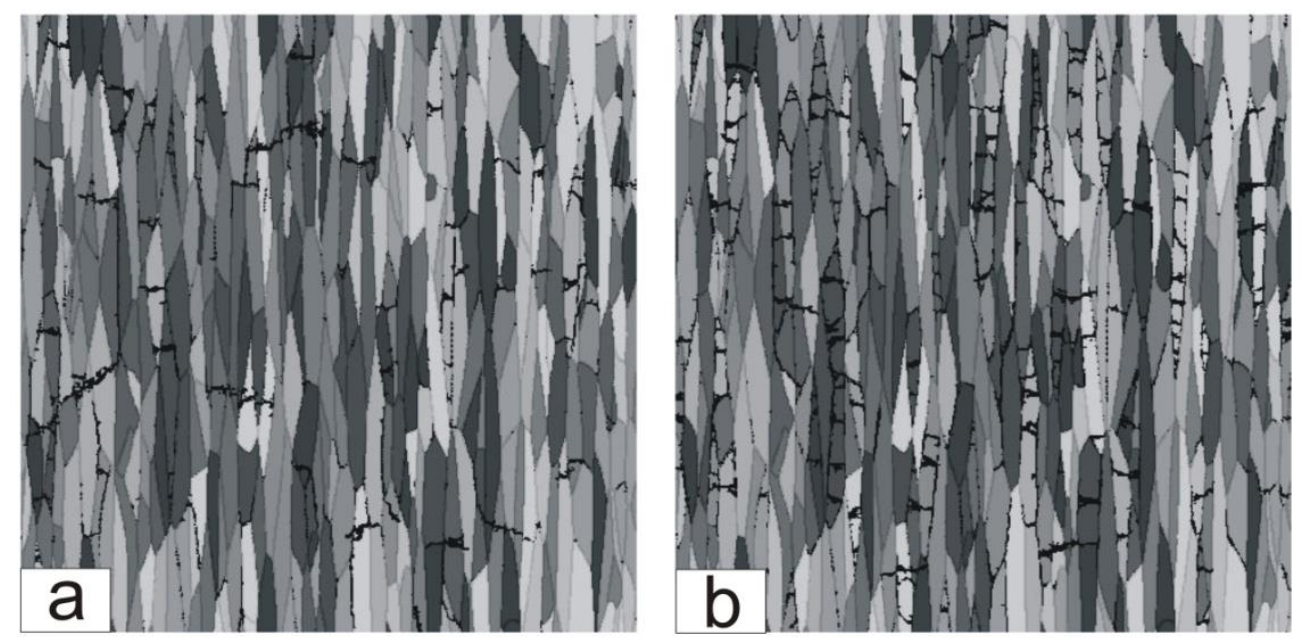

Fig. 5.5 Simulations of microcracking in an elongated-grain calcite marble with random texture and a nominal grain size of $1 \mathrm{~mm}$ : (a) upon heating by a temperature differential $+50^{\circ} \mathrm{C}$; (b) upon cooling by a temperature differential $-50^{\circ} \mathrm{C}$.

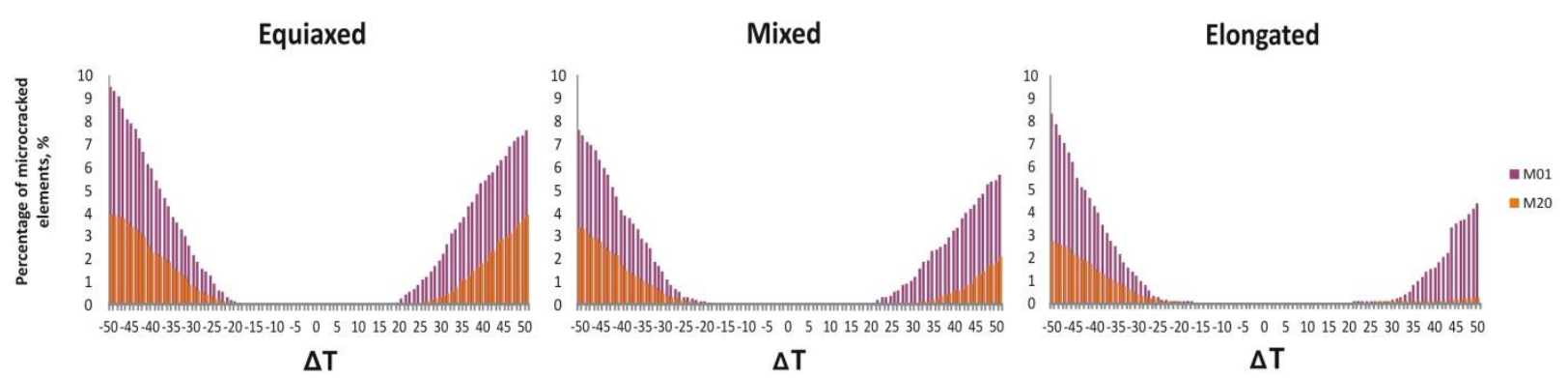

Fig. 5.6 Representative responses (a single replication of each ODF) of the percentage of microcracked elements for the three idealized calcitic marble microstructures with a nominal grain size of $1 \mathrm{~mm}$ upon heating and cooling. Random texture is denoted as M01; twenty times random texture is denoted as M20.

In the present simulations initiation of microcracks was generally observed to occur at grain triple junctions and along single grain-boundary facets or partial facets. Subsequent microcracking was mixed mode with a combination of intergranular, intragranular and transgranular fracture. 


\subsubsection{Spatial distribution of microcracks}

To investigate the relation between maximum principal stress and microcrack initiation and propagation, high-stress regions in an uncracked material were compared to the microcracks in the cracked material. Microstructural response maps show the spatial dependence of microcracking and maximum principal stress for an equiaxed microstructure with a random ODF (Fig.5.7) and for a mixed grain microstructure with a high degree of LPO texture ( $\boldsymbol{M = 2 0}$ ) (Fig. 5.8). Microstructural response maps are shown for $\Delta \mathrm{T}=50^{\circ} \mathrm{C}$ and $\Delta \mathrm{T}=-50^{\circ} \mathrm{C}$ in both uncracked and cracked materials. As was pointed out by Weiss et al. (2002) cracks that occurred in microstructure upon heating do not form upon cooling and vice versa. Regions with high maximum principal stress in the uncracked state correspond to microcracks in the cracked material. Most of these regions in cracked material have high maximum principal stress as well but the values are smaller than those in the uncracked state. For the uncracked state in a mixed grain microstructure with $\boldsymbol{M = 2 0}$ texture there are fewer regions with high maximum principal stress than in the equiaxed grain microstructure with random texture, i.e., the propensity for microcracking is less.
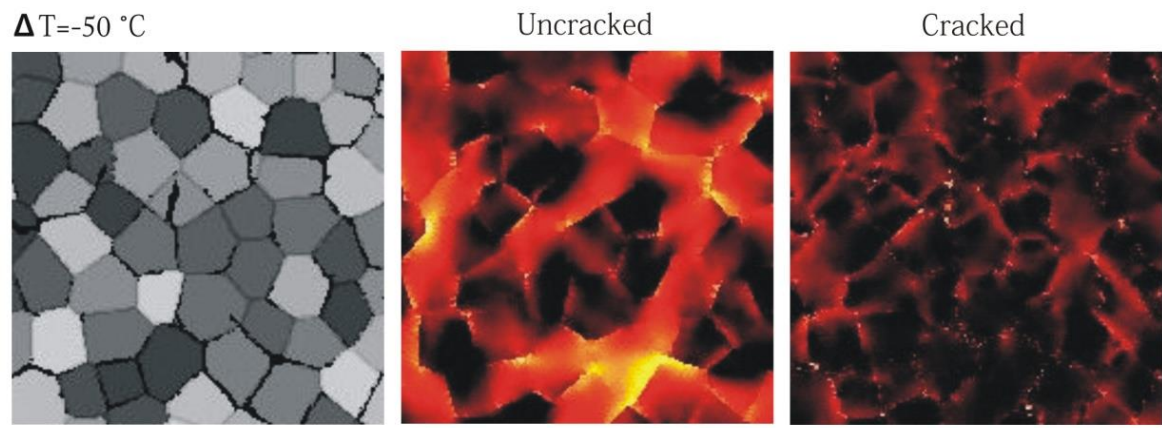

$\Delta \mathrm{T}=50{ }^{\circ} \mathrm{C}$
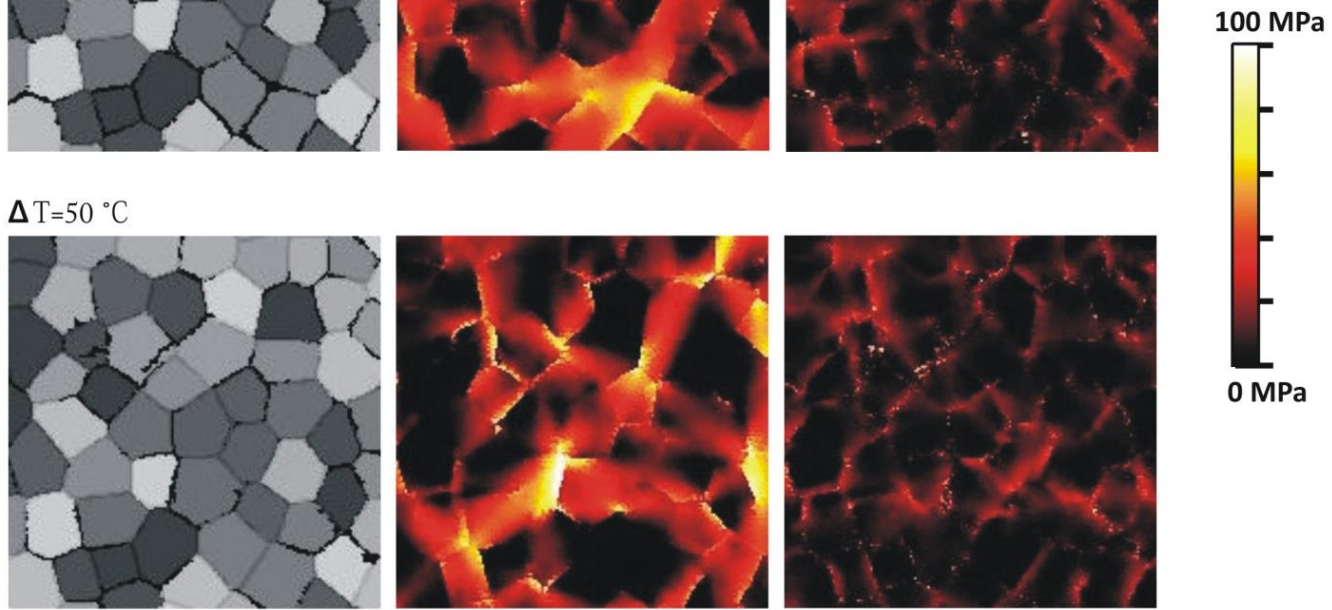

Fig. 5.7 A cropped selection (170x170 pixels) from a microstructural response map showing the spatial dependence of the maximum principal stress for an uncracked and cracked equiaxed-grain calcitic marble microstructure with a nominal grain size of $1 \mathrm{~mm}$ and a random ODF for a temperature changes of $\Delta \mathrm{T}=-50^{\circ} \mathrm{C}$ and $\Delta \mathrm{T}=+50^{\circ} \mathrm{C}$. 

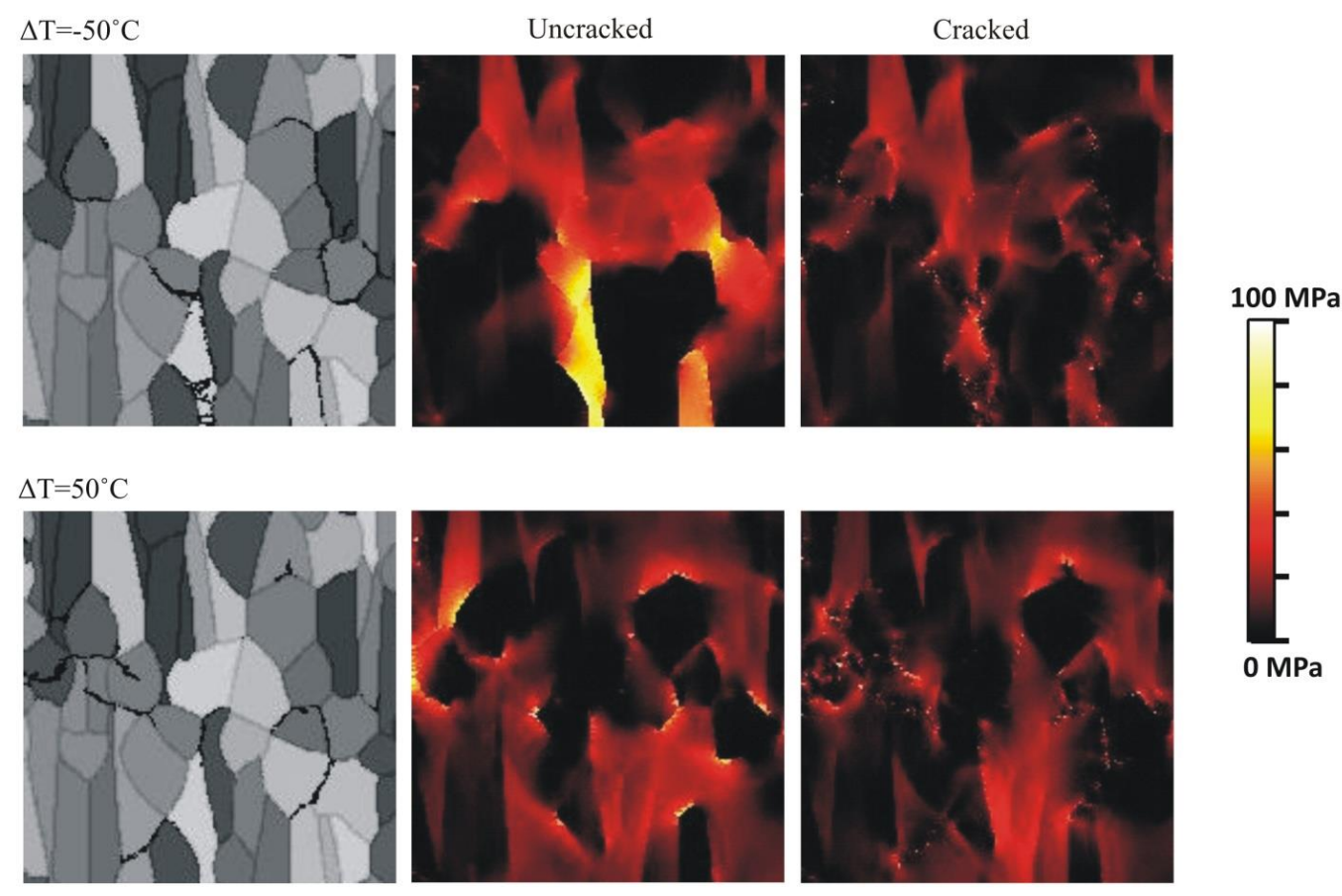

Fig. 5.8 A cropped selection (170x170 pixels) from a microstructural response map showing the spatial dependence of the maximum principal stress for an uncracked and cracked mixed-grain calcitic marble microstructure with a nominal grain size of $1 \mathrm{~mm}$ and a highly texture ODF $(\boldsymbol{M}=20)$ for a temperature changes of $\Delta \mathrm{T}=-50^{\circ} \mathrm{C}$ and $\Delta \mathrm{T}=+50^{\circ} \mathrm{C}$.

\subsubsection{Effect of grain size and marble composition}

Extensive microcracking is expected to occur in coarse grain microstructures composed of grains that have a high thermal expansion anisotropy (Cleveland and Bradt 1978). Indeed, given a temperature change, one expects the amount of microcracking to diminish with grain size until a critical grain size is reached, below which microcracking does not occur in finer grain materials. For a temperature change of $\Delta T=50^{\circ} \mathrm{C}$ the critical grain size for calcite is approximately $45 \mu \mathrm{m}$ and that for dolomite is approximately $80 \mu \mathrm{m}$. Thus, in all the grain sizes considered here microcracking is expected to occur for temperature changes of $\pm 50^{\circ} \mathrm{C}$. However, decreasing amounts of microcracking are expected as the grain size decreases from $2 \mathrm{~mm}$ to $1 \mathrm{~mm}$ to $200 \mu \mathrm{m}$.

Accordingly, simulations were performed for calcitic marbles with nominal grain sizes of $200 \mu \mathrm{m}$ and $1 \mathrm{~mm}$, and for dolomitic marbles with nominal grain sizes of $1 \mathrm{~mm}$ and $2 \mathrm{~mm}$. The percentages of microcracked area for the different grain sizes and marble compositions are presented in Table 5.1. For the $1 \mathrm{~mm}$ grain-size calcitic marble the results are averaged over three replications of the ODF to give a mean and standard 
Microcracking in calcite and dolomite marble: microstructural influences and effects on properties deviation. For all others fabric configurations the results are only for one replication of the ODF, but one expects similar variability as that for the $1 \mathrm{~mm}$ grain-size calcite.

Table 5.1. Percentage of microcracked area for three microstructures: equiaxed grains, a mixture of equiaxed and elongated grains, and elongated grains of calcite and dolomite marbles with random texture (denoted as M01) and with strong texture (denoted as M20) after heating and cooling in $1^{\circ} \mathrm{C}$ increments for a total temperature differential of $50^{\circ} \mathrm{C}$.

\begin{tabular}{|c|c|c|c|c|c|c|}
\hline & \multicolumn{6}{|c|}{$200 \mu \mathrm{m}$ grain-size Calcite } \\
\hline & \multicolumn{2}{|c|}{ equiaxed grains } & \multicolumn{2}{|c|}{ mixed grains } & \multicolumn{2}{|c|}{ elongated grains } \\
\hline & M01 & M20 & M01 & M20 & M01 & M20 \\
\hline heating & $0.5 \%$ & $0.1 \%$ & $0.3 \%$ & $0.004 \%$ & $0.007 \%$ & $0.00 \%$ \\
\hline \multirow[t]{4}{*}{ cooling } & $0.4 \%$ & $0.1 \%$ & $0.2 \%$ & $0.07 \%$ & $0.03 \%$ & $0.01 \%$ \\
\hline & \multicolumn{6}{|c|}{$1 \mathrm{~mm}$ grain-size Calcite } \\
\hline & \multicolumn{2}{|c|}{ equiaxed grains } & \multicolumn{2}{|c|}{ mixed grains } & \multicolumn{2}{|c|}{ elongated grains } \\
\hline & M01 & M20 & M01 & M20 & M01 & M20 \\
\hline heating & $7.8 \pm 0.2 \%$ & $3.8 \pm 0.1 \%$ & $5.9 \pm 0.3 \%$ & $2.2 \pm 0.4 \%$ & $4.0 \pm 0.6 \%$ & $0.3 \pm 0.1 \%$ \\
\hline \multirow[t]{4}{*}{ cooling } & $9.1 \pm 0.3 \%$ & $4.0 \pm 0.2 \%$ & $7.2 \pm 0.5 \%$ & $3.4 \pm 0.3 \%$ & $6.8 \pm 1.3 \%$ & $2.8 \pm 0.4 \%$ \\
\hline & \multicolumn{6}{|c|}{$1 \mathrm{~mm}$ grain-size Dolomite } \\
\hline & \multicolumn{2}{|c|}{ equiaxed grains } & \multicolumn{2}{|c|}{ mixed grains } & \multicolumn{2}{|c|}{ elongated grains } \\
\hline & M01 & M20 & M01 & M20 & M01 & M20 \\
\hline heating & $4.9 \%$ & $1.6 \%$ & $2.8 \%$ & $0.6 \%$ & $1.4 \%$ & $0.04 \%$ \\
\hline \multirow[t]{4}{*}{ cooling } & $5.1 \%$ & $2.2 \%$ & $3.5 \%$ & $1.4 \%$ & $2.5 \%$ & $1.3 \%$ \\
\hline & \multicolumn{6}{|c|}{2 mm grain-size Dolomite } \\
\hline & \multicolumn{2}{|c|}{ equiaxed grains } & \multicolumn{2}{|c|}{ mixed grains } & \multicolumn{2}{|c|}{ elongated grains } \\
\hline & M01 & M20 & M01 & M20 & M01 & M20 \\
\hline heating & $8.4 \%$ & $2.6 \%$ & $6.4 \%$ & $2.8 \%$ & $5.0 \%$ & $0.4 \%$ \\
\hline cooling & $10.8 \%$ & $4.1 \%$ & $8.4 \%$ & $3.8 \%$ & $7.7 \%$ & $3.1 \%$ \\
\hline
\end{tabular}

As expected, the percentage of microcracked area for a total temperature change of $\Delta \mathrm{T}=50^{\circ} \mathrm{C}$ is significantly reduced for the $200 \mu \mathrm{m}$ nominal grain-size calcite material in comparison to the $1 \mathrm{~mm}$ grain-size material. In the equiaxed-grain material with random crystallographic texture the microcrack percentage is only $0.5 \%$ of whole area upon 
heating compared to $7.8 \%$ for the $1 \mathrm{~mm}$ grain-size material. Upon a negative temperature change (cooling) the microcrack percentage is dimensioned even more from $9.1 \%$ to $0.4 \%$. While the amount of microcracking for a highly textured material $(\boldsymbol{M}=20)$ is less than that for a material with random texture $(\boldsymbol{M}=1)$, and is not as asymmetric in heating versus cooling, the reduction in the amount of microcracking with grain size is more pronounced: approximately one fortieth when reducing the grain size from $1 \mathrm{~mm}$ to $200 \mu \mathrm{m}$. The mixed grain-shape materials exhibit an even greater decrease in the percentage of microcrack area with grain-size reduction (see Table 5.1). Moreover, the amount of reduction is strongly dependent on the LPO. The $200 \mu \mathrm{m}$ grain-size, elongated grain-shape microstructure showed the most significant reduction in microcracking compared to the $1 \mathrm{~mm}$ grain-size material. Almost no microcracking was observed for the $50^{\circ} \mathrm{C}$ temperature change. Furthermore, the reduction in the amount of microcracking for these fabric conditions was strongly dependent on the LPO. For the $200 \mu \mathrm{m}$ elongated-grain microstructure the percentage of microcracked area was $0.007 \%$ upon heating and $0.03 \%$ upon cooling when the texture is random; and basically $0 \%$ upon heating and $0.1 \%$ upon cooling when there is high LPO texture.

The percentage of microcracked area is also reduced for the $1 \mathrm{~mm}$ nominal grain-size dolomite material compared to the $2 \mathrm{~mm}$ grain-size material (see Table 5.1). Furthermore, the $1 \mathrm{~mm}$ grain-size dolomite marble was observed to have less propensity for microcracking than the $1 \mathrm{~mm}$ grain-size calcite marble, i.e., microcracking begins at higher temperature differential and the percentage of cracked area is less (see Table 5.1). For instance, upon heating an equiaxed microstructure with random texture $(\boldsymbol{M}=1)$ the onset temperature for thermal microcracking occurs at $14^{\circ} \mathrm{C}$ for calcite marble, while the dolomite marble does not begin to crack until $19{ }^{\circ} \mathrm{C}$. While dolomite is stiffer than calcite, calcite has a greater thermal expansion anisotropy resulting in a higher microstructural maximum principal stresses. The percentage of microcracked area in dolomitic marbles with a nominal grain size of $2 \mathrm{~mm}$ is comparable with results for calcitic marble with a nominal grain size of $1 \mathrm{~mm}$.

The simulations also reveal a significant influence of the SPO and LPO fabric parameters on the temperature change $(\Delta T)$ require for microcrack initiation. The equiaxed-grain calcite microstructure with random texture and a nominal grain size of $200 \mu \mathrm{m}$ begins to crack upon heating at $\Delta \mathrm{T}=31^{\circ} \mathrm{C}$ and upon cooling at $\Delta \mathrm{T}=-37^{\circ} \mathrm{C}$. In 
the mixed grain-shape calcite with random texture microcracking commences at $\Delta \mathrm{T}=34^{\circ} \mathrm{C}$ upon heating and at $\Delta \mathrm{T}=-34^{\circ} \mathrm{C}$ upon cooling. Microcracking in the elongated-grain calcite commences at $\Delta \mathrm{T}=45^{\circ} \mathrm{C}$ and at $\Delta \mathrm{T}=-40{ }^{\circ} \mathrm{C}$ upon heating and cooling, respectively. For the highly textured calcite $(\boldsymbol{M}=20)$ a larger temperature differential is required for microcracking, namely, $\Delta \mathrm{T}=38^{\circ} \mathrm{C}$ and at $\Delta \mathrm{T}=-41^{\circ} \mathrm{C}$ in the equiaxed microstructure, $\Delta \mathrm{T}=48^{\circ} \mathrm{C}$ and $\Delta \mathrm{T}=-34^{\circ} \mathrm{C}$ in mixed-shape microstructure, and $\Delta \mathrm{T}=50^{\circ} \mathrm{C}$ and $\Delta \mathrm{T}=-44^{\circ} \mathrm{C}$ in the elongated-shape microstructure. Indeed, for the elongated-shape fabric microcracking was just initiated at these temperatures, i.e., the first mutated elements in OOF (the procedure in OOF1 for modifying element properties to simulate fracture) occurred at these temperatures.

\subsubsection{Effect of grain-boundary toughness}

Simulations for dolomite marble with grain size $1 \mathrm{~mm}$ have been performed. The fracture algorithm assumes that the critical fracture energy of the grain boundary is different from that of the grain interior. Simulations with two grain boundaries toughness are presented, to study the transition from the intragranular to the intergranular mode of crack growth (see section 2.6).

More microcracking was observed when the grain-boundary toughness ( $\boldsymbol{Y}_{\boldsymbol{i g}}$ ) was $20 \%$ of the grain fracture surface energy $\left(\boldsymbol{V}_{\boldsymbol{x} t a l}\right)$ than when it was $40 \%$ of $\boldsymbol{Y}$ xtal. Additionally, the microstructure with $\boldsymbol{V}_{i g}=0.2 \boldsymbol{V}_{\boldsymbol{x} \text { tal }}$ commences to crack at a smaller temperature differential. Spatial maps of the extent of microcracking for a total temperature change of $+50{ }^{\circ} \mathrm{C}$ are shown in Fig.5.9. When the grain-boundary toughness is as weak as $20 \%$ of that of the grains, intragranular cracking is essentially reduced completely. Microcracks initiate on single grain-boundary facets or on partial grain-boundary facets, and then propagate along the grain boundaries. 

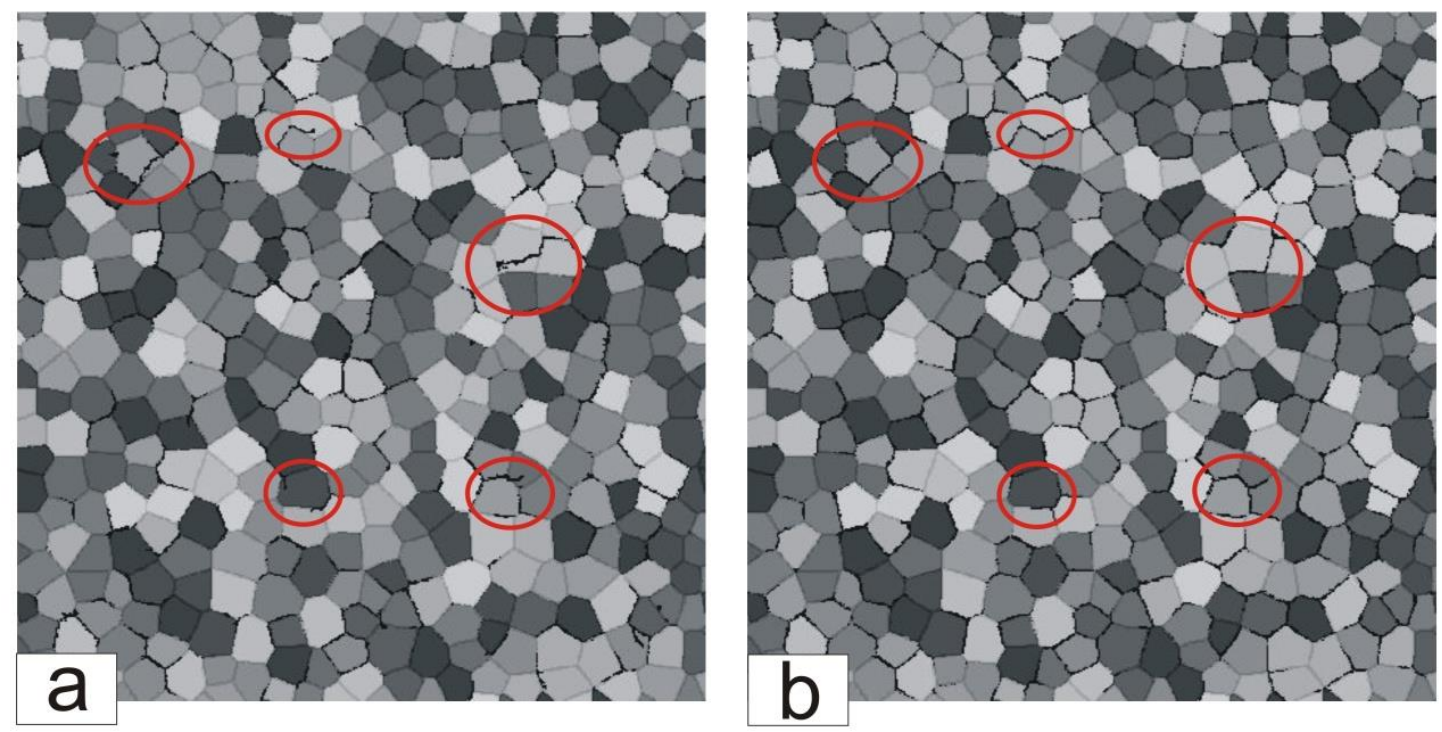

Fig. 5.9 Simulations of microcracking in dolomite marble with a nominal grain size of $1 \mathrm{~mm}$ upon heating by a temperature differential $+50^{\circ} \mathrm{C}$ : (a) equiaxed microstructure with random texture and grain-boundary toughness of $0.40 \mathrm{Yxtal}$; (b) equiaxed microstructure with random texture with grain-boundary toughness of $0.20 \gamma_{x t a l}$. The red ellipses identify representative area of comparison.

\subsubsection{Coefficients of thermal expansion}

The thermal expansion coefficients were computed for a given total temperature change, i.e., for $\Delta T=50^{\circ} \mathrm{C}$ and $\Delta T=-50^{\circ} \mathrm{C}$, and a given microstructure configuration, i.e., for a calcitic and a dolomitic marble with a nominal grain size of $1 \mathrm{~mm}$ and a grainboundary toughness $0.40 \gamma_{x t a l}$. The thermal expansion coefficient in the $\boldsymbol{x}$-direction, denoted as $\boldsymbol{\alpha}_{\boldsymbol{x}}$, is computed from the relative displacement change of the right and left sides of the microstructure. The thermal expansion coefficient in the $\boldsymbol{y}$-direction direction, denoted as $\boldsymbol{\alpha}_{\boldsymbol{y}}$, is computed from the relative displacement change of the top and bottom of the microstructure. Fig. 5.10 illustrates the influence of LPO and SPO on $\boldsymbol{\alpha}_{x}$ and $\boldsymbol{\alpha}_{y}$. Numerical results are presented in Table 5.2 for the calcitic and dolomitic marbles upon heating and cooling for a total temperature differential of $50{ }^{\circ} \mathrm{C}$. Results are also shown for the case when no microcracking occurs. For these simulations fracture, or microcracking, was inhibited by turning off the cracking algorithm in OOF. 
Table 5.2 The coefficients of thermal expansion in units of $10^{-6} \mathrm{~K}^{-1}$ in the $\boldsymbol{x}$ and $\boldsymbol{y}$ directions, are denoted as $\alpha_{x}$ and $\alpha_{y}$, respectively, upon heating and cooling by a temperature differential $50{ }^{\circ} \mathrm{C}$ and $-50{ }^{\circ} \mathrm{C}$ for microstructure allowing microcracking and for microstructure with no microcracking. Results are presented for calcite and dolomite marble with a nominal grain size of $1 \mathrm{~mm}$.

\begin{tabular}{|c|c|c|c|c|}
\hline & \multicolumn{4}{|c|}{$1 \mathrm{~mm}$ grain size Calcite } \\
\hline & & equiaxed & mixed & elongated \\
\hline \multirow{3}{*}{ M01 } & heating & $\begin{array}{l}\alpha_{x}=9.84 \\
\alpha_{y}=9.27\end{array}$ & $\begin{array}{l}\alpha_{x}=10.2 \\
\alpha_{y}=8.48\end{array}$ & $\begin{array}{l}\alpha_{x}=9.59 \\
\alpha_{y}=7.28\end{array}$ \\
\hline & cooling & $\begin{array}{l}\alpha_{x}=-0.64 \\
\alpha_{y}=0.04\end{array}$ & $\begin{array}{l}\alpha_{x}=-1.00 \\
\alpha_{y}=0.38\end{array}$ & $\begin{array}{l}\alpha_{x}=-0.11 \\
\alpha_{y}=0.80\end{array}$ \\
\hline & no cracked & $\begin{array}{l}\alpha_{x}=4.38 \\
\alpha_{y}=4.26\end{array}$ & $\begin{array}{l}\alpha_{x}=4.81 \\
\alpha_{y}=3.96\end{array}$ & $\begin{array}{l}\alpha_{x}=5.63 \\
\alpha_{y}=3.85\end{array}$ \\
\hline & & & & \\
\hline \multirow{5}{*}{ M20 } & heating & $\begin{array}{l}\alpha_{x}=-0.005 \\
\alpha_{y}=-0.301\end{array}$ & $\begin{array}{l}\alpha_{x}=-0.488 \\
\alpha_{y}=-1.043\end{array}$ & $\begin{array}{l}\alpha_{x}=-1.580 \\
\alpha_{y}=-2.529\end{array}$ \\
\hline & cooling & $\begin{array}{l}\alpha_{x}=-3.838 \\
\alpha_{y}=-3.940\end{array}$ & $\begin{array}{l}\alpha_{x}=-3.290 \\
\alpha_{y}=-3.622\end{array}$ & $\begin{array}{l}\alpha_{x}=-2.512 \\
\alpha_{y}=-3.553\end{array}$ \\
\hline & no cracked & $\begin{array}{l}\alpha_{x}=-2.221 \\
\alpha_{y}=-2.370\end{array}$ & $\begin{array}{l}\alpha_{x}=-1.734 \\
\alpha_{y}=-2.350\end{array}$ & $\begin{array}{l}\alpha_{x}=-1.648 \\
\alpha_{y}=-2.597\end{array}$ \\
\hline & \multicolumn{4}{|c|}{$1 \mathrm{~mm}$ grain size Dolomite } \\
\hline & & equiaxed & mixed & elongated \\
\hline \multirow{3}{*}{ M01 } & heating & $\begin{array}{l}\alpha_{x}=14.9 \\
\alpha_{y}=14.4\end{array}$ & $\begin{array}{l}\alpha_{x}=14.5 \\
\alpha_{y}=10.9\end{array}$ & $\begin{array}{l}\alpha_{x}=14.1 \\
\alpha_{y}=12.7\end{array}$ \\
\hline & cooling & $\begin{array}{l}\alpha_{x}=10.5 \\
\alpha_{y}=10.9\end{array}$ & $\begin{array}{l}\alpha_{x}=11.1 \\
\alpha_{y}=10.8\end{array}$ & $\begin{array}{l}\alpha_{x}=12.1 \\
\alpha_{y}=11.2\end{array}$ \\
\hline & no cracked & $\begin{array}{l}\alpha_{x}=12.4 \\
\alpha_{y}=12.3\end{array}$ & $\begin{array}{l}\alpha_{x}=12.7 \\
\alpha_{y}=12.1\end{array}$ & $\begin{array}{l}\alpha_{x}=13.3 \\
\alpha_{y}=12\end{array}$ \\
\hline \multirow{3}{*}{ M20 } & heating & $\begin{array}{l}\alpha_{x}=8.9 \\
\alpha_{y}=8.63\end{array}$ & $\begin{array}{l}\alpha_{x}=8.8 \\
\alpha_{y}=8.2\end{array}$ & $\begin{array}{l}\alpha_{x}=8.76 \\
\alpha_{y}=7.99\end{array}$ \\
\hline & cooling & $\begin{array}{l}\alpha_{x}=7.66 \\
\alpha_{y}=7.55\end{array}$ & $\begin{array}{l}\alpha_{x}=8.2 \\
\alpha_{y}=7.8\end{array}$ & $\begin{array}{l}\alpha_{x}=8.54 \\
\alpha_{y}=7.67\end{array}$ \\
\hline & no cracked & $\begin{array}{l}\alpha_{x}=8.3 \\
\alpha_{y}=8.18\end{array}$ & $\begin{array}{l}\alpha_{x}=8.6 \\
\alpha_{y}=8.2\end{array}$ & $\begin{array}{l}\alpha_{x}=8.75 \\
\alpha_{y}=7.99\end{array}$ \\
\hline
\end{tabular}




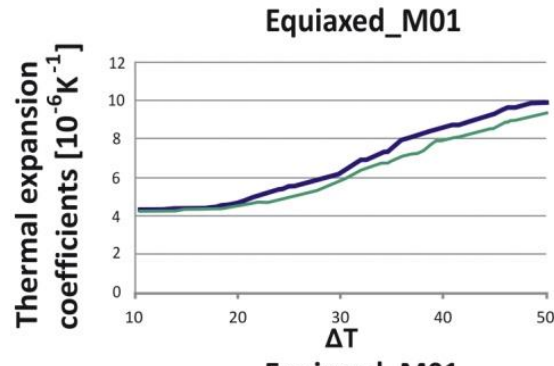

Equiaxed_M01

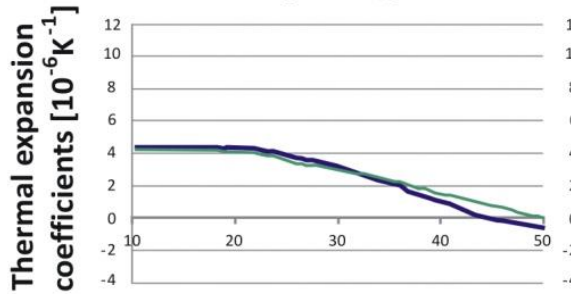

$-\Delta \mathrm{T}$

Equiaxed_M20

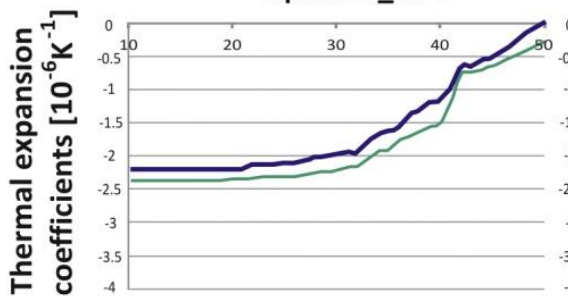

$\Delta T$

Equiaxed_M20

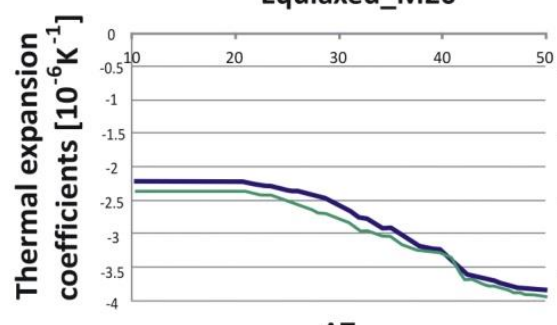

$-\Delta T$
Mixed_M01

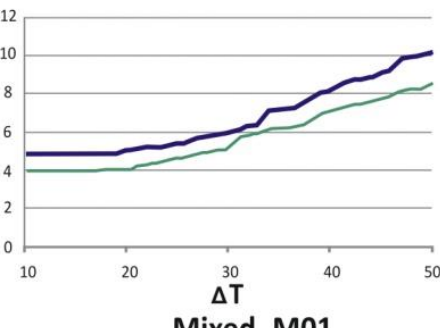

Mixed_M01

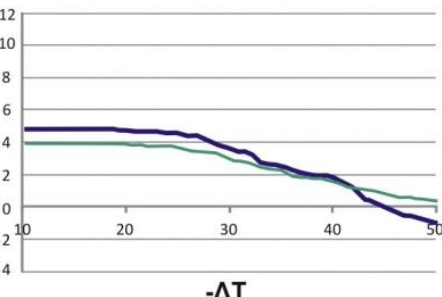

$-\Delta \mathrm{T}$

Mixed_M20

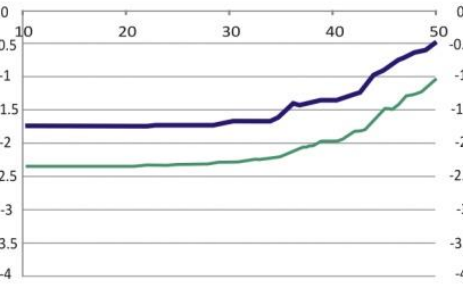

$\Delta \mathrm{T}$

Mixed_M20

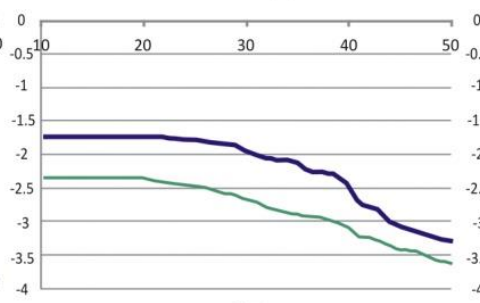

$-\Delta \mathrm{T}$
Elongated_M01

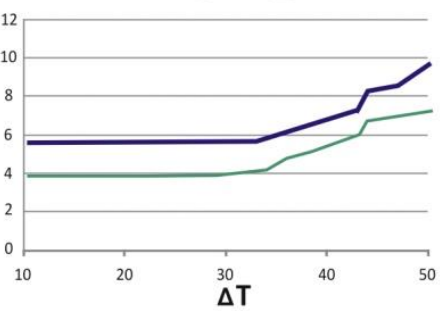

Elongated_M01

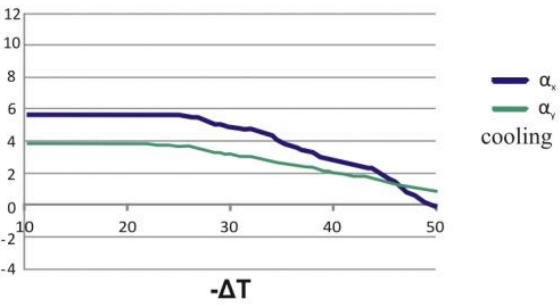

Elongated_M20

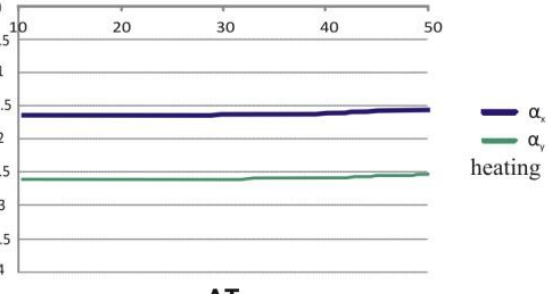

Elongated_M20

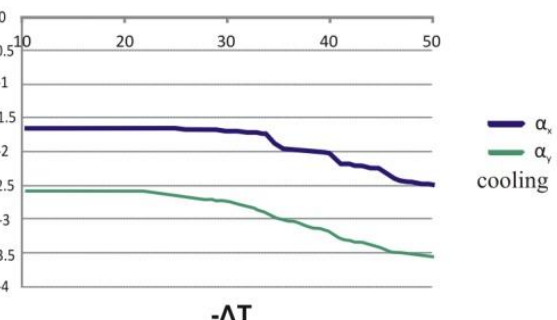

Fig. 5.10 Polycrystalline thermal expansion coefficients in the $\boldsymbol{x}$ - and $\boldsymbol{y}$-directions (denoted as $\boldsymbol{\alpha}_{\boldsymbol{x}}$ and $\boldsymbol{\alpha}_{\boldsymbol{y}}$, respectively) upon heating and cooling by a total temperature differential $50^{\circ} \mathrm{C}$ and $-50^{\circ} \mathrm{C}$ for a calcitic marble with a nominal grain size of $1 \mathrm{~mm}$. Results are shown for one replication.

In microstructures with no microcracking the coefficients of thermal expansion (the natural polycrystalline values) are constant during heating and cooling, and the same for both conditions. When microcracking is allowed the coefficients of thermal expansion in the cracked microstructure are greater than the natural polycrystalline values during heating and less than the natural polycrystalline values during cooling (see Fig. 5.10 and Table 2.1). This result is indicative of the extra expansion of the microstructure upon microcracking. Microcracks expand the microstructure. So, on heating this additional extension adds to the thermal expansion of the microstructure, thereby giving 
a larger result. On cooling, this additional expansion due to the microcracks subtracts from the thermal contraction of microstructure, thereby giving a diminished result. With increasing SPO (i.e., equiaxed grains to mixed grain shapes to elongated grains) and increasing LPO (i.e., random crystallographic texture, $\mathbf{M}=1$, to highly textured, $\mathbf{M}=20$ ), microcracking becomes more spatially anisotropic. When this happens, the difference between $\boldsymbol{\alpha}_{\boldsymbol{x}}$ and $\boldsymbol{\alpha}_{\boldsymbol{y}}$, i.e., $\left(\boldsymbol{\alpha}_{x}-\boldsymbol{\alpha}_{\mathrm{y}}\right)$, increases (see Fig. 5.10). Numerical results in Table 5.2 for both calcitic and dolomitic materials show a strong dependence on the degree of LPO, and almost no dependence on SPO.

\subsection{Summary and conclusions}

The thermal-elastic response of marble and concomitant degradation by microcracking depend on many fabric parameters. The present study revealed certain combination of shape preferred orientation (SPO), lattice preferred orientation (LPO), grain size, grainboundary toughness, and marble composition that have significant influence on the thermomechanical and degradation behaviour of marble.

The elastic strain energy density and the maximum principal stress that result from the thermal expansion anisotropy of the marble crystalline grains and their spatial distribution in the microstructure are excellent indicators of microcracking. Regions in the microstructure with the high values of these two microstructural properties in uncracked state are expected to indicate regions with a propensity for microcracking (Shushakova et al. 2011). It was observed that regions with high maximum principal stress in the uncracked state correspond to microcracks in the cracked material. The onset and degree of microcracking strongly depend on the fabric parameters. With decreasing grain size and increasing LPO and SPO microcracking is less prominent and occurs at a larger temperature differential. Microcracking upon heating is predominantly less than that upon cooling (see Fig. 5.4). For the case of the mixedgrain and the elongated-grain microstructures with strong crystallographic texture, this asymmetry is significant. The percentage of microcracked area upon heating is one tenth that upon cooling.

Marble composition plays an important role in the degree of microcrack degradation. Microcracking in a dolomitic marble commences at higher temperature differential and exhibits less of a tendency to microcrack than for a calcitic marble with the same 
microstructure and texture. Thus, finite-element simulations indicate that dolomitic marbles are more resistance against thermal degradation. While dolomite is stiffer than calcite, calcite has a greater thermal expansion anisotropy, resulting in higher strain energy densities. In agreement, Zeisig et al. (2002) showed experimentally that dolomitic marbles do not have residual strains after thermal treatment. Fig. 5.11 is used to illustrate the influence of fabric parameters, such as marble composition, SPO and LPO, on microcracking. Another fabric parameter that affects microcracking is the grainboundary toughness $\left(\boldsymbol{Y}_{i g}\right)$. In the simulations the grain-boundary toughness was chosen to be $40 \%$ and $20 \%$ of the grain fracture surface energy ( $\left.\boldsymbol{Y}_{\boldsymbol{x} t a l}\right)$ to elucidate the fracture behavior of both intragranular and intergranular crack-growth modes and to bracket the value of the grain-boundary fracture toughness that delineates the transition from intragranular fracture to intergranular fracture. For the case of $\boldsymbol{Y}_{\boldsymbol{i g}}=0.4 \boldsymbol{V}_{\boldsymbol{x} t a l}$ microcracking initiated as a grain-boundary microcrack either along a single grainboundary facet or partially along such a facet. Subsequent microcrack extension occurred predominantly along grain boundaries, i.e., intergranular fracture, but occasional excursions through some grains were observed, i.e., transgranular cracks. When the grain-boundary toughness decreased to $20 \%$ of $\boldsymbol{V} x$ tal, the amount of intragranular cracks was greatly reduced, or vanished all together (e.g., see Fig. 5.9).

Finally, microstructure-based finite-element modeling provides excellent insight and elucidation of influences of rock fabric and crystal texture on the thermal-elastic behavior and microcracking response of marbles. 


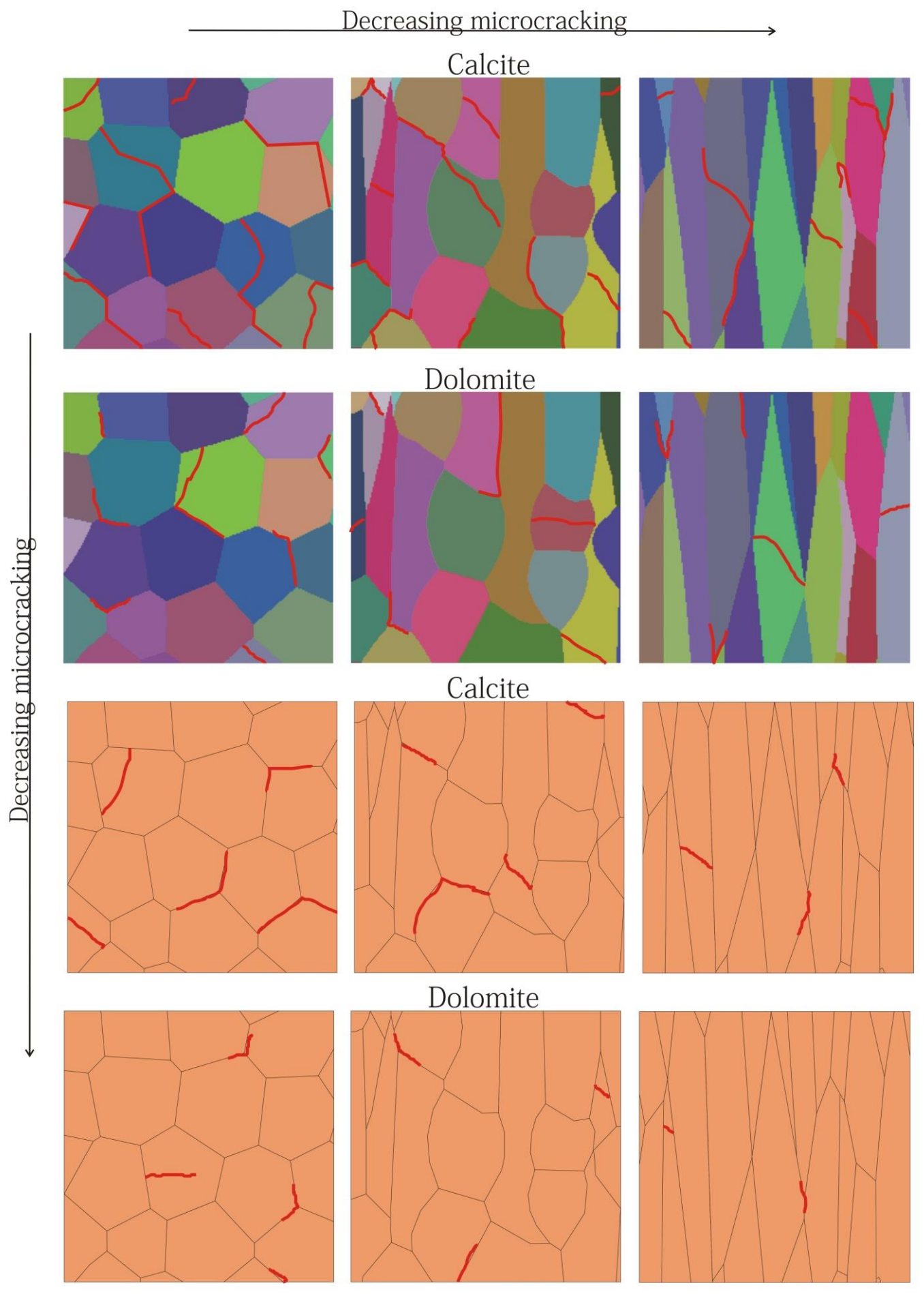

Fig. 5.11 Idealized illustration of results for calcitic and dolomitic marbles with a grain size of $1 \mathrm{~mm}$ for a temperature change of $\Delta \mathrm{T}=-50^{\circ} \mathrm{C}$. Results are shown for three cropped selections of extremes of microstructures (equiaxed grains, a mixture of equiaxed and elongated grains, and elongated grains) with random texture (different "colors" correspond to different random orientations) and strong texture (similar "colors" correspond to similar crystalline orientations (i.e., a textured ODF)). With increasing the degree of texture and shape preferred orientation microcracking (red curves) is decreasing. 


\section{Marble decay induced by thermal strains: simulations and experiments}

6.1 Image processing

Validation of the models using artificial microstructures and modeled texture is explored by performing numerical simulations and conducting complementary experiments for real marble samples. Microstructures and crystallographic orientations of grains were determined for the eight investigated marble samples using the electron backscatter diffraction (EBSD) technique (see 3.5.1, 3.5.2 sections). The procedure for measuring crystallographic orientations by EBSD and the manipulation of the EBSD data are described elsewhere (e.g., section 3.2, Halfpenny 2010). EBSD data for a marble section consist of an ordered data set of $(\mathrm{x}, \mathrm{y})$ coordinates and three Bunge Euler angles (Bunge 1985) for describing the rotation of the orientation of the crystalline material at each data point from the sample reference frame to the crystal reference frame. Singlecrystal orientations were thereby measured on a grid with a step size of $20 \mu \mathrm{m}$, thus yielding an orientation map, or an Euler-angle map, where grain orientations are represented by a specific color (Fig. 6.1). In the present case study the XZ-plane was measured for all samples, where $X$ is the direction of lineation and $Z$ is the normal to the foliation planes.

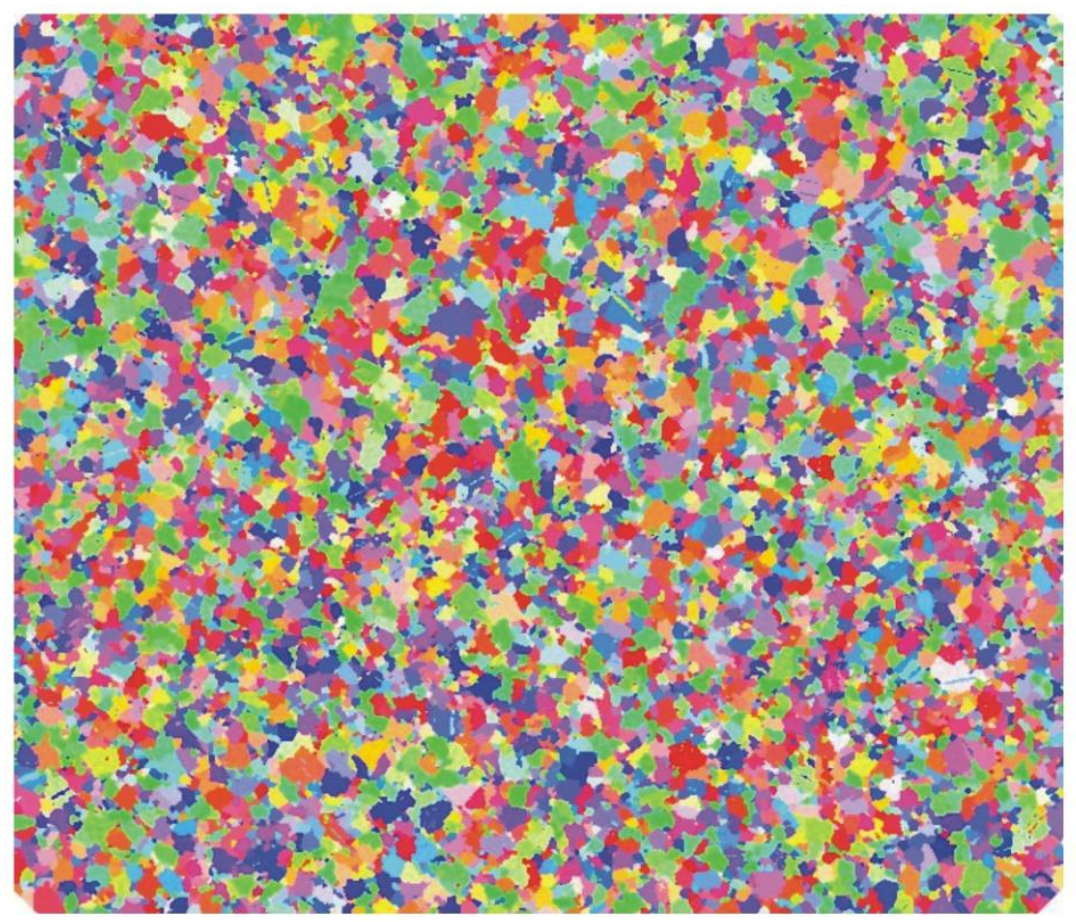

Fig. 6.1 Microstructure of Arabescato Altissimo Carrara (AA) marble used for the finite-element simulations. The average grain size is 200 to $300 \mu \mathrm{m}$. The color mapping indicates the grain orientation. 
As EBSD maps are collected automatically, the data often contains non-indexed points, i.e., data points for which the crystallographic orientation could not be determined. Four ways were developed to handle these non-indexed data points. The simplest method is to give these data points the crystallographic orientation of the sample reference frame. This approximation is not correct, but when the number of undefined points is sparse, the results are not significantly different from a correct value. Nonetheless, this method was not generally used. A better approximation is to treat these undefined data points as voids. Indeed, some of the undefined data points are most likely voids. This approximation works well for most finite element meshes, but empty finite elements (i.e., elements with elastic constants which are zero) can lead to numerical instabilities in the finite element solver. To avoid these numerical instabilities, a third approximation was to assign soft isotropic elastic properties to these void regions. Typically, a Young's modulus of $0.001 \mathrm{GPa}$ and a Poisson's ratio of zero were used to model these soft (stabilizing) void space elements. To verify that this approximation has minimal influence on the results, meshes that were solvable when empty elements were used were also tested using soft isotropic elements for the voids. The thermal-elastic responses computed for both cases were in excellent agreement; the differences were typically less than $0.1 \%$. Here, when the number of undefined data points was small, simulations were typically performed using these soft isotropic elements to model the void space.

In several cases (e.g., the Thassos marble sample) the undefined regions are clearly not voids, but are regions where the sample for some reason (e.g., large deformation or missing pieces) did not index properly. For these samples a fourth method was developed to clean the EBSD images. A Voronoi decomposition algorithm was developed whereby defined data regions adjacent to an undefined region randomly expand into the undefined nearest-neighbor region. This process continues until all of the undefined regions are consumed by the surrounding defined regions. The result is a cleaned EBSD microstructure with no undefined regions. A computer program written in Perl was used to implement this algorithm. A comparison of an original EBSD Euler map (the black areas are the undefined regions) and a cleaned version of this image is presented in Fig.6.2 for a Thassos marble. This procedure of cleaning the microstructure is used for all EBSD data sets which have a relatively large number of undefined data points. 

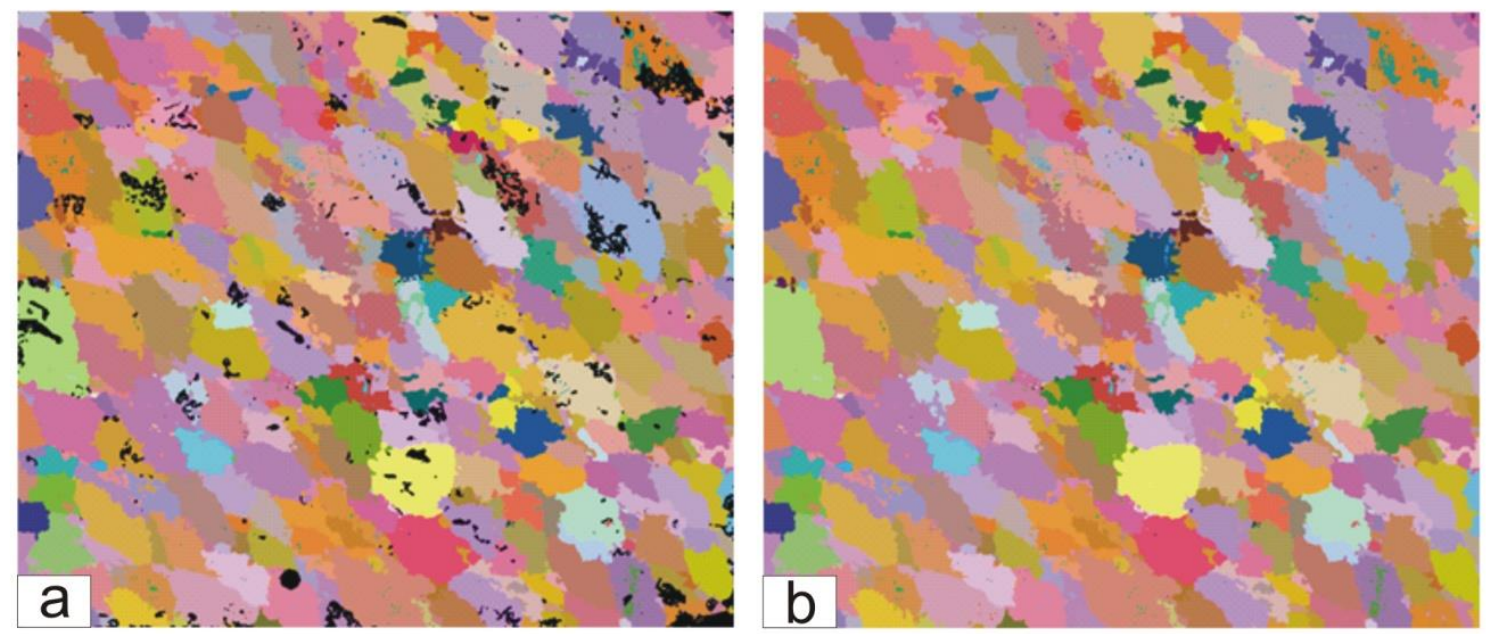

Fig. 6.2 Two images of a Thassos marble sample: (a) original EBSD Euler-angle map (the black regions are the undefined regions); and (b) a cleaned EBSD Euler-angle map.

\subsection{Finite-element simulations}

A simple meshing algorithm was applied to create a finite-element mesh. Each EBSD data point, or image pixel on the EBSD orientation map, was converted into two triangular elements. The diagonal dividing each pixel was alternated from pixel to pixel so that the orientations of the right-triangle elements were not all the same.

Typical EBSD data files for measured marbles contain $700 \times 600$ pixels, or 420,000 $(x, y)$ coordinates (or pixels) with a step size $20 \mu \mathrm{m}$. A simple mesh would have 840,000 elements. As computer resources were not available to solve this mesh, the images were cropped into nine subsections of $200 \times 200$ pixels by cropping 50 pixels off either side of the 700 pixel width. An example is shown in Fig. 6.3 for a Lasa calcitic marble sample. 


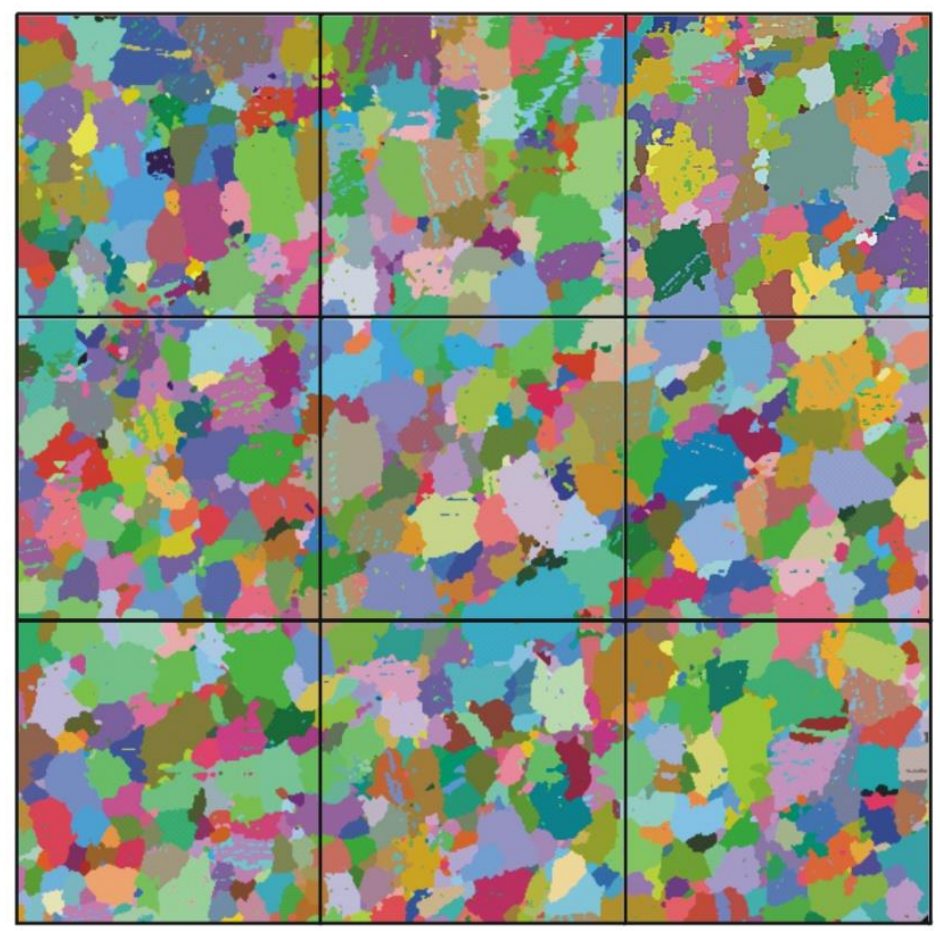

Fig. 6.3 EBSD Euler-angle map for the Lasa calcitic marble, which has been subdivided into nine $200 \times 200$ pixel subsections. The color mapping shows the crystal orientation of each data point via the Bunge Euler angles $\left(\varphi_{1}, \Theta, \varphi_{2}\right)$ which are mapped into the (red, green, blue) color of each pixel by the mapping: red $=256 \varphi_{1} / 180 ;$ green $=256 \Theta / 180 ;$ blue $=256 \varphi_{2} / 120$.

The subsections of the EBSD data sets were converted into the pixel-based triangular finite element mesh with the thermal-elastic properties of the constituent marble. The result is a triangular finite-element mesh with each element having the thermal-elastic properties (i.e., the fourth-rank elastic constant tensor and second-rank thermal expansion tensor) of either dolomite or calcite marble with the crystallographic thermalelastic tensors rotated to the sample reference frame by the Euler rotations for that pixel data point. The single crystal elastic constant tensors for both minerals, $\boldsymbol{C}_{i j}$, (Bass 1995) and the crystalline coefficients of thermal expansion for calcite (Kleber 1959) and dolomite (Reeder and Markgraf 1986) are given in Table 2.1.

The crystallographic orientations obtained by EBSD are given via three Euler-angles. To convert the Bunge definition of Euler angles in the Euler angle definition used in OOF1, the following equations were used: 
Marble decay induced by thermal strains: simulations and experiments

$$
\begin{gathered}
\alpha=\vartheta \\
\beta=\bmod \left[\left(90-\varphi_{2}\right), 360\right] \\
\gamma=\bmod \left[\left(90-\varphi_{1}\right), 360\right]
\end{gathered}
$$

where $(\alpha, \beta, \gamma)$ are the input Euler angles in OOF1 and $\left(\varphi_{1}, \vartheta, \varphi_{2}\right)$ are Bunge angles, and the mod function is a function that returns the remainder of a number $n$ after it is divided by a divisor $d$ :

$$
\bmod [n, d]=n-d \cdot \operatorname{int}[n / d]
$$

where the int function is a function that rounds a number down to the closest integer.

With the undefined regions cleaned by one of the methods given above, thermal-elastic responses were computed for each of the subsections of the EBSD data sets for the misfit strains produced by a $100^{\circ} \mathrm{C}$ temperature change. The finite-element calculations are based on two-dimensional elasticity with a plane-stress assumption, and thereby simulated the results for a free surface. The typical thermal-elastic responses that are computed are the maximum principal stress and the elastic strain energy density. Thermal expansion coefficients were calculated as well from the dilations of the subsection in both the $\mathrm{X}$ and $\mathrm{Z}$ directions.

\subsection{Calculations of polycrystalline thermal expansion properties}

To calculate the thermal expansion properties of a polycrystalline aggregate of calcite or dolomite one needs the single crystal tensor $\left(\alpha_{i j}\right)$, LPO data, and some knowledge of the individual grain areas in two dimensions. LPO data measured in the form of EBSD orientation maps are very suitable for estimating anisotropic physical properties as the orientation data is weighted by the fractional surface area. A map pixel with an orientation $(g)$ and surface area $(\delta A)$ is the smallest map component. The first step in the calculation of thermal expansion properties of a polycrystalline aggregate is the rotation of the single crystal tensor $\alpha_{i j}$ into the orientation of the map pixel by the inverse rotation matrix $g^{-1}=g^{\text {Transpose }}$ : 
Marble decay induced by thermal strains: simulations and experiments

$$
\alpha_{i j}(g)=g_{k i} \cdot g_{l j} \cdot \alpha_{k l}
$$

where $\alpha_{i j}(g)$ is thermal expansion tensor in the sample, or pole figure coordinates and $g=g\left(\varphi_{1}, \vartheta, \varphi_{2}\right)$ is the rotation matrix from the sample coordinate system to the crystal coordinate system defined by the Bunge Euler angles $\varphi_{1}, \vartheta$ and $\varphi_{2}$ The second step is to sum the contribution of all the tensors associated with each map pixel,

$$
<\alpha_{i j}>=\sum(\delta A / A) \cdot \alpha_{i j}(g)
$$

where $\left\langle\alpha_{i j}>\right.$ is the ensemble average of the thermal expansion tensors of the pixels and $(\delta A / A)$ is the fractional area of each pixel. This average corresponds to the Voigt average of elasticity. The thermal expansion of the polycrystalline sample in any pole figure direction $X$ is given by:

$$
\alpha(X)=<\alpha_{i j}>\cdot X_{i} \cdot X_{j}
$$

In the present case experimental measurements were made of thermal expansion of the samples in various directions. To compare these measurements with the ensemble average thermal expansion calculated from the EBSD data, the reference frame of the experimental thermal expansion tensor needs to be rotated into coincidence with the frame of EBSD calculated tensor. Normally this would be complex task, but in the case of a $2^{\text {nd }}$ rank symmetrical tensor, like the thermal expansion tensor, it has an intrinsic orthogonal reference frame given by the 3 eigenvectors of the tensor. The eigenvectors corresponds to the directions with the maximum, intermediate, and minimum eigenvalues of the tensor. The angles between the eigenvectors of the experimental tensor and the EBSD tensor allows the construction of a transformation matrix $\boldsymbol{R}$ and the application of the formula,

$$
<\alpha_{i j}^{E B S D}>=R \cdot<\alpha_{i j}^{E x p t}>\cdot R^{\text {Transpose }}
$$

to calculate the experimental tensor in the same frame as the EBSD tensor. All of these calculations were done using MTEX, the open-source MATLAB toolbox for texture analysis (Hielscher and Schaeben 2008), which has been extended for the calculation of $2^{\text {nd }}$ and $4^{\text {th }}$ rank tensors of anisotropic physical properties (Mainprice et al. 2011). 
Marble decay induced by thermal strains: simulations and experiments

\subsection{Results and discussion}

\subsubsection{Thermal dilatation and residual strains}

Thermal dilatation [in $\mathrm{mm} / \mathrm{m}$ ] describes the relative change of the sample's length (Grüneisen 1926). The investigated marble samples showed different types of thermal dilation behavior and residual strain behavior. According to the classification given in section 3.3 these types are shown in Table 6.1 along with the representative marbles investigated here.

Table 6.1 Marble classification according to thermal expansion and residual strain behavior after Siegesmund et al. (2008).

\begin{tabular}{|c|c|c|}
\hline & Isotropic thermal behavior & Anisotropic thermal behavior \\
\hline $\begin{array}{c}\text { Without residual } \\
\text { strain }\end{array}$ & Type (a) & $\begin{array}{c}\text { Type (b) } \\
\text { Sölk (SK) } \\
\text { Thassos (Th) } \\
\text { Wachau (W) } \\
\text { Carrara (AA) }\end{array}$ \\
\hline With residual strain & Bianco Carrara (BC) & $\begin{array}{c}\text { Type (d) } \\
\text { Lasa (LA) } \\
\text { Trechisches Volakas (G) }\end{array}$ \\
\hline
\end{tabular}

Figure 6.4 illustrates the thermal expansion and residual strain behavior for marble samples Arabescato Altissimo Carrara marble (AA), Sölk marble (SK), Bianco Carrara marble (BC), and High-Temperature Carrara marble (HT) (as they are representatives of four different types of thermal behavior and show four typical types of texture), and their dependence on the $X, Y, Z$ directions upon four repeated heating-cooling cycles. Carrara marbles $A A$ and $B C$ exhibit isotropic thermal expansion, as there is a less pronounced directional dependence of the thermal expansion, for example in comparison to the Sölk marble, which has strong directional dependence. For the Arabescato Altissimo Carrara marble the maximum residual strain after four cycles is $0.03 \mathrm{~mm} / \mathrm{m}$, while for the Bianco Carrara marble a larger expansion of $0.1 \mathrm{~mm} / \mathrm{m}$ is observed. The behavior for the Lasa marble is different. The smallest thermal expansion $(0.06 \mathrm{~mm} / \mathrm{m})$ is observed for the $Y$-direction and the largest expansion $(0.12 \mathrm{~mm} / \mathrm{m})$ is observed for Z- direction. The High-Temperature Carrara marble exhibits the largest residual strain of all the investigated marbles. The Z-direction sample has a residual 
Marble decay induced by thermal strains: simulations and experiments

strain of $0.4 \mathrm{~mm} / \mathrm{m}(0.04 \%)$. The Sölk marble (SK) sample shows anisotropic behavior with small residual strain. The maximum residual strain for the SK sample after four cycles is $0.03 \mathrm{~mm} / \mathrm{m}(0.003 \%)$ and is in the $X$ direction. Values of residual strains for all investigated marbles in three directions after four heating-cooling cycles are listed in Table 6.2.

Table 6.2 Residual strains for eight investigated marbles in X-, Y-, Z-directions after four repeated heating-cooling cycles. Values are given in $\mathrm{mm} / \mathrm{m}$.

\begin{tabular}{|c|c|c|c|}
\hline \multirow{2}{*}{ Marble sample } & \multicolumn{3}{|c|}{ Residual strain, $\mathbf{m m} / \mathbf{m}$} \\
\cline { 2 - 4 } & X-direction & Y-direction & Z-direction \\
\hline AA & -0.03 & 0 & -0.02 \\
\hline BC & 0.05 & 0.08 & 0.10 \\
\hline G & 0.08 & 0.08 & 0.06 \\
\hline HT & 0.20 & 0.08 & 0.40 \\
\hline LA & 0.11 & 0.06 & 0.12 \\
\hline SK & 0.03 & 0 & 0.01 \\
\hline Th & -0.03 & -0.02 & -0.04 \\
\hline W & 0.01 & 0.02 & 0.03 \\
\hline
\end{tabular}

The influence of crystalline texture is evidenced in the thermal dilatation behavior of marbles (Ruedrich et al. 2002, Zeisig et al. 2002, Siegesmund et al. 2008). The Carrara marbles, which exhibit isotropic thermal expansion behavior, have the smallest maxima of multiples of random distribution (MRD) in their pole figures with maximum $M R D=1.39$ for $A A$ and maximum $M R D=1.33$ for $B C$. In contrast, Sölk marble (SK) with a c-axis maximum MRD of 3.32 has a strong directional dependence of its thermal expansion behavior. The impact of grain size is not significant in the present study. The medium-grained marble such as SK shows almost no residual strain, while both finegrained Carrara marbles $A A$ and $B C$ exhibit difference in thermal expansion behavior, notably for $A A$ the residual stress is almost zero and $B C$ has expansion of $0.1 \mathrm{~mm} / \mathrm{m}$. The small-grained size HT Carrara marble has the largest thermal dilatation, which expands to $0.4 \mathrm{~mm} / \mathrm{m}$. The role of grain boundaries is also not important (Zeisig et al. 2002, Siegesmund et al. 2008). The HT Carrara marble with polygonal structure as well as the Lasa marble with interlobate grain boundaries both have a residual strain. 

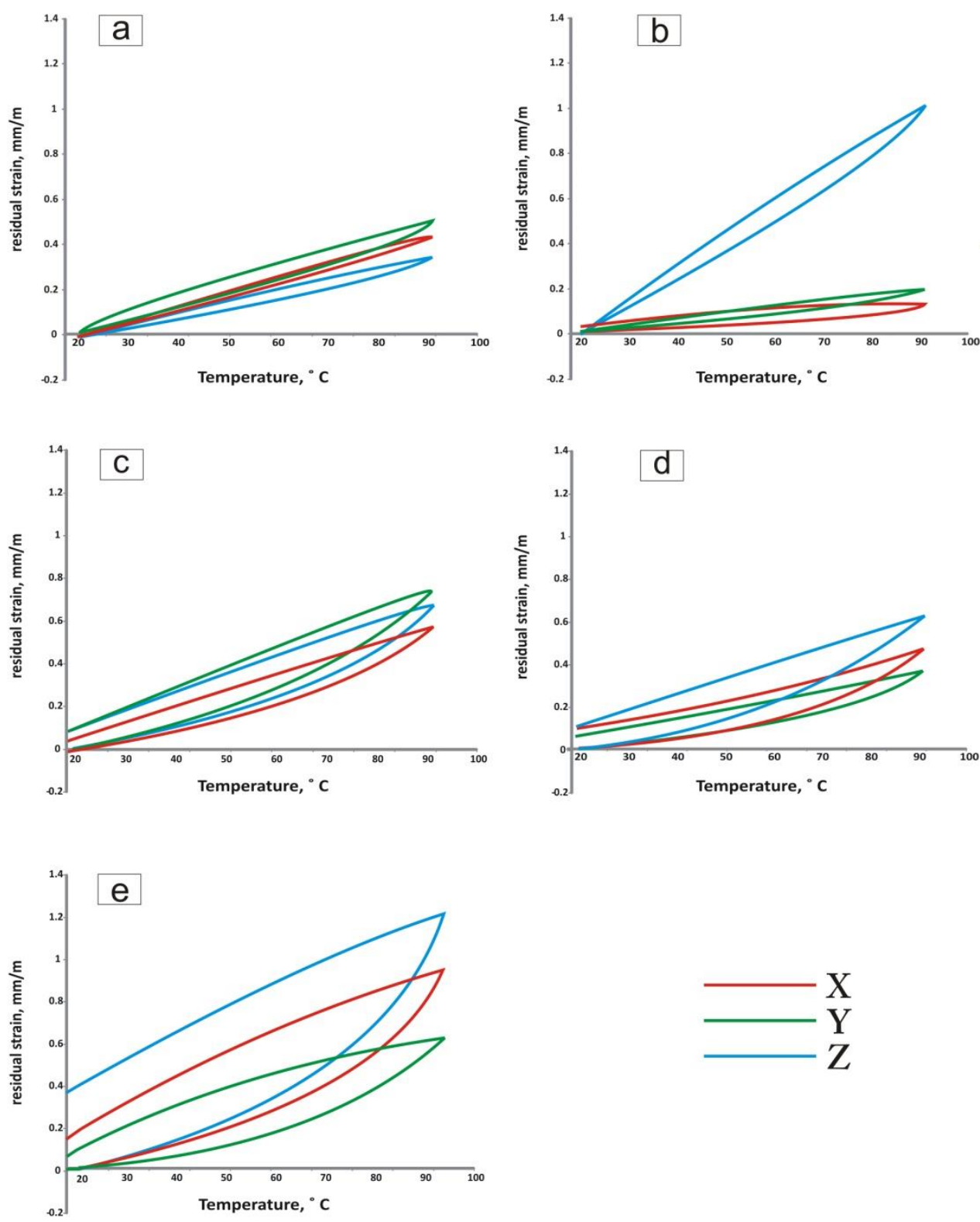

Fig. 6.4 Experimentally determined residual strain as a function of temperature: (a) Arabescato Altissimo Carrara marble (AA); (b) Sölk marble (SK); (c) Bianco Carrara marble (BC); (d) Lasa marble (LA); (e) High-Temperature Carrara marble (HT). The curves are given for $\mathrm{X}, \mathrm{Y}$, and $\mathrm{Z}$ directions.

\subsubsection{Thermal-elastic response}

Thermal-elastic response maps for each of the marbles were generated for the nine subsections of the EBSD maps. Maximum principal stress maps for the nine subsections of LA microstructure in Fig. 6.3 are shown in Fig. 6.5. From each response map the average thermal-elastic response for that subsection and its standard deviation over that subsection (the microstructural standard deviation) were computed. The 
average value of the nine subsection values and its standard deviation were then calculated. Additionally, the coefficients of thermal expansion for each subsection were computed for both the $\mathrm{X}$ and $\mathrm{Z}$ directions and averaged over the nine subsections. These values will be compared with the experimentally measured values for these marbles samples.

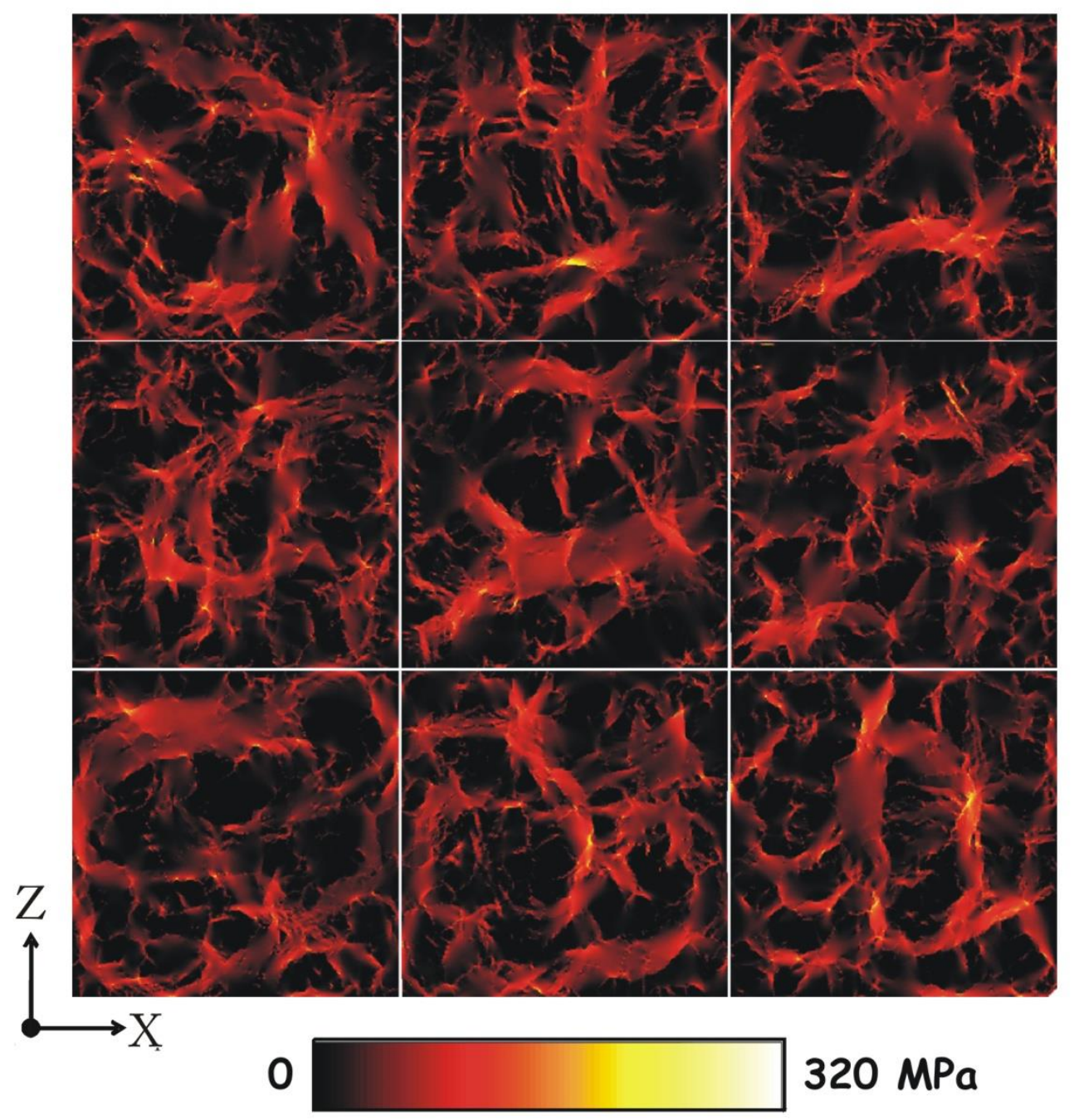

Fig. 6.5 Thermal-elastic response maps showing the spatial dependence of the maximum principal stress for each of the nine subsections of the EBSD Euler-angle map for the Lasa calcitic marble shown in Fig. 6.3. The reference frame used for the finite-element simulations is given.

The results indicate that the smallest maximum principal stress $18.7 \pm 2.5 \mathrm{MPa}$ is observed for the Thassos dolomitic marble. The difference between dolomitic and calcitic marbles can be explained by the thermal expansion anisotropy and the differences in the single-crystal elastic constants of these two major rock-forming minerals. While dolomite is stiffer than calcite, calcite has a greater thermal expansion anisotropy resulting in a higher maximum principal stress. 
The largest values of the average maximum principal stress $(35.0 \pm 0.5 \mathrm{MPa}$ and $34.9 \pm 0.9 \mathrm{MPa}$ ) were observed for the Arabescato Altissimo (AA) and Bianco Carrara (BC) marbles, respectively, where only a weak preferred orientation is evident (maximum $\mathrm{MRD}=1.39$ for $\mathrm{AA}$ and maximum $\mathrm{MRD}=1.33$ for $\mathrm{BC}$ ). The HighTemperature Carrara marble shows a comparable value of the average maximum principal stress $(34.6 \pm 1.5 \mathrm{MPa})$. While the Sölk marble, which has a much more pronounced LPO with a maximum MRD of 3.32 exhibits a smaller value of average maximum principal stress $(29.9 \pm 1.2 \mathrm{MPa})$. Lasa marble with girdle texture (and maximum MRD of 2.3) shows an average maximum principal stress of $31.0 \pm 1.0 \mathrm{MPa}$. Values of maximum principal stresses of eight investigated marbles are given in Table 6.3.

Table 6.3 Maximum principal stress for marble samples: averaged from the nine subsections computed from the finite-element simulations with standard deviation. Values are given in MPa.

\begin{tabular}{|c|c|}
\hline Marble sample & Maximum principal stress, MPa \\
\hline AA & $35.0 \pm 0.5$ \\
\hline BC & $34.9 \pm 0.9$ \\
\hline G & $27.2 \pm 3.1$ \\
\hline HT & $34.6 \pm 1.5$ \\
\hline LA & $31.0 \pm 1.0$ \\
\hline SK & $29.9 \pm 1.2$ \\
\hline Th & $18.7 \pm 2.5$ \\
\hline W & $31.5 \pm 1.8$ \\
\hline
\end{tabular}

Figure 6.6 illustrates the difference between maximum principal stress maps for marbles with weak and strong texture and the influence of marble composition as well. In chapter 5 was revealed that regions with high maximum principal stress in the uncracked state correspond to microcracks in the cracked material. The Thassos marble shows fewer regions with high maximum principal stress in comparison to the AA and SK marbles (Fig. 6.6), i.e. its propensity of microcracking is less. In agreement with the results for the idealized microstructures (Shushakova et al. 2011), increasing LPO leads to a decrease in the observed maximum principal stress and dolomitic 
marbles show smaller maximum principal stress and hence are more resistant against thermal degradation (Shushakova et al. 2011, Shushakova et al. 2012).
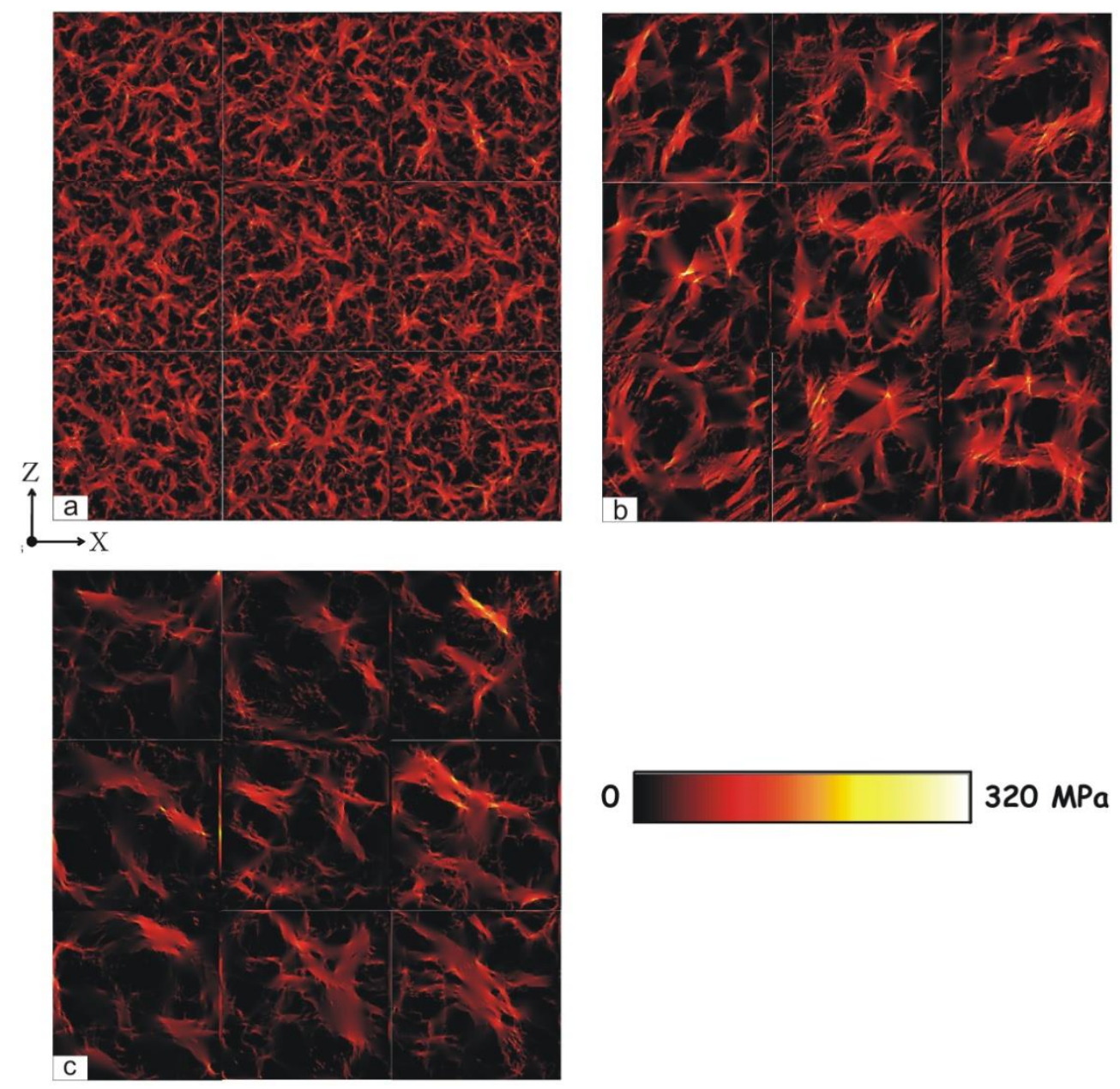

Fig. 6.6 Thermal-elastic response maps showing the spatial dependence of the maximum principal stress for each of the stitched together nine subsections of the EBSD Euler-angle map for (a) AA calcitic marble with weak texture (MRD=1.39); (b) SK calcitic marble with strong texture $(M R D=3.32)$; (c) Th dolomitic marble with strong texture (MRD=7.6).

Results revealed that such fabric parameters as grain size and grain boundary configuration don't have significant influence on the thermal-elastic response. The finegrained marbles (e.g., AA, BC) exhibit higher maximum principal stress than mediumgrained marbles (e.g., SK, W) and marbles with polygonal structure (e.g., G) show comparable values of maximum principal stress with marbles with interlobate grain boundaries (e.g., SK). 
6.4.3 Thermal expansion: correlation between modeled and experimental results

In OOF simulations the coefficients of thermal expansion were calculated for each of the marbles. They were computed for the nine subsections of the EBSD maps and then were averaged. The thermal expansion coefficient in the $X$ direction, $\alpha_{x_{-} O O F}$, is calculated as the relative displacement change of the right and left sides of each of nine subsections. The thermal expansion coefficient in the $Z$ direction, $\alpha_{z}$ oof, is computed from the relative displacement change of the top and bottom of subsection. A temperature differential of $100{ }^{\circ} \mathrm{C}$ was used.

The coefficient of thermal expansion tensor was computed from the EBSD texture measurements in the Voigt approximation (Bunge 1982) in EBSD reference frame using the MTEX software.

Coefficients of thermal expansion from the experimental measurements were calculated from the dilations in the $\mathrm{X}-, \mathrm{Y}$ - and Z- directions after the first heating from $20{ }^{\circ} \mathrm{C}$ to $90{ }^{\circ} \mathrm{C}$ (see eq. 3.7) for a temperature differential of $70{ }^{\circ} \mathrm{C}$. The coefficient of thermal expansion tensor was reconstructed from the thermal expansion values measured in six directions. The reconstructed tensor was rotated to EBSD reference frame in order to compare the results with coefficients from Voigt average calculations and OOF simulations.

Table 6.4 shows the modeled coefficients of thermal expansion $\alpha_{\mathrm{OOF}}$; the experimental values $\alpha_{\text {expt }}$ in the sample reference frame and in the EBSD reference frame; and coefficients of thermal expansion $\alpha_{\text {voigt }}$ modeled from the texture measurements by applying the Voigt model for the investigated marbles. 
Marble decay induced by thermal strains: simulations and experiments

Table 6.4 Thermal expansion coefficients for investigated marbles: averaged from the nine subsections computed from the finite-element simulations $\alpha_{O O F}$ with standard deviation, calculated from thermal expansion measurements $\alpha_{\text {expt, }}$ in the sample reference frame and in the EBSD reference frame, and modeled from textures applying Voigt model $\alpha_{\text {Voigt }}$ Values are given in units of $10^{-6} \mathrm{~K}^{-1}$.

\begin{tabular}{|c|l|l|l|l|}
\hline Marbles & \multirow{2}{*}{$\boldsymbol{\alpha}_{\text {OOF }},\left(\mathbf{1 0}^{-6} \mathbf{K}^{-1}\right)$} & \multicolumn{2}{|c|}{$\boldsymbol{\alpha}_{\text {expt }},\left(\mathbf{1 0}^{-6} \mathbf{K}^{-1}\right)$} & \multirow{2}{*}{$\boldsymbol{\alpha}_{\text {Voigt }},\left(\mathbf{1 0}^{-6} \mathbf{K}^{-1}\right)$} \\
\cline { 3 - 5 } & & $\begin{array}{l}\text { in the sample } \\
\text { reference frame }\end{array}$ & $\begin{array}{l}\text { in the EBSD } \\
\text { reference frame }\end{array}$ & \\
\hline AA & $\alpha_{x}=4.4 \pm 0.5 \alpha_{z}=3.5 \pm 0.6$ & $\alpha_{x}=6.3 \alpha_{z}=5.0$ & $\alpha_{x}=6.9 \alpha_{z}=4.8$ & $\alpha_{x}=4.9 \alpha_{z}=4.1$ \\
\hline BC & $\alpha_{x}=3.7 \pm 0.4 \alpha_{z}=3.7 \pm 0.4$ & $\alpha_{x}=8.0 \alpha_{z}=9.2$ & $\alpha_{x}=8.6 \alpha_{z}=8.8$ & $\alpha_{x}=4.3 \alpha_{z}=4.3$ \\
\hline LA & $\alpha_{x}=6.7 \pm 1.6 \alpha_{z}=2.6 \pm 0.8$ & $\alpha_{x}=6.0 \alpha_{z}=8.3$ & $\alpha_{x}=8.0 \alpha_{z}=6.0$ & $\alpha_{x}=7.1 \alpha_{z}=3.5$ \\
\hline HT & $\alpha_{x}=5.7 \pm 0.7 \alpha_{z}=4.5 \pm 0.8$ & $\alpha_{x}=11.6 \alpha_{z}=13.5$ & $\alpha_{x}=13.0 \alpha_{z}=12.0$ & $\alpha_{x}=6.3 \alpha_{z}=5.2$ \\
\hline SK & $\alpha_{x}=6.4 \pm 2.3 \alpha_{z}=4.5 \pm 1.1$ & $\alpha_{x}=1.9 \alpha_{z}=14.4$ & $\alpha_{x}=8.5 \alpha_{z}=6.3$ & $\alpha_{x}=6.8 \alpha_{z}=5.0$ \\
\hline Th & $\alpha_{x}=12.9 \pm 0.7 \alpha_{z}=15.6 \pm 0.9$ & $\alpha_{x}=14.0 \alpha_{z}=4.7$ & $\alpha_{x}=8.0 \alpha_{z}=9.7$ & $\alpha_{x}=12.9 \alpha_{z}=15.1$ \\
\hline W & $\alpha_{x}=4.2 \pm 1.1 \alpha_{z}=5.7 \pm 0.9$ & $\alpha_{x}=6.2 \alpha_{z}=9.7$ & $\alpha_{x}=5.8 \alpha_{z}=8.0$ & $\alpha_{x}=3.3 \alpha_{z}=5.3$ \\
\hline G & $\alpha_{x}=9.4 \pm 0.6 \alpha_{z}=0.8 \pm 0.7$ & $\alpha_{x}=11.2 \alpha_{z}=13.4$ & $\alpha_{x}=13.6 \alpha_{z}=10.4$ & $\alpha_{x}=9.3 \alpha_{z}=0.8$ \\
\hline
\end{tabular}

The coefficients from the finite-element simulations and those modeled from texture measurements show good directional correlation. Coefficients of thermal expansion obtained in thermal dilatation measurements are larger. Siegesmund et al. (2000) also observed larger experimental coefficients of thermal expansion, and attributed the difference to be due primarily to the presence of microcracks, since they contribute an additional expansion. Since the computation simulations here do not allow the occurrence of microcracks, we expect the computational results to be smaller.

The MTEX software was also used to plot a pole figure projection of the thermal expansion tensor in any pole figure direction $\boldsymbol{X}$ (see eq. 6.7).

Such thermal expansion pole figure plots were generated for both the experimental thermal expansion coefficients and the thermal expansion tensor computed from the EBSD texture measurements. The directional dependence of the thermal expansion tensor is evident in Fig. 6.7, which shows the thermal expansion projection for the Sölk marble. Pole figures are shown for the thermal expansion tensor calculated from the EBSD measurements and for the experimentally measured tensor both in the sample reference frame and in the EBSD reference frame. The resemblance of Figs. 6.7.a and 6.7.c to the $\{001\}$ pole figure in Fig. 3.10.b is noted. 

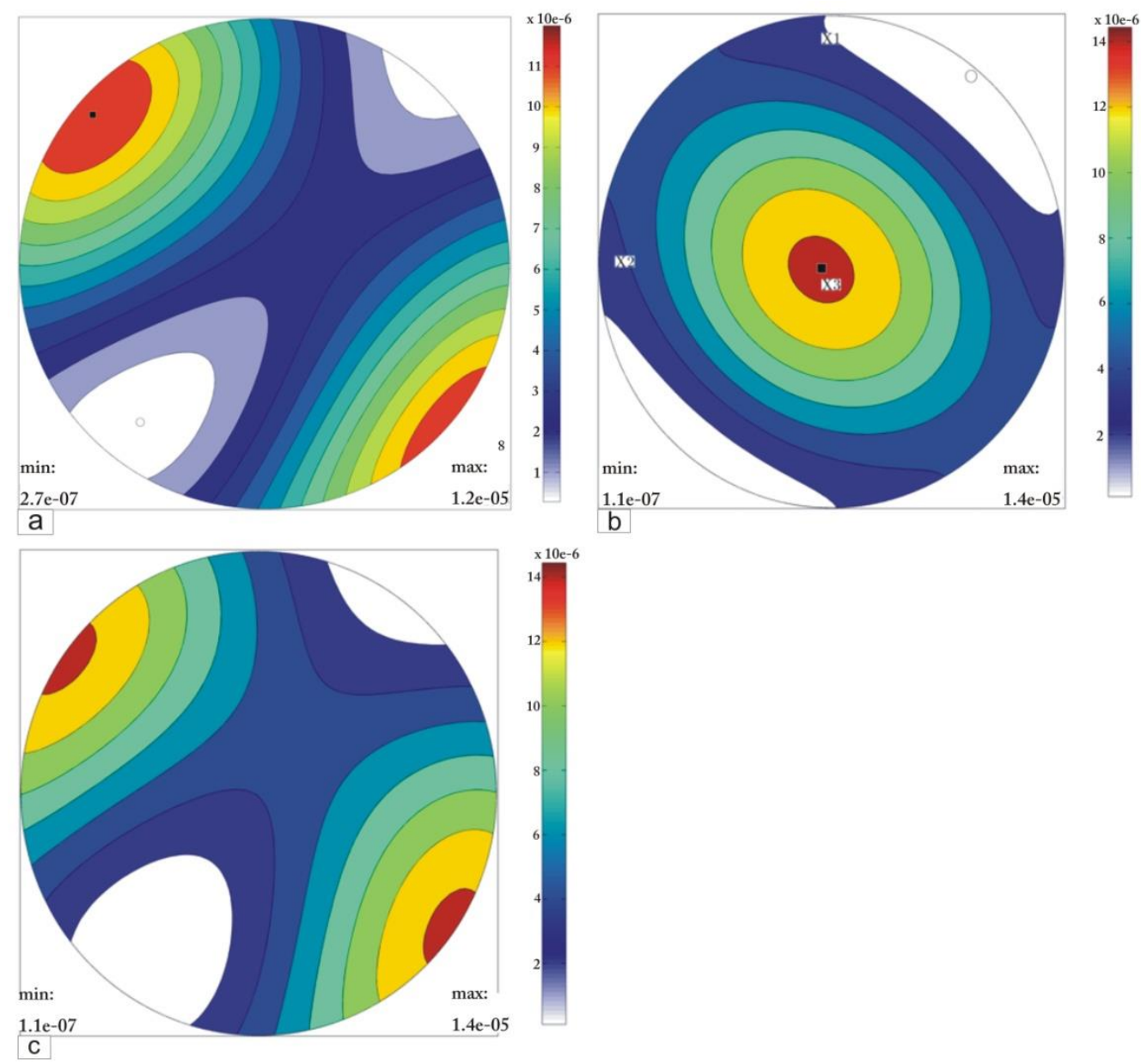

Fig. 6.7 The plots of tensors of thermal expansion coefficients for SK marble: (a) the plot of the thermal expansion Voigt average tensor derived from the texture in the frame of the EBSD data (b) the plot of the experimental thermal expansion tensor in the sample reference frame, $(\mathbf{c})$ the plot of the rotated experimental thermal expansion tensor to the EBSD frame.

\subsection{Summary and conclusions}

The thermal-elastic behavior of marble was modeled and experimentally measured. In the present case study a combination of different techniques, such as finite-element simulations, EBSD measurements, thermal expansion experiments, was used to elucidate the main factors that leading to marble degradation. A significant observation is that the thermal behavior of marbles can be modeled in good agreement with experiments.

The effect of the different fabric parameters was investigated. The marble composition, grain size, grain boundary geometry and texture significantly influence the thermal behavior of marble (Siegesmund et al. 2000, Zeisig et al. 2002, Weiss et al. 2002, 2003, 
Marble decay induced by thermal strains: simulations and experiments

2004b, Siegesmund et al. 2008, Shushakova et al. 2012). The present case study revealed that fabric parameters and certain combination of them trigger a propensity for the thermal deterioration of marble.

Thermal-elastic response maps, showing the spatial dependence of the maximum principal stress, confirm that the Thassos dolomitic marble with strong texture (Fig. 6.6.c) has a minimal tendency for microcracking. Indeed, finite-element modeling of Weiss et al. (2002) and Shushakova et al. (2012) and the systematic experimental study of Zeisig et al. (2002) indicated that dolomitic marbles are more resistance to thermal degradation due to the smaller crystalline thermal expansion anisotropy. Furthermore, with increasing LPO microcracking is less prominent and occurs at a larger temperature differential (Shushakova et al. 2012). This observation is in good agreement with the results of the thermal expansion measurements. It was seen that marbles with strong texture exhibit minimal residual strain after the thermal treatment.

The grain size and grain boundary character do not play such important role in thermal degradation processes. The presence or absence of a residual strain after thermal treatment was independent of whether the marbles had a fined grain size or a medium grain size. Furthermore, marbles with polygonal structure and interlobate grain boundaries do not show significant differences in their thermal expansion behavior.

It was observed that the texture controls the magnitude and directional dependence of the coefficient of thermal expansion, since the coefficients that are modeled from texture are in a good agreement with experimental coefficients (see Table 6.3). Differences between the experimental values and the modeled ones are explained as the occurrence of microcracks during thermal treatment, which are not allowed in the modeling.

The influence of fabric parameters on residual strain upon thermal treatment, and hence on marble degradation, has been demonstrated. A major conclusion from both the modeling and the experimental findings is that the dolomitic marbles with strong texture are more resistant to marble thermal degradation. 
Decay index: a new quantitative measure of marble decay

\section{Decay index: a new quantitative measure of marble decay}

\subsection{Preface}

As was discussed in 3.3 section temperature changes with and without the presence of water can lead to a volume change of rock. The volume extension index of marble, based on thermal expansion measurements under dry and water-saturated conditions, is proposed as a decay index for quantifying sample stability and for defining the directions of maximum and minimal dilatation.

The thermal expansion response of a rock sample can exhibit anisotropic behavior, i.e., the amount of expansion can depend on the measurement direction of the sample with respect to the formation or structure from which it was taken. In such cases, the sample must have directions with a maximum and minimum value of thermal expansion. Additionally, these directions should be independent on the individual sample choice. A second rank tensor is used to describe the thermal expansion behavior of marble samples. Components of this tensor can be obtained from thermal expansion measurements in six independent directions and can be used to find directions of the maximum and minimum thermal dilatation. The validity of such an approach can be demonstrated by determining the decay index for three rock samples that were cut from the same piece of marble but oriented differently relative to the coordinate system of the global reference frame. Once it is proved that decay index for each of three cubes is comparable with two others, the decay index can be used as the measure of sample stability for any marble sample.

\subsection{Volume expansion index}

On the basis of several measured relative length changes of a sample one can reconstruct the analog of a deformation tensor $\varepsilon_{i j}$ of the material (Nye 1985, Sirotin and Shaskolskaya 1975). Isotropic behavior can be described with a spherical pointing surface, which can be considered as a zero-degree approximation. The second-degree approximation corresponds to an ellipsoid that is defined by a symmetric matrix with six values. The corresponding tensor is defined on the basis of experimental measurements of six independent sample dilatations. Here the X-, Y-, Z-, XY-, XZ-, YZdirections were considered. Eigenvalues of this tensor define the volume change. 
However, for small deformations the volume change is approximately given by the trace of the tensor.

A strain ellipsoid can be envisioned as an imaginary sphere within a rock body that gets transformed into an ellipsoid upon heating or cooling. Corresponding to the Flinn diagram (Flinn 1962), there are two main types of finite-strain ellipsoids after the deformation event (Park 2005): (i) a prolate spheroid for extension along the axially symmetric direction (like a cigar); and (ii) an oblate spheroid for compression along the axially symmetric direction (like a pancake). These deformation states are illustrated in the Flinn diagram in Fig. 7.1.

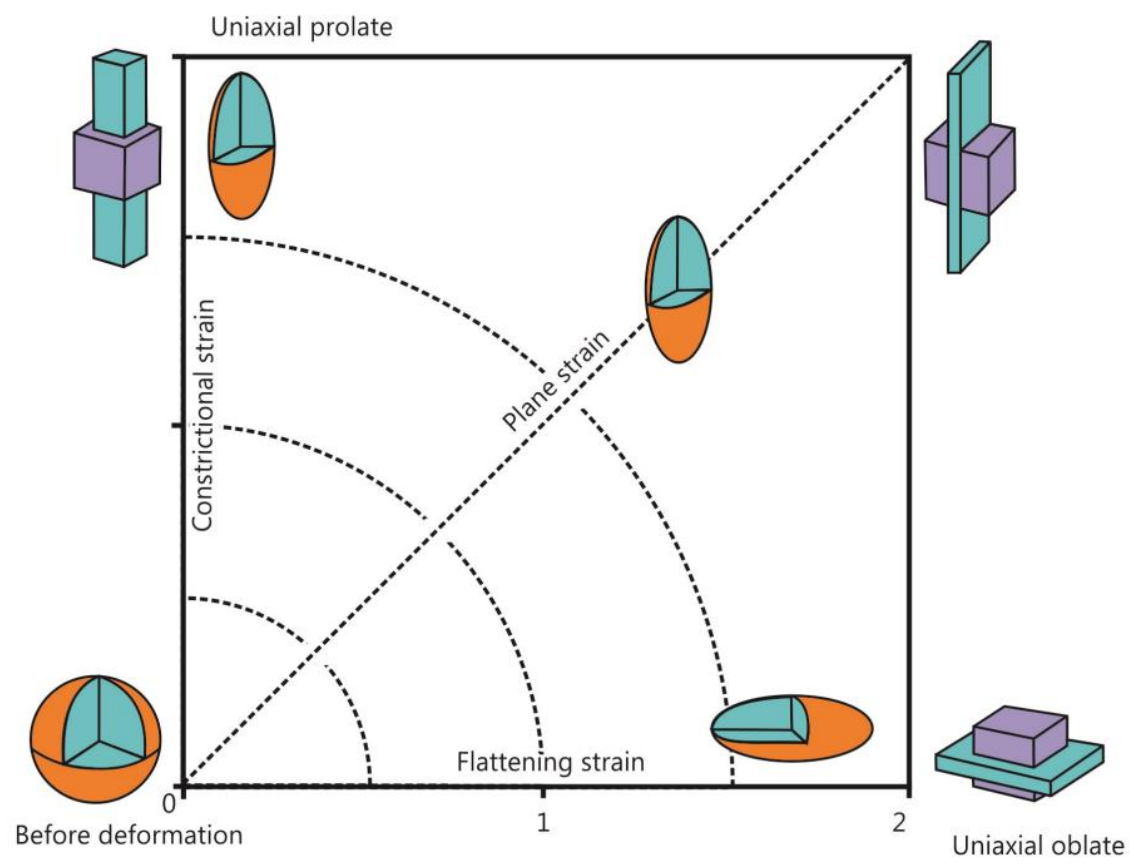

Fig. 7.1 Flinn diagram (modified after http://www.geosci.usyd.edu.au/users/prey/Teaching/Geol3101/Strain02/strain_ellipsoid.htm).

Quantitatively, a continuous surface can be described by the following series.

$$
F\left(x_{1}, x_{2}, x_{3}\right)=a_{0}^{(0)}+a^{(1)}{ }_{i} x_{i}+a^{(2)}{ }_{i j} x_{i} x_{j}+a^{(3)}{ }_{i j k} x_{i} x_{j} x_{k}+\ldots
$$

where summation over repeated indexes is implied (the Einstein summation convention). The central symmetry implies that only even term will be present. Accordingly, up to fourth-order terms the continuous surface is described by: 
Decay index: a new quantitative measure of marble decay

$$
F\left(x_{1}, x_{2}, x_{3}\right)=a_{0}^{(0)}+a^{(2)}{ }_{i j} x_{i} x_{j}+\ldots
$$

The matrix $a_{i j}^{(2)}$ has to be symmetric and therefore, given by 6 independent elements, which can be found if at least 6 values of $F\left(x_{1}, x_{2}, x_{3}\right)$ are known from the dilatation experiments. In general the second-order surface describing the shape change is complex surface, but as seen below, is well approximated as an ellipsoid.

In most practical instances the deformation surface for marble is an ellipsoid to very high accuracy due to the axial symmetry of the deformation with respect to the crystallographic c-axis. Accordingly, the dilatation experiment data are analyzed by the ellipsoidal approximation. The symmetrical second rank tensor $a^{(2)}{ }_{i j}$ is given by the following matrix:

$$
a_{i j}^{(2)}=\left(\begin{array}{lll}
a^{(2)}{ }_{11} & a^{(2)}{ }_{12} & a^{(2)}{ }_{13} \\
a^{(2)}{ }_{21} & a^{(2)}{ }_{22} & a^{(2)}{ }_{23} \\
a^{(2)}{ }_{31} & a^{(2)} & a^{(2)}{ }_{33}
\end{array}\right) \quad \text { and } \quad \begin{aligned}
& a^{(2)} a_{12}^{(2)}=a^{(2)}{ }_{21} \\
& a^{(2)}{ }_{31} \\
& a^{(2)}{ }_{23}=a^{(2)}{ }_{32}
\end{aligned}
$$

It's values can be found from the following set of equations

$$
F^{k}\left(x^{k}{ }_{1}, x^{k}{ }_{2}, x^{k}{ }_{3}\right)=a^{(2)}{ }_{i j} x^{k}{ }_{i} x^{k}, k=1, \ldots, 6
$$

Thus, the matrix $a^{(2)}{ }_{i j}$ is defined as:

$$
a^{(2)} i j=\left(\begin{array}{lll}
\varepsilon_{x} & \varepsilon_{x y}-\left(\varepsilon_{x}+\varepsilon_{y}\right) / 2 & \varepsilon_{x z}-\left(\varepsilon_{x}+\varepsilon_{z}\right) / 2 \\
\varepsilon_{x y}-\left(\varepsilon_{x}+\varepsilon_{y}\right) / 2 & \varepsilon_{y} & \varepsilon_{y z}-\left(\varepsilon_{y}+\varepsilon_{z}\right) / 2 \\
\varepsilon_{x z}-\left(\varepsilon_{x}+\varepsilon_{z}\right) / 2 & \varepsilon_{y z}-\left(\varepsilon_{y}+\varepsilon_{z}\right) / 2 & \varepsilon_{z}
\end{array}\right)
$$

where $\varepsilon_{x}, \varepsilon_{y}, \varepsilon_{z}, \varepsilon_{x y}, \varepsilon_{x z}, \varepsilon_{y z}$ are values of residual strain measured in these directions (see Fig. 3.4).

When the matrix elements are found it is possible to determine matrix eigenvalues and eigenvectors, by solving the equation:

$$
a^{(2)}{ }_{i j} y_{i}=\lambda_{j} y_{j}
$$

Each $3 \times 3$ matrix has 3 eigenvectors and 3 corresponding eigenvalues. The relative volume change of the finite deformation is given by the three eigenvalues according to: 
Decay index: a new quantitative measure of marble decay

$$
\frac{\Delta V}{V}=\left(1+\lambda_{1}\right)\left(1+\lambda_{2}\right)\left(1+\lambda_{3}\right)-1
$$

For infinitesimal deformations, the volume change can be approximated by:

$$
\frac{\Delta V}{V} \approx \lambda_{1}+\lambda_{2}+\lambda_{3}
$$

This value of the relative volume change represents a decay index. A larger value of this index corresponds to greater instability of the material and to its consequent failure upon heating or cooling.

The eigenvalues are also useful in another very important sense, notably the smallest eigenvalue is equal to the smallest dilatational strain and the largest eigenvalue is equal to the largest dilatational strain. Additionally, the directions of corresponding eigenvectors correspond to the directions of minimal and maximal dilatation, respectively. As will be seen below the samples directions do not necessarily coincide with the directions of minimal and maximal dilatation. The sample choices for the thermal expansion experiments are illustrated in Fig. 3.4.

\subsection{Results and discussions}

\subsubsection{Verification of approach}

Three marble cubes were cut from the same piece of Carrara marble (See Fig 7.2).

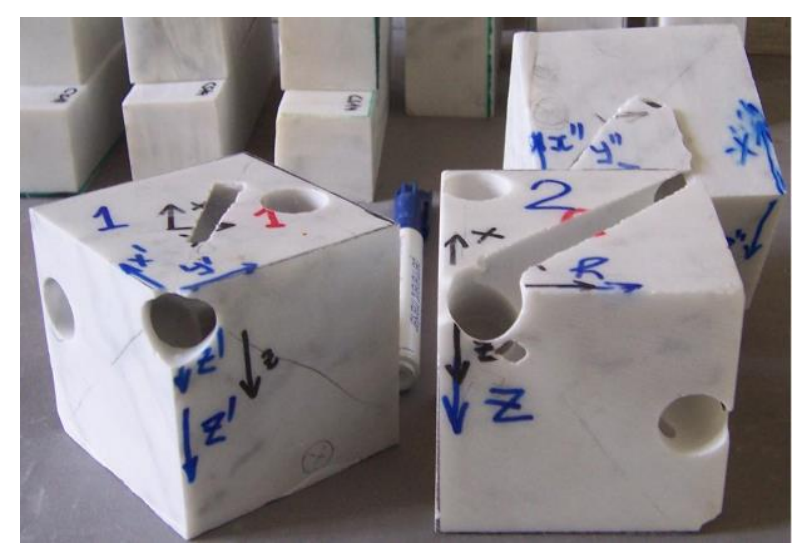

Fig. 7.2 Samples for thermal expansion experiments, showing the local coordinate system in the blue color and the global coordinate system in the black color. Also seen are holes from where the thermal dilatometry samples were cut. 
On each cube local coordinate system marked with blue color and the global one with black color. Cube number 2 is the reference sample. Cube number 1 is rotated with respect to cube number 2 by 30 degrees about the $Z$ axis; cube number 3 is rotated with respect to cube number 2 by 30 degrees about the $Y$ axis. From each cube six samples (X-, Y-, Z-, XZ-, XY-, YZ- direction) were cut for the thermal dilatation measurements.

Five repetitive heating-cooling cycles were carried out under dry conditions and afterwards ten cycles were carried out under water-saturated conditions (see section 3.3). During thermal dilatation experiments of a marble sample the residual strain is measured. The thermal dilatation as a function of the number thermal cycles under dry (cycle 1 to 5 ) and wet (cycle 6 to 15) conditions is plotted for each of three cubes in Fig.7.3.

Cube 1

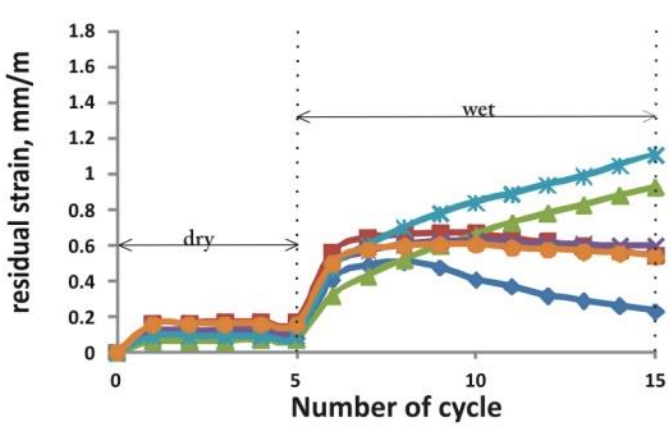

Cube 3

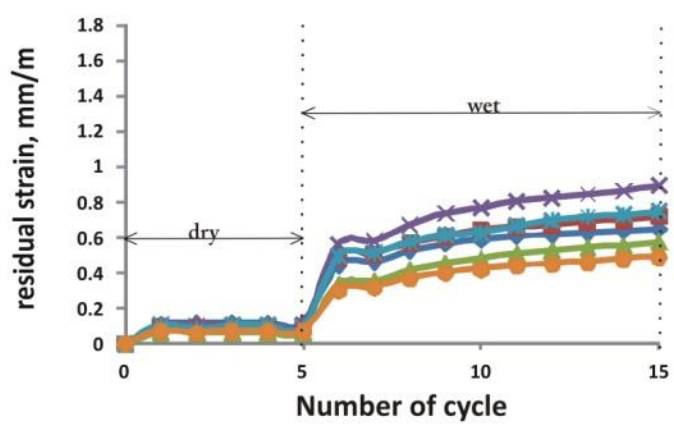

Cube 2
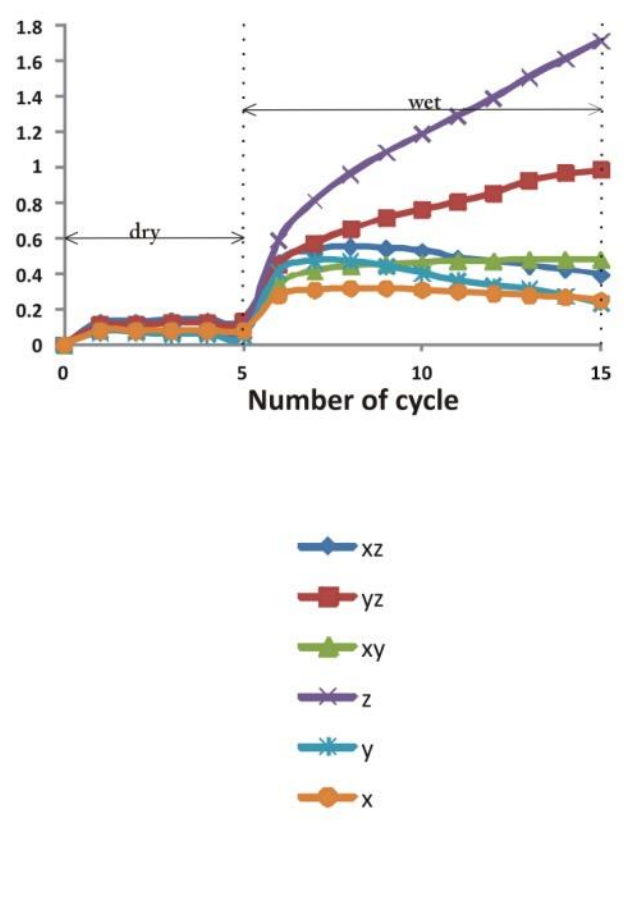

Fig. 7.3 The residual strain as a function of the numbers of heating-cooling cycles $\left(20-90-20^{\circ} \mathrm{C}\right)$ under dry (from 1 to 5 cycle) and water-saturated (from 6 to 15 cycle) conditions for the three cubes in X-,Y-, Z-, XYYZ-, XZ- directions. 
Decay index: a new quantitative measure of marble decay

The directional dependence under dry conditions is not pronounced for all three cubes, i.e., they show isotropic thermal behavior with the largest total residual strains after five cycles being comparable. The largest residual strain of $0.17 \mathrm{~mm} / \mathrm{m}$ is observed in $\mathrm{YZ}$ direction for cube 1, XZ-direction for cube 2 exhibits $0.14 \mathrm{~mm} / \mathrm{m}$ expansion and the thermal dilatation of $0.11 \mathrm{~mm} / \mathrm{m}$ is observed in XZ-direction for cube 3 . Under wet conditions the thermal behavior for the three cubes has totally changed (see Fig. 7.3). The directional dependence of thermal expansion is pronounced for cube 1 and cube 2, while for cube 3 it is not significant. The largest and the smallest amount of residual strain after ten wet cycles for cube 1 are $1.1 \mathrm{~mm} / \mathrm{m}$ in the $Y$-direction and $0.23 \mathrm{~mm} / \mathrm{m}$ in the XZ-direction, whereas the largest and the smallest thermal expansion observed for cube 2 are in the Z-direction $(1.71 \mathrm{~mm} / \mathrm{m})$ and the $Y$-direction $(0.24 \mathrm{~mm} / \mathrm{m})$, respectively. For cube 3 strains of $0.89 \mathrm{~mm} / \mathrm{m}$ in the Z-direction and $0.49 \mathrm{~mm} / \mathrm{m}$ in the $\mathrm{X}$-direction are the largest and the smallest thermal expansion.

As one can see from the Fig 7.3 different cubes can show quite different behavior, so the problem of comparing the data from these cubes is actual. Moreover, since as all these cubes belong to same marble block one needs a unique quantity to characterize them. Accordingly, the total relative volume change is proposed. This total relative volume change, or decay index, is calculated for the three cubes. The results under dry and wet conditions are presented in Table 7.1.

Table 7.1 Calculated decay index for three cubes after dry and wet conditions. Values are multiplied by $10^{-3}$.

\begin{tabular}{|c|c|c|}
\hline \multirow{2}{*}{ Cube } & \multicolumn{2}{|c|}{ Decay index } \\
\cline { 2 - 3 } & after five dry cycles & after ten wet cycles \\
\hline Cube 1 & 0.38 & 3.61 \\
\hline Cube 2 & 0.21 & 2.59 \\
\hline Cube 3 & 0.29 & 3.90 \\
\hline
\end{tabular}

The decay index is comparable for the three cubes after the five dry cycles, while a difference in values is observed after wet cycles. Such a difference could be caused by the influence of the shape preferred orientation and pre-existing microcracks on thermal response of marble (Siegesmund et al. 1999, 2000). The presence of water has significant impact as well (Sage et al. 1988, Koch and Siegesmund 2004). 
Decay index: a new quantitative measure of marble decay

In order to compare the direction of the maximum and minimum thermal dilatation and its coincidence after the thermal treatment under wet conditions for the three cubes pole figure projections of the second rank tensors were plotted in the reference frame of cube 2. The plots of residual strain tensors are shown in Fig. 7.4.

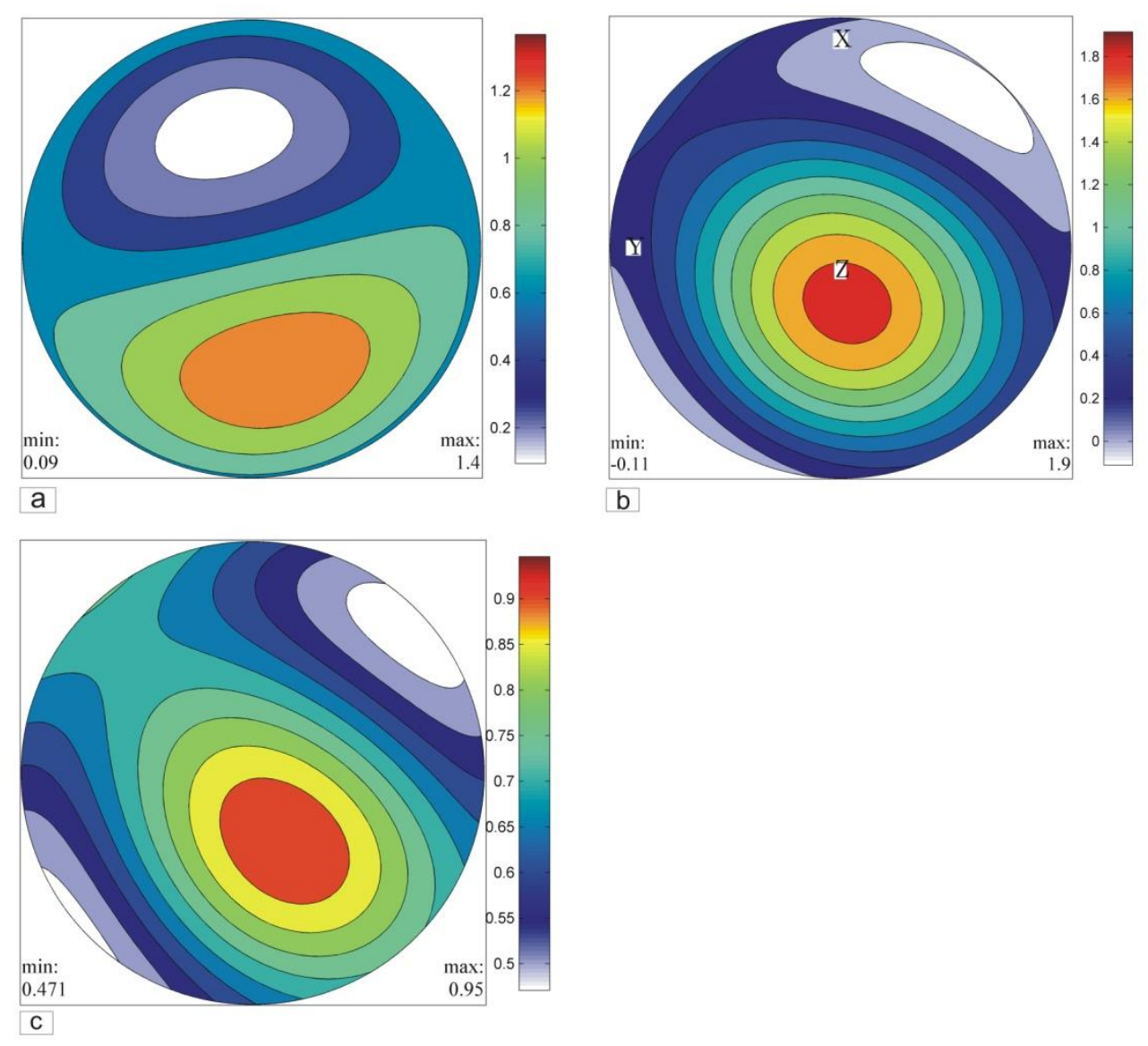

Fig. 7.4 Plots of residual strain tensors after ten wet cycles (a) cube 1, (b) cube 2 and (c) cube 3 in the reference frame of sample 2 .

In spite of differences in the values of the decay index, all three samples show large values for the relative volume change (Table 7.1) and the quite same direction of maximum and minimum dilatation (Fig.7.4) and hence, this marble type (Carrara), from which the three cubes were cut, is supposed to be instable under thermal exposure and has high risk associated with failure. The studies of Weiss et al. 1999, Koch et al. 2004, Siegesmund et al. 2008 revealed that objects fabricated from this Carrara marble exhibit rapidly deterioration. Thus, the decay index is a good quantification tool to predict the thermal behavior of marble, and such an approach was applied for the characterization of the investigated marbles. 


\subsubsection{Decay indexes for the investigated marbles}

The reference frame of each marble was defined according to the macroscopically visible elements of foliation and lineation. Six independent directions for each sample (Fig. 3.4) were cut for the thermal expansion measurements. Four cycles under dry conditions (see chapter 6 ) and seven cycles under wet conditions were carried out. The resulted residual strains in X-, Y-, Z- directions after the wet cycles for the eight investigated marbles are listed in Table 7.2 (see the results after the dry cycles for the eight marble samples in Table 6.2). Decay indexes were calculated for each of the eight marble samples on the basis of thermal expansion measurements after the dry and wet cycles. The results are given in Table 7.3.

Table 7.2 Residual strains for eight investigated marbles in X-, Y-, Z-directions after seven repeated heating-cooling cycles under water-saturated conditions. Values are given in $\mathrm{mm} / \mathrm{m}$.

\begin{tabular}{|c|c|c|c|}
\hline \multirow{2}{*}{ Marble sample } & \multicolumn{3}{|c|}{ Residual strain after wet cycles, mm/m } \\
\cline { 2 - 4 } & X-direction & Y-direction & Z-direction \\
\hline $\begin{array}{c}\text { Arabescato Altissimo } \\
\text { (Carrara) [AA] }\end{array}$ & 1.00 & 0.63 & 0.46 \\
\hline Bianco Carrara [BC] & 0.39 & 1.06 & 0.79 \\
\hline $\begin{array}{c}\text { Grechisches Volakas } \\
\text { [G] }\end{array}$ & 0.78 & 0.60 & 0.77 \\
\hline $\begin{array}{c}\text { High-temperature } \\
\text { Carrara marble [HT] }\end{array}$ & 0.58 & 0.29 & 0.33 \\
\hline Lasa [LA] & 0.19 & 0.18 & -0.04 \\
\hline Sölk [SK] & -0.16 & -0.20 & 0.22 \\
\hline Thassos [Th] & -0.26 & -0.16 & -0.10 \\
\hline Wachau [W] & -0.07 & 0.04 & 0.28 \\
\hline
\end{tabular}


Table 7.3 Defined decay indexes of investigated marble samples after dry and wet cycles. Values are multiplied by $10^{-3}$.

\begin{tabular}{|c|c|c|}
\hline \multirow{2}{*}{ Sample } & \multicolumn{2}{|c|}{ Decay index } \\
\cline { 2 - 3 } & after four dry cycles & after seven wet cycles \\
\hline AA & 0.05 & 3.46 \\
\hline BC & 0.23 & 3.49 \\
\hline G & 0.22 & 3.65 \\
\hline HT & 0.82 & 1.63 \\
\hline LA & 0.31 & 0.23 \\
\hline SK & 0.04 & -0.52 \\
\hline Th & 0.09 & -0.60 \\
\hline W & 0.06 & 0.09 \\
\hline
\end{tabular}

Decay indexes are quite different under dry and water-saturated conditions. After the dry cycles marbles such as AA, SK, Th, W show small deterioration indexes (less than $0.01 \%$ volume expansion). A larger value of the decay index is observed for a majority of the samples after the wet cycles. A significant increase is evidenced for the AA marble (from 0.05 to 3.46 ); the $B C$ and $G$ marbles also exhibit large decay indexes with water presence (3.49 and 3.65, respectively). HT with the largest deterioration decay index of all the investigated marbles after the dry cycles (0.82) has a medium value of 1.62 after the wet cycles. The decay index for the LA marble decreases from 0.31 after the dry cycles to 0.29 after the wet cycles. Even the negative decay indexes are obtained for the SK and Th marbles, which corresponds to a volume compression. Only the $\mathrm{W}$ marble doesn't exhibit any significant change between dry and wet conditions (from 0.06 to 0.09 ).

To elucidate maximum and minimum thermal dilatation, plots of residual strain tensor after dry and wet conditions were created for each marble sample. Two examples, the AA marble and the SK marble, are illustrated in Fig. 7.5. 

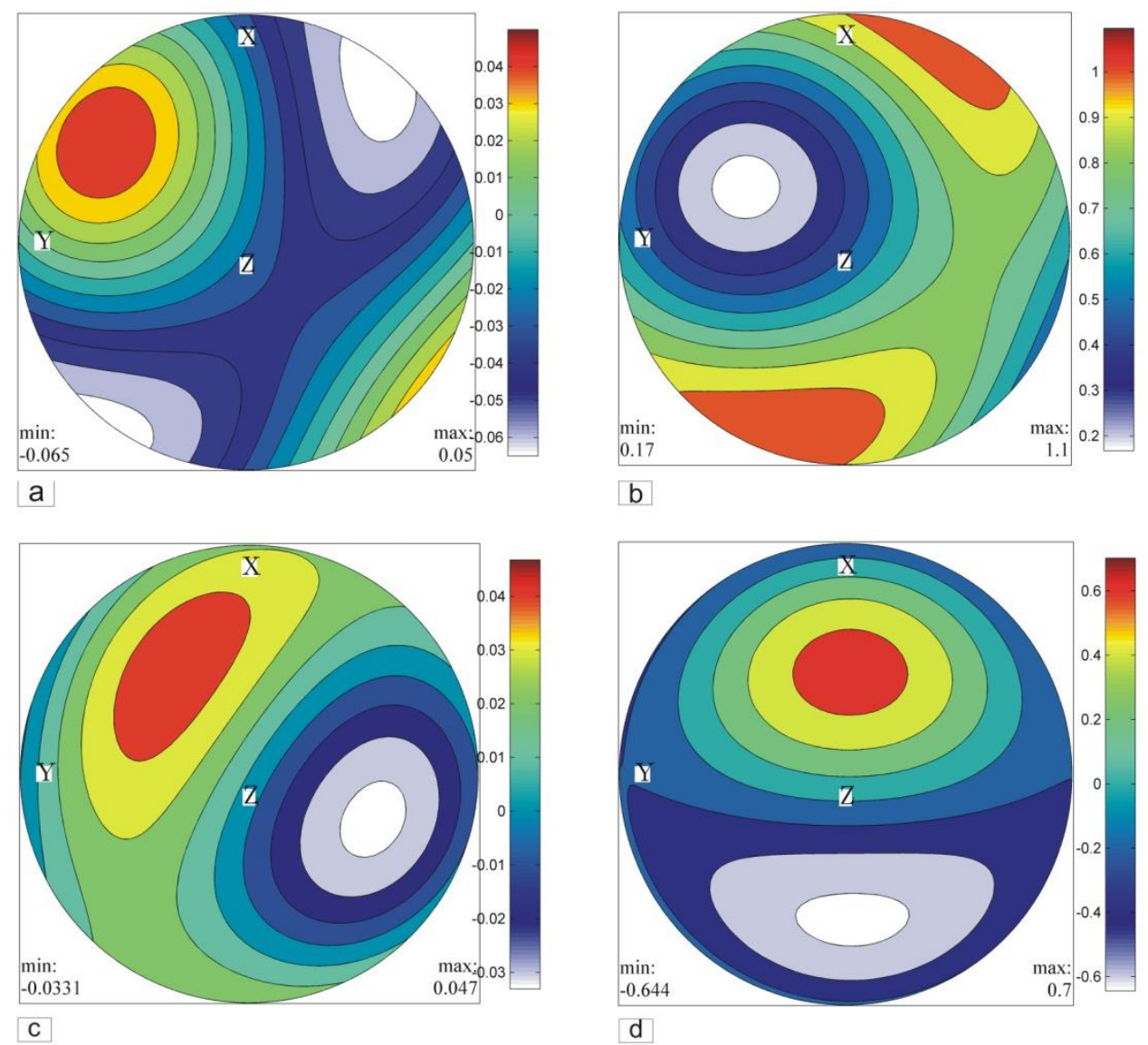

Fig. 7.5 Plots of residual strain tensors after four dry cycles (left) and after seven wet cycles (right) in the sample reference frame, respectively (a), (b) for the AA marble; (c), (d) for the SK marble.

The direction of maximum and minimum thermal expansion changes with the presence of moisture. The AA marble with the weak texture exhibits a significant directional change, while the SK marble with strong texture shows only a slight difference. This is not such case for all the marbles with strong texture. Some of them have directional change as well. Eigenvectors corresponding to the largest and the smallest dilatation could be found and defined in the reference frame of the marble. On the basis of this knowledge one could cut samples for thermal dilatation experiments along these directions and they would show the most extreme values. If one would cut the plates perpendicular to the direction that shows the largest thermal expansion, then that plate will show the smallest thermal expansion properties within the plate and the maximum thermal expansion perpendicular to the plane of the plate. 


\subsection{Summary and conclusions}

The results for three cubes that were cut from the same marble piece but in different directions were observed to be in good agreement. Thereby, it was shown that on the basis of dilatation experiments it is possible to extract invariant information concerning relative volume change after thermal cycling. However, verification of the decay index as a quantitative measure of marble degradation is preliminary since the investigated marble sample (Carrara) shows one type of thermal behavior (i.e. isotropic with residual strain), when four types are possible types (see 3.3 section). Thus, to fulfill the verification of the decay index approach, it is necessary to conduct the same experiments and calculations for other marble samples, which are representatives of the other three types of thermal behavior. This will be done in the future. Nevertheless, such an approach was implemented to characterize stability of investigated marbles. The difference in decay index, as well as the direction of maximum and minimum thermal expansion under dry and water-saturated conditions, is predominantly significant. Because of such differences, the use of various marble types can be recommended for interior (e.g., AA, SK, Th, W) or exterior applications (W). According to the value of decay index some marble samples would not be suggested for use at all (e.g., BC, G). The minimum and maximum dilatations, as well as directions of the corresponding extreme dilatations, are determined and hence the optimal direction to cut sample in order to have minimum thermal dilatation could be defined in the reference frame of the marble piece. 


\section{Conclusions}

The marble deterioration phenomena caused by thermal expansion was studied on the basis of idealized models (i.e. artificial microstructures and modeled textures with extremes of SPO and LPO) and real marble samples (eight well-known marble types with different fabric parameters). The aim of this thesis was to elucidate the influence of the main fabric parameters on thermal-related marble decay by using microstructurebased modeling and experimental techniques. To investigate the influence of SPO, LPO and marble composition finite-element simulations using the idealized models were performed and predictions of the extent of microcracking were proposed (chapter 4). Then, in order to simulate an actual degradation phenomenon of marble structures, i.e., microcracking, in chapter 5 computational simulations with a microcracking algorithm using the same idealized models were carried out and the influence of fabric parameters such as SPO, LPO, marble composition, grain size, grain-boundary toughness on marble deterioration related to microcracking nucleation and propagation was investigated. The estimations from the modeling without microcracking were confirmed in the modeling with allowed microcracking. Validation of the models using artificial microstructures and modeled texture was explored by performing numerical simulations and conducting complementary experiments for real marble samples. Therefore, fabrics of real marble samples obtained by EBSD technique were taken into account in the numerical modeling (see chapter 6). Eight marble samples (calcitic and dolomitic) were considered. They exhibit four typical types of texture for marble, show four basic types of thermal expansion behavior, vary widely in grain size range and grain boundary configuration. Thus, the present research thesis involves the modeling of wide range of marble structures and hence elaborates quantitatively the influence of the different parameters on marble degradation phenomena. Microcracking precursors such as elastic strain energy density and maximum principal stress; and coefficients of thermal expansion were computed from the all presented finite-element simulations. Experimental measurements of the thermal expansion were performed on the investigated marble samples and compared with the modeling results. A quantification of rock fabrics and their correlation with physical and mechanical properties may contribute significantly to the understanding of rock weathering. Finally, in chapter 7 the evaluation of stability of investigated marble samples upon dry and water-saturated conditions was done on the basis of a volumetric extension index which was developed 
as a marble decay index. This decay index was evaluated from thermal expansion measurements and its uniqueness with respect to sample orientation was validated. The following main conclusions can be drawn.

Conclusions from modeling using artificial microstructures and modeled textures: In marble structures when the c-axis align perpendicular to SPO (attributed to realistic configuration in marble) with increasing LPO and SPO thermal-elastic responses such as elastic strain energy density and maximum principal stress are decreasing, it indicates that the propensity of microcracking is diminishing, since crystallographic texture reduces the misfit strains from the thermal expansion anisotropy. Surprisingly and unexpectedly, for randomly textured microstructures SPO does not have any influence on the thermal-elastic responses, thought the networks of high maximum principal stress mimic the SPO and hence this spatial dependence may have an influence. The variation of marble content, considering pure calcitic, pure dolomitic marbles and marbles with the mixed content of calcite $(50 \%)$ and dolomite $(50 \%)$ showed that the dolomitic marbles are more resistance to microcracking than calcitic marbles with the same structure, since dolomite has a smaller anisotropy of the coefficients of thermal expansion compared to calcite and has all positive values parallel to the crystallographic axes. While the single-crystal elastic constants of dolomite are stiffer than those of calcite, which would tend to make dolomitic marbles less resistant to microcracking, the larger thermal expansion anisotropy of calcite, makes the calcitic marbles less resistant to microcracking. Marbles with the mixed content of calcite and dolomite exhibited larger thermal-elastic response than pure calcitic marbles since dolomite crystals produce the additional contraction with calcite crystals in such structures. The spatial variation of the maximum principal stress is inhomogeneous. This observation is confirmed by the standard deviations within microstructure, since they are as large as, or larger than the variables themselves.

The influence of fabric parameters on the onset and propensity of microcracking in marble structures was studied by including fracture as a phenomenon in the finiteelement simulations. Given an identical microstructure and crystallographic texture, calcite showed larger thermal stresses than dolomite, had an earlier onset of microcracking upon heating and cooling, and a greater amount of microcracked area at a given temperature differential. Microstructures with the smallest grain size and the 
highest amount of SPO and LPO had the smallest tendency for microcrack and microcracking, when it did occur, began at larger temperature differentials. Decreasing the grain boundary toughness changed the mode of microcracking from intragranular to intergranular fracture. Since elastic strain energy density is converted to fracture surface energy on microcracking, stored elastic strain energy density is correlated with the amount of microcracking; when it is larger, the percentage of microcracked area is larger. Regions with large values of the maximum principal stress in the uncracked state correspond to microcracks in the cracked state. Such an observation was expected from the modeling without microcracking. A significant observation for all microstructures was an asymmetry in microcracking upon heating and cooling: more microcracking was observed upon cooling than upon heating. This phenomenon can be explained by the influence of SPO. With increasing SPO such asymmetry becomes more pronounced. Additionally, with increasing SPO and LPO microcracking becomes more spatially anisotropic, as shown by the directional dependence of coefficients of thermal expansion.

Conclusions from the modeling using real marble fabrics:

Marbles with strong c-axis fiber texture showed a higher directional dependence of the thermal expansion coefficients and had smaller microstructural values of the maximum principal stress and strain energy density throughout the marble fabric. In contrast, marbles with weak c-axis fiber texture showed isotropic thermal expansion behavior, had a higher propensity to microcracking, and exhibited higher values of maximum principal stress and strain energy density. Marble with high-temperature texture type exhibited values of maximum principal stress that were just as large as those from marbles with weak c-axis fiber texture. While marble with girdle texture showed smaller thermal-elastic response, which indicates that such a marble structure is less prone to microcracking. As it was expected dolomitic marble showed the smallest thermal-elastic response in comparison to calcitic marbles. The observed influence of grain size when modeling using artificial models is contradictory with observations from the modeling using the fabrics of real marble samples, i.e., the fine-grained marbles show larger thermal-elastic response than medium-grained marbles. Such contradiction can be explained as following. When fracture is included as a phenomenon in finite-element simulations (in case of the modeling using artificial microstructures), the material has a 
length scale (namely, the fracture surface energy divided by an elastic modulus), by which to measure grain size. When microcracking algorithm is not allowed (in simulations using real marble fabrics) outputs from microstructure-based simulations (e.g., elastic strain energy density and maximum principal stress) are independent of grain size and therefore grain size has no meaning. The influence of grain boundary configuration is not significant, marbles with polygonal structure and marble samples with interlobate grain boundaries have comparable values of maximum principal stress and hence the same propensity of microcracking.

Conclusions from experimental measurements of thermal expansion:

Both of the weak textured fine-grained Carrara marbles show different amount of residual strain upon thermal treatment, such observation seem not to be in agreement with the modeling results where values of maximum principal stress are quite similar and it was expected that the thermal-elastic behavior should be rather the same. Such contradiction could be explained by the presence of preexisting microcracks and inclusions of other minerals; and increasing porosity during temperature changes in real marble structures, these factors were not taken into account in the modeling. Grain boundary configuration does not play important role as well as grain size, since marbles with polygonal structure have the same amount of residual strain as marbles with interlobate grain boundaries; and fine-grained marbles exhibit the comparable thermal expansion as medium-grained marble. Thus, grain boundary structure and grain size are considered not to be the important factors in marble degradation phenomena. The coefficients of thermal expansion have a directional dependence, which is obviously controlled by the texture (direction of maximum in plots of coefficients of thermal expansion tensor corresponds to the maximum of texture in pole figure). The difference between the thermal expansion coefficients computed from the texture in the Voigt approximation and those measured experimentally can be attributed to the presence of microcracks after the thermal treatment, which produced an additional expansion in the microstructure.

When thermal expansion measurements upon water-saturated conditions were carried out it was observed that the presence of water continuously enhanced the degradation of marble and changed the directions of maximum and minimum thermal expansions. In order to describe stability and durability marble under exposure a decay index was 
proposed based on the relative volume change. While the investigation of decay index is preliminary, results are in good coincidence with the previous studies (i.e., observation of degradation rates of buildings which were constructed of the presented marble types). For a majority of the investigated marble samples a significant change of the amount of residual strain, and hence change of the decay index, was observed when the water was presented. The invariant volume change determined from the thermal expansion measurement data can be used for choosing the proper marble type for a specific application.

General conclusions:

SPO, LPO and marble composition have significant influence on marble degradation caused by thermal expansion, they play the dominant role in combination with other fabric parameters. As was shown in finite-element simulations and experimental measurements SPO, LPO and marble composition control the amount and directional dependence of microcracking. Dolomitic marbles with strong texture and elongated SPO are supposed to be the most resistance against marble deterioration (when the water presence is not considered). Considering the different thermal behavior under dry and water-saturated conditions some marble types can be recommended to be used only for the interior applications and some for both interior and exterior applications. Additionally, taken into account the asymmetry of microcracking upon heating and cooling "summer" and "winter" houses should be constructed according to the peculiarities of climate. 
References

\section{References}

Alnæs L, Koch A, Schouenborg B \& Akesson U, Moen K (2004) Influence of rock and mineral properties on the durability of marble panels. In: Prikryl R (ed) Dimension Stone 2004, Taylor \& Francis Group, London, pp 245-251.

Atkinson BK (1984) Subcritical crack growth in geological materials. J. Geophysical Res. 89 [B6]: 4077-4114.

Bass JD (1995) Elasticity of minerals, glasses, and melts. In: Handbook of Physical Constants, Ed. Ahrens TJ. American Geophysical Union, Washington, DC, 45-63.

Battaglia S, Franzini M, Mango F (1993) High sensitivity apparatus for measuring linear thermal expansion: preliminary results on the response of marbles. II Nuovo Cimento 16: 453-461.

Becher PF, Freiman SW (1978) Crack propagation in alkaline-earth fluorides. J Appl Phys 49(7): 3779-3783.

Bland W, Rolls D (1998) Weathering. Arnold, London.

Blendell JE, Vaudin MD, Fuller ER (2004) Determination of texture from individual grain orientation measurements. J. Amer. Ceram. Soc., 82 [11]: 3217-3220.

Borradaile GJ, Powell C, Bayly B (1982) Atlas of deformational and metamorphic rock fabrics. Springer-Verlag.

Bortz SA, Erlin B, Monk CB (1988) Some field problems with thin veneer building stones. New stone technology, design, and construction for exterior wall systems. ASTM STP 996, B. Donaldson, Ed., American Society for Testing and Materials, Philadelphia: 11-31.

Bunge HJ (1982) Texture analysis in material sciences. Butterworth, London. 
Bunge HJ (1985) Representation of preferred orientations. In: Preferred Orientation in Deformed Metals and Rocks: An Introduction to Modern Texture Analysis. Academic Press, New York, 73-108.

Burkhard M (1993) Calcite twins, their geometry, appearance and significance as stress-strain markers and indicators of tectonic regime: a review. Journal of Structural Geology 15.3: 351-368.

Carter WC, Langer SA \& Fuller ER (1998) The OOF manual: Version 1.0. National Institute of Standards and Technology (NIST), NISTIR No.6256.

Carter WC, Langer SA \& Fuller ER (2003) The OOF manual: Version 1.1.7, http://www.ctcms.nist.gov/oof/oof1/Manual/Manual.html.

Chawla N, Patel BV, Koopman M, Chawla KK, Saha R, Patterson BR, Fuller ER, Langer SA (2003) Microstructure-based simulation of thermomechanical behavior of composite materials by Object-Oriented Finite element analysis. Mater Charac 49: 395-407.

Cleveland JJ, Bradt RC (1978) Grain Size/Microcracking Relations for Pseudobrookite Oxides. J Am Ceram Soc 61(11-12): 478-481.

Dingley DJ, Randle V (1992) Journal of Materials Science 274545

Dollase WA (1986) Correction of intensities for preferred orientation in powder diffractometry: Application of the March model. J Appl Crystallogr 19:267-272.

Fassina V, Favaro M, Naccari A (2002) Principal decay patterns on Venetian monuments. In: Siegesmund S, Weiss T, Vollbrecht A (eds) Natural stone, weathering phenomena, conservation strategies and case studies. Geological Society Special Publication No. 205, The Geological Society of London, London, pp 381-391. 
Ferrill DA (1998) Critical re-evaluation of differential stress estimates from calcite twins in coarse-grained limestone." Tectonophysics 285.1: 77-86.

Flinn D (1962) On folding during three-dimensional progressive deformation. Quarterly Journal of the Geological Society of London 118: 385-433.

Franzini M (1995) Stones in monuments: natural and anthropogenic deterioration of marble artifacts. European Journal Mineralogy 7: 735-743.

Galal Yousef S, Rödel J, Fuller ER, Zimmermann A, El-Dasher BS (2005) Microcrack Evolution in Alumina Ceramics: Experiment and Simulation. J Am Ceram Soc 88(10): 2809-2816.

Grelk B, Goltermann P, Schouenborg B, Koch A, Alnæs L (2004) The laboratory testing of potential bowing and expansion of marble. In: Přikryl R (ed) Dimension Stone 2004, Taylor \& Francis Group, London, pp 253-260.

Griffith AA (1921) The Phenomena of Rupture and Flow in Solids. Phil Trans Royal Soc London A 221: 163-198.

Grimm WD (1999) Beobachtungen und Überlegungen zur Verformung von Marmorobjekten durch Gefügeauflockerung. In: Siegesmund S, Snethlage R, Vollbrecht A, Weiss T (eds) Marmor-Konservierung. Zeitschrift der Deutschen Geologischen Gesellschaft, 150 [2]: 195-235.

Grossi CM, Esbert RM, Butlin RN, Lewry AJ (1994) Weathering of building carbonate rocks under SO2 polluted atmospheres. 7-th International Congress of the International Association of Engineering Geology, Balkema: 3573-3582.

Grüneisen E (1926) Zustand des festen Körpers. In: Geiger H, Scheel K (eds) Handbuch der Physik, Bd. 10: Thermische Eigenschaften der Stoffe. Springer, Berlin Heidelberg New York. 
Halfpenny A (2010) Some important practical issues for the collection and manipulation of Electron Backscatter Diffraction (EBSD) data from geological samples. In: (Ed.) M.A. Forster, and John D. Fitz Gerald, The Science of Microstructure - Part I, Journal of the Virtual Explorer, Electronic Edition, ISSN 1441-8142, volume 35, paper 3, DOI:10.3809/jvirtex.2011.00272.

Henry JP, Paquet J, Tancrez JP (1978) Experimental study of crack propagation in calcite rocks. Int. J. Rock Mech. Min. Sci. Geomech. Abstr. 14: 85-91.

Hielscher R, Schaeben H (2008) A novel pole figure inversion method: specification of the MTEX algorithm. Journal of Applied Crystallography, 41, 1024-1037, DOI: $10.1107 / S 0021889808030112$.

HKL Technology CHANNEL 5 Manual (2007) Oxfords Instruments HKL. [http://caf.ua.edu/wp-content/uploads/docs/JEOL-7000FOxford_Channel_5_User_Manual.pdf]

Ito O, Fuller ER (1993) Computer modelling of anisotropic grain microstructure in two dimensions. Acta metall. mater. 41 [1]: 191-198.

Kern H, Wenk HR (1983) Calcite texture development in experimentally induced ductile shear zones. Contr. Min. Pet. 83: 231-236.

Kranz RL (1983) Microcracks in rocks: a review. Tectonophysics 100 (1-3), 449-480.

Kleber W (1959) Einführung in die Kristallographie. VEB Verlag Technik, Berlin.

Kessler DW (1919) Physical and chemical tests on the commercial marbles of the United States. Technologic Papers Bureau of Standards, No. 123, Government Printing Office, Washington, DC.

Koch A, Siegesmund S (2002) On site damage analysis of buildings showing bowing of marble slabs: Fabric vs. type and degree of damage. In: Siegesmund S, Weiss T, 
Vollbrecht A (eds) Natural Stone, Weathering Phenomena, Conservation Strategies and Case Studies. Geological Society Special Publication No. 205, The Geological Society of London, London, pp 298-314.

Koch A, Siegesmund S (2004) The combined effect of moisture and temperature on the anomalous behaviour of marbles. Environmental Geology 46: 350-363.

Koch A (2006) Deformation von Fassadenplatten aus Marmor: Schadenskartierungen und gesteintechnische Untersuchungen zur Verwitterungsdynamik von Marmorfassaden. Universitätsverlag Göttingen.

Langer SA, Fuller ER, Carter WC (2001) OOF: an image-based finite-element analysis of material microstructures. Computing Sci. Engn. 3: 15-23. [OOF is freely available at http://www.ctcms.nist.gov/oof/]

Leiss B, Ullemeyer K (1999) Texture characterisation of carbonate rocks and some implication for the modeling of physical anisotropies, derived from idealized texture types. Z. Deut. Geol. Ges. 150: 259-274.

Leiss B, Molli G (2003) High-temperature texture in naturally deformed Carrara marble from Alpi Apuane, Italy. J Struct. Geol. 25: 649-658.

Logan JM, Hastedt M, Lehnert D, Denton M (1993) A case study of the properties of marble as building veneer. Int. J. Rock Mech. Mining Sci. \& Geomech. Abstr., 30 [7]: 1531-1537.

Luque A (2010) Andalusian marbles: durability criteria applied in its use as ornamental stone. PhD thesis, University of Granada.

Luque A, Ruiz-Agudo E, Cultrone G, Sebastián E, Siegesmund S (2011) Direct observation of microcrack development in marble caused by thermal weathering. Environmental Earth Sciences, Volume 62, No. 7: 1375-1386. 
Mainprice D, Hielscher R, Schaeben H (2011) Calculating anisotropic physical properties from texture data using the MTEX open source package. In: Prior DJ, Rutter EH, Tatham DJ (eds) Deformation Mechanisms, Rheology and Tectonics: Microstructures, Mechanics and Anisotropy. Geological Society, London, Special Publications, 360, pp 175-192. [MTEX is freely available at https://code.google.com/p/mtex/]

Maitland T, Sitzman S (2010) Electron Backscatter Diffraction (EBSD) Technique and Materials:Characterization Examples. In: Weili Zhou, Zhong Lin Wang Scanning (eds) Microscopy for Nanotechnology: Techniques and Applications, SpringerVerlag.

Means WD (1976) Stress and Strain, Springer-Verlag, New York.

Miodownik M, Godfrey AW, Holm EA, Hughes DA (1999) On boundary misorientation distribution functions and how to incorporate them into three-dimensional models of microstructural evolution. Acta Mater., 47 [9]: 2661-2668.

Moore AC (1970) Descriptive terminology fort the textures of rocks in granulite facies terrains. Lithos 3, 123-127.

Nye JF (1985) Physical Properties of Crystals: Their Representation by tensors and Matrices. Oxford science publications.

Ondrasina J, Kirchner D, Siegesmund (2002) Freeze-thaw cycles and their influence on marble deterioration: a long-term experiment. In: Siegesmund S, Weiss T, Vollbrecht A (eds) Natural stone, weathering phenomena, conservation strategies and case studies. Geological Society Special Publication No. 205, The Geological Society of London, London, pp 9-18.

Park RG (2005) Foundation of Structural Geology. $3^{\text {rd }}$ ed. Abingdon: Routledge

Passchier CW, Trouw RAJ (1996) Microtectonics. Springer-Verlag, Berlin. 
Press WH, Vetterling WT, Teukolsky SA, Flannery BP (2002) Numerical Recipes in C++: The Art of Scientific Computing, Second Edition, Cambridge University Press, New York 448-455.

Rabinowitzt M, Carr J (2012) The New York Public Library Statuary-Marble Deterioration \& Conservation. In: 12th International congress on deterioration and conservation of stone, New York (in print).

Reeder R, Markgraf SA (1986) High temperature crystal chemistry of dolomite. American Mineralogist 71: 795-804.

Reid A CE, Lua RC, Garcia RE, Coffman F, Langer SA (2009) Modelling Microstructures with OOF2. Int. J. Materials and Product Technology, Nos. 3/4.

Ritter H (1992) Die Marmorplatten sind falsch dimensioniert. Stein H. 1/1992: 18-19.

Royer-Carfagni G (1999) On the thermal degradation of marble. International Journal of Rock Mechanics and Mining Science 1999; 36: 119-26.

Ruedrich J, Weiss T, Siegesmund S (2002) Thermal behaviour of consolidated marbles. In: Siegesmund S, Weiss T, Vollbrecht A (eds) Natural stone, weathering phenomena, conservation strategies and case studies. Geological Society Special Publication No. 205, The Geological Society of London, London, pp 255-271.

Ruedrich J (2003) Gefügekontrollierte Verwitterung natürlicher und konservierter Marmore. PhD thesis, University Göttingen.

Ruedrich J, Kirchner D, Siegesmund S (2011) Physical weathering of building stones induced by freeze-thaw action: a laboratory long-term study. Environ Earth Sci 63: 1573-1586. 
Sage JD (1988) Thermal microfracturing of marble. In: Marinos PG, Koukis GC (eds) Engineering Geology of Ancient Works, Monuments and Historical Sites. Vol. 2. A. A. Balkema, Rotterdam. pp 1013-1018.

Saylor DM, Fridy J, El-Dasher BS, Jung KY, Rollett AD (2004) Statistically representative three-dimensional microstructures based on orthogonal observation sections. Metall. Mater. Trans. A 35A: 1969-1979.

Saylor DM, Fuller ER, Weiss T (2007) Thermal-elastic response of marble polycrystals: Influence of grain orientation configuration. Intl. J. Mat. Res. (formerly Z. Metallkd.) 98 [12]: 1256-1263.

Schouenborg B, Grelk B, Alnæs L, Brundin JA, Blasi P, Yates T, Marini P, Tschegg E, Unterweger R, Tokarz B, Koch A, Bengtsson T, Mladenovic A, Goralczyk S (2003) TEAM- Testing and Assessment of Marble and Limestone Cladding. International Symposium on Industrial Minerals and Building Stones, Instanbul.

Shelley D (1993) Igneous and metamorphic rocks under the microscope. Chapmann and Hall, London.

Shushakova V, Fuller ER, Siegesmund S (2011) Influence of shape fabric and crystal texture on marble degradation phenomena: simulations. Environ Earth Sci 63: 1587-1601.

Shushakova V, Fuller ER, Siegesmund S (2012) Microcracking in calcite and dolomite marble: microstructural influences and effects on properties. Environ Earth Sci DOI 10.1007/s12665-012-1995-2.

Siegesmund S, Weiss T, Vollbrecht A, Ullemeyer K (1999) Marble as a natural building show: rock fabrics, physical and mechanical properties. Z Dtsch Geol Ges 150: 237-257. 
Siegesmund S, Ullemeyer K, Weiss T, Tschegg EK (2000) Physical weathering of marbles caused by anisotropic thermal expansion. Int. J. Earth Sci. 89: 170-182.

Siegesmund S, Ruedrich J, Weiss T (2004) Marble deterioration. In Prikryl R (ed.) Dimension Stone 2004. Taylor\&Francis Group, London, pp. 211-217.

Siegesmund S, Koch A, Ruedrich J (2007) Ursachen mangelnder Formbeständigkeit von Fassadenplatten: Fallstudie Universitätsbibliothek der Universität Göttingen. In: Siegesmund S, Ehling A (eds) Rohstoff Naturstein Teil 1. Z dt Ges Geowiss 158: $630-648$.

Siegesmund S, Ruedrich J, Koch A (2008) Marble Bowing: Comparative studies of different public building facades. In: Siegesmund S, Snethlage R, Ruedrich J (eds) Monumental future: climate change, air pollution, stone decay and conservation. Environmental Geology 56: 473-494.

Siegesmund S, Dürrast H (2011) Physical and mechanical properties of rocks. In: Siegesmund S, Snethlage R (eds) Stone in Architecture. Springer-Verlag, Berlin.

Siegesmund S, Török Á (2011) Building stones. In: Siegesmund S, Snethlage R (eds) Stone in Architecture. Springer-Verlag, Berlin.

SirotinYuM., Shaskolskaya MP (1975) Basics of the crystallophysics. Nauka (in Russian).

Steiger M, Charola E (2011) Weathering and Deterioration. In: Siegesmund S, Snethlage R (eds) Stone in Architecture. Springer-Verlag, Berlin.

Strohmeyer (2003) Gefügeabhängigkeit technischer Eigenschaften. PhD thesis, University Göttingen.

Trewitt TJ, Tuchmann J (1988) Amoco may replace marble on Chicago headquarters. ENR March: 11-12. 
References

Tschegg E, Widhalm C, Eppensteiner W (1999) Ursachen mangelnder Formbestaetigkeit von Marmorplatten. Zeitschrift der Deutschen Geologischen Gesellschaft, 150 (2), pp 283-297.

Vollbrecht A, Dürrast H, Weber K (1993) Open microcracks: indicators for in situ stress directions. KTB-Report 93-2: 227-230.

Wanner T, Fuller ER, Saylor DM (2010) Homology metrics for microstructure response fields in polycrystals. Acta Mater. 58: 102-110.

Weiss T, Oppermann H, Leiss B, Siegesmund S (1999) Microfabric of fresh and weathered marbles: Implications and consequences for the reconstruction of the Marmorpalais Potsdam. Z. d Deut. Geol. Ges. 150: 313-332.

Weiss T, Siegesmund S, Fuller ER (2002) Thermal stresses and microcracking in calcite and dolomite marbles via finite element modelling. In: Siegesmund $\mathrm{S}$, Weiss T, Vollbrecht A (eds) Natural Stone, Weathering Phenomena, Conservation Strategies and Case Studies. Geological Society Special Publication No. 205, The Geological Society of London, London, pp 89-102.

Weiss T, Siegesmund S, Fuller ER (2003) Thermal degradation of marble: indications from finite-element modelling. Building and Environment, 38 [9-10]: 1251-1260.

Weiss T, Siegesmund S, Kirchner D, Sippel J (2004a) Environmental Geology 46: 402413.

Weiss T, Saylor DM, Fuller ER, Siegesmund S (2004b) Prediction of the degradation behaviour of calcareous rocks via finite-element modelling. 10th Int. Congress on Deterioration and Conservation of Stone, Stockholm: pp. 163-170.

Wenk HR, Takeshita T, Bechler E, Erskine BG, Matthies S (1987) Pure shear and simple shear on calcite textures. Comparison of experimental, theoretical and natural data. J. Struct. Geology 9: 731-745. 
White GS, Freiman SW, Fuller ER, Baker TL (1988) Effects of Crystal Bonding on Brittle Fracture. J Mater Res 3(3): 491-497.

Widhalm C, Tschegg E, Eppensteiner (1996) Anisotropic thermal expansion causes deformation of marble cladding. Journal of Performance of Constructed Facilities, 10, pp 5-10.

Wimmenauer W (1985) Petrographie der magmatischen und metamorphen Gesteine. Enke Verlag Stuttgart.

Winkler EM (1994) Stone in Architecture: Properties, Durability. Third edition. SpringerVerlag, Berlin.

Zeisig A, Siegesmund S, Weiss T (2002) Thermal expansion and its control on the durability of marbles. In: Siegesmund S, Weiss T, Vollbrecht A (eds) Natural Stone, Weathering Phenomena, Conservation Strategies and Case Studies. Geological Society Special Publication No. 205, The Geological Society of London, London, pp 65-80.

Zezza U, Massara EP, Massa V, Venchiarutti D (1985) Effect of temperature on intergranular decohesion of the marbles. Fifth International Congress on Deterioration and Conservation of Stone. Luasanne, Vol.1: 131-140.

Zimmermann A, Carter WC, Fuller ER (2001) Damage Evolution During Microcracking of Brittle Solids. Acta mater 49: 127-137. 


\section{Acknowledgments}

This dissertation would not have been possible without the guidance and the help of people who in one way or another contributed to the completion and success of this research. First of all I am very grateful to Prof. Dr. Siegfried Siegesmund and Prof. Dr. Edwin Fuller for their supervision, for their great help in every possible way, sharing their experience with me, fruitful discussions, support, and believe in me. Moreover, I thank them a lot for their comments on writing. Additionally, I thank their wives Brigitte and Barbara, respectively. In the first year of my stay in Göttingen I felt homesick and it was so kind of Siggi and Brigitte to invite me to the "Russian evening" and other events at Siegesmund's house to feel like home. And I will never forget how Ed and Barbara helped us survive the hurricane Sandy in New York and finally get tickets to fly back to Germany.

I thank Prof. Dr. Jonas Kley for being my co-reviewer and member of my thesiscommittee.

I thank Dr. Helmut Klein for helpful discussions and for interesting lectures in crystallography and also being the member of my thesis-committee.

I would like to convey my special thanks to Dr. Florian Heidelbach, who introduced me EBSD technique and helped a lot with EBSD measurements. I thank also Prof. Dr. David Mainprice for his calculations in MTEX that made very important contribution to our paper. I would like to thank David M. Saylor for generating the artificial microstructures used in the present thesis. Thomas Weiss is gratefully acknowledged for very helpful discussions.

I would like to thank my Russian professors Tatyana Ivanovna Savelova and Dmitry Igorevich Nikolayev, who inspired me to do a PhD in Germany and have always supported me. Additionally, I am very grateful to Dmitry Igorevich for helping with the chapter dedicated to decay index.

Also I gratefully acknowledge a long-term DAAD fellowship grant for financing my $\mathrm{PhD}$ and people who were providing me with guidance the whole time and helped me solve question with the final-final elongation, I wish to thank Michael Pawlaschyk and Thomas Prahl. 
I greatly appreciate help of Axel Vollbrecht, Heinrichs Till, David Hindle, Klaus Wemmer, Bernd Leiss, Jens Walter for introducing me to geology, helping with experimental procedures and giving their consideration.

I give my special thanks to our secretary Frau Hesse for helping with many administrative issues and for her kindness.

I thank a lot Manuela Morales Demarco (Manu), who was always ready to help me in every way, for her patience to teach me so many geological principles and for her openminded and positive approach to life. Also I wish to express gratitude to Filiz Afsar and Jan Duda for their help to write official letters in german, to correct my applications and for amazing "Scrabble-Abend" and other events at their place.

I would like to thank my colleagues at the university for their help, advice, teaching me and time-sharing with me: Birte Graue, Heidrun Stück, Frithjof Bense, Malte Drobe, Wanja Wedekind, Stefan Löbens, Christiane Schneider.

My life in Göttingen would not have been such eventful and interesting without my friends: Kristina Saliy, Katya Ershova, Julia Krause, Nikita Tretyakov, Anara Smagulova, Sergey Zayko, Vlad Zbarskyy, Sveta Miron, Bogdan Papiniu, Oresta Ohorchak, Nikolai Chapochnikov, Valya Rishko, Alexander Tyapkov, Vuong Truong Xuan, Tiku Olloni, Rodolfo Nobrega. Thank you all for being there with me!

Furthermore, I would like to thank all my friends from Russia, who are so far away from me geographically but at the same time so close emotionally: Katya Markelova, Igor Markelov, Sasha Dalechina, Varya Kholina, Anton Titov, Kseniya Khemilikova, Dasha Puzanova, Lena Novikova, Pasha Ryabov, Lena Samchuk, Timur Sitdykov. Thank you for support and believing in me and of course for our awesome meetings when I come to visit you!

I am immensely grateful to my family for their love, enormous support, for their wise advice, their care and affection. And of course my warmest thanks goes out to my love, my husband Vladimir (Vova), who has always been with me, supporting in everything I am doing, giving me his love and taking unlimited care of me! My gratitude knows no bounds!!! 


\section{Curriculum Vitae}

Nationality: Russian

Date and place of birth: $17^{\text {th }}$ December 1986 , Zhambil, Kazakhstan

\section{Education}

October 2009 - present

PhD student in Geowissenschaftliches Zentrum der Universität Göttingen (GeorgAugust University)

Structural geology and geodynamics department

$2004-2009$

MEPhl (Moscow Engineering Physical Institute, Moscow)

Diploma of Applied Mathematics and Informatics

\section{List of publications}

V. Shushakova, E. R. Fuller, Jr., F. Heidelbach, D. Mainprice, S. Siegesmund (2013)

Marble decay induced by thermal strains: simulations and experiments.

Environmental Earth Sciences (reviewed).

V. Shushakova, E. R. Fuller, Jr., S. Siegesmund (2012) Microcracking in calcite and dolomite marble: microstructural influences and effects on properties.

Environmental Earth Sciences DOI 10.1007/s12665-012-1995-2.

V. Shushakova, E. R. Fuller, Jr., F. Heidelbach, and S. Siegesmund (2012) Fabric influences on microcrack degradation of marbles. Proceedings of 12th International Congress on the Deterioration and Conservation of Stone, New York (in print)

V. Shushakova, E.R. Fuller, S. Siegesmund (2011) Influence of shape fabric and crystal texture on marble degradation phenomena: simulations. Environmental Earth Sciences 63: 1587-1601. 